Aus der Klinik für Neurologie

(Prof. Dr. med. M. Bähr)

der Medizinischen Fakultät der Universität Göttingen

\title{
Untersuchung der Rolle von Eotaxin-1 (CCL11) nach ischämischem Schlaganfall im Mausmodell: Neuroprotektion, Neuroregeneration oder destruktiv pro-inflammatorische Rolle?
}

\author{
INAUGURAL-DISSERTATION \\ zur Erlangung des Doktorgrades \\ der Medizinischen Fakultät der \\ Georg-August-Universität zu Göttingen
}

vorgelegt von

Simone Lieschke

aus

Trier 
Dekan:

\section{Betreuungsausschuss}

Betreuer/in:

Ko-Betreuer/in:

\section{Prüfungskommission}

Referent/in:

Ko-Referent/in:

Drittreferent/in:

Datum der mündlichen Prüfung: 15.04.2021
Prof. Dr. med. T. R. Döppner, M. Sc.

Prof. Dr. med. M. Oppermann

Prof. Dr. med. T. R. Döppner, M. Sc.

Prof. Dr. med. M. Oppermann

Prof. Dr. med. A. Flügel 
Hiermit erkläre ich, die Dissertation mit dem Titel "Untersuchung der Rolle von Eotaxin-1 (CCL11) nach ischämischem Schlaganfall im Mausmodell: Neuroprotektion, Neuroregeneration oder destruktiv pro-inflammatorische Rolle?" eigenständig angefertigt und keine anderen als die von mir angegebenen Quellen und Hilfsmittel verwendet zu haben.

Göttingen, den 
Die Daten, auf denen die vorliegende Arbeit basiert, wurden teilweise publiziert:

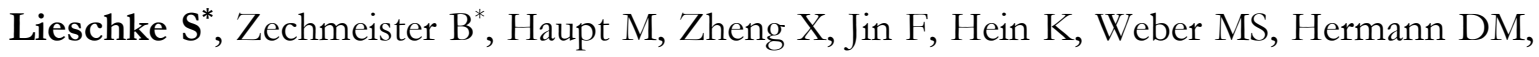
Bähr M, Kilic E and Doeppner TR (2019): CCL11 differentially affects post-stroke brain injury and neuroregeneration in mice depending on age. Cells $\underline{9}, 66$

*Authors contributed equally to this work. 


\section{Inhaltsverzeichnis}

Abbildungsverzeichnis ........................................................................................ III

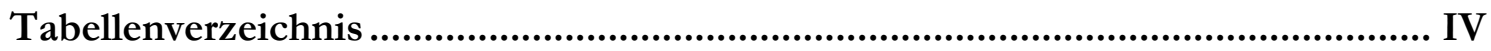

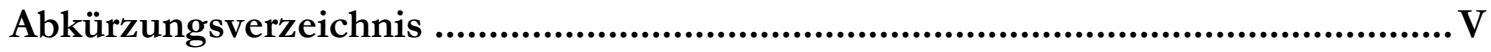

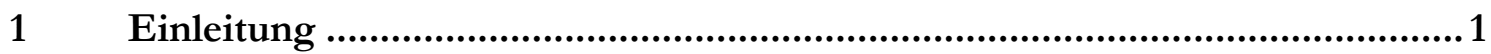

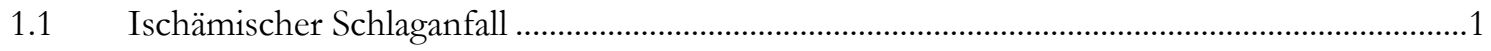

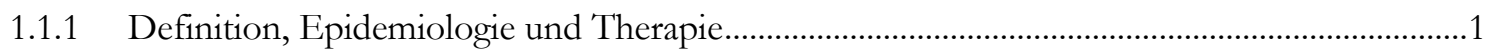

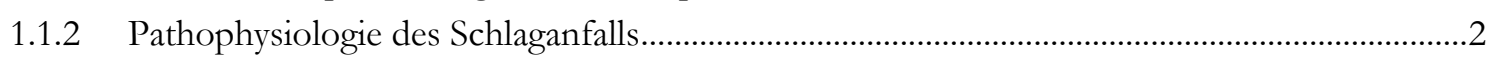

1.1.3 Regenerationsmechanismen nach zerebraler Ischämie .........................................................6

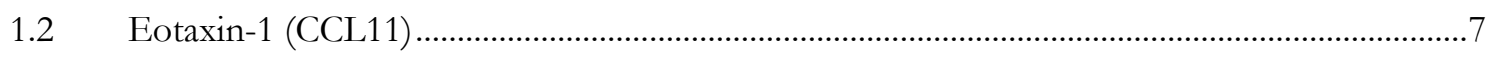

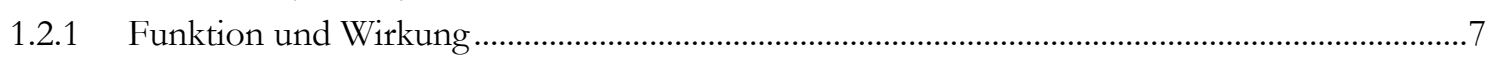

1.2.2 Wirkungen von Eotaxin-1 im ZNS ..................................................................................

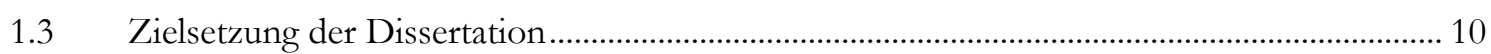

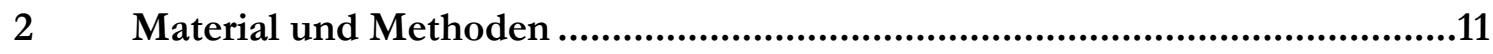

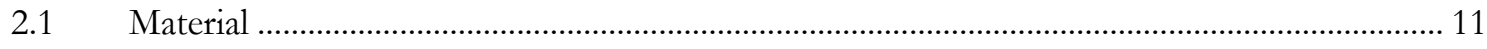

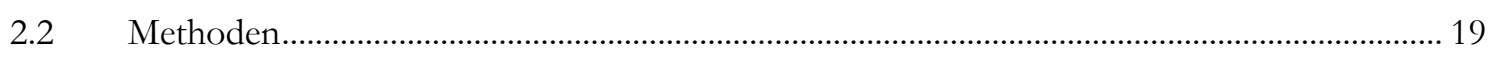

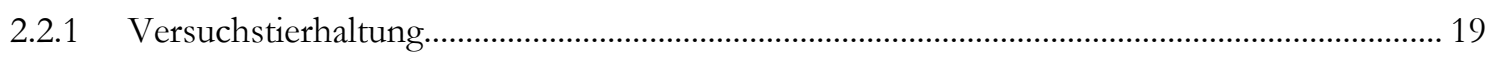

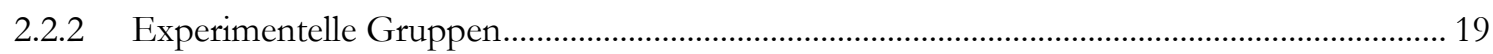

2.2.3 Okklusion der Arteria cerebri media (MCAO) ........................................................................ 22

2.2.4 Darstellung der post-ischämischen Zellproliferation mittels BrdU.......................................... 23

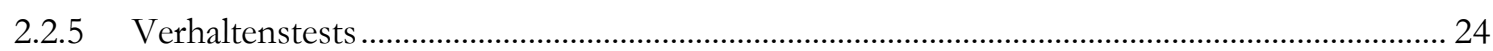

2.2.6 Darstellung des post-ischämischen Gewebeschadens mittels TTC-Färbung.......................... 24

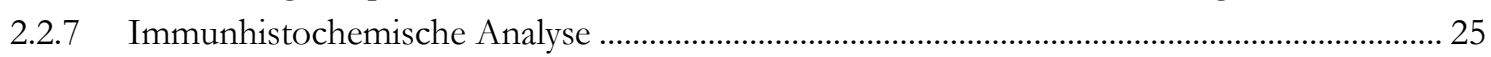

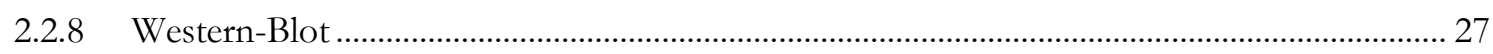

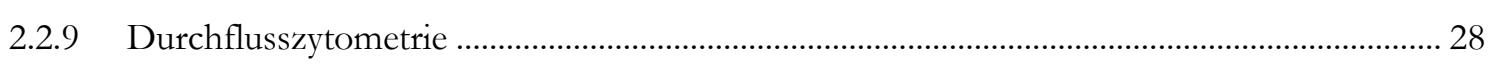

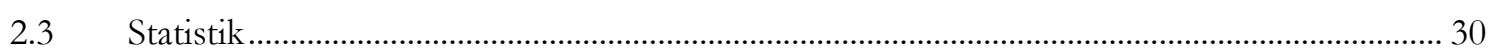

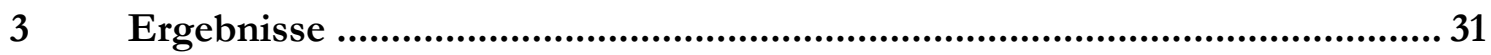

3.1 Eotaxin-1 führt zu einer Zunahme des akuten post-ischämischen Gewebeschadens in adulten Mäusen ................................................................................................................ 31

3.2 Eotaxin-1 moduliert die post-ischämische neurologische Erholung in adulten Mäusen...... 34

3.3 Eotaxin-1 fördert Regenerationsmechanismen in adoleszenten Mäusen und hemmt die Neurogenese in adulten Mäusen .................................................................................................. 36

3.4 Eotaxin-1 modifiziert die post-ischämische periphere und zentrale Immunantwort............. 41

3.5 Eotaxin-1 führt zu keiner Modulation von Autophagie oder pro-apoptotischer Signalwege45

3.6 Die Inhibition von CCR3 ist neuroprotektiv in adulten Mäusen ............................................... 50

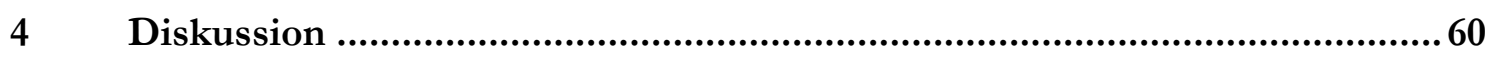

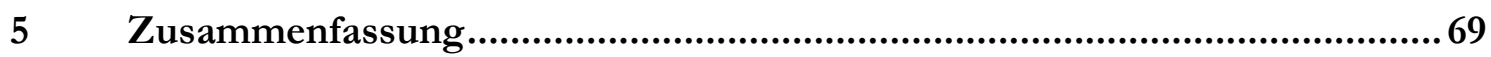




\section{Abbildungsverzeichnis}

Abbildung 1: Versuchsaufbau des Langzeitversuches mit Eotaxin-1.................................................... 20

Abbildung 2: Versuchsaufbau des Langzeitversuches mit SB297006 .................................................. 22

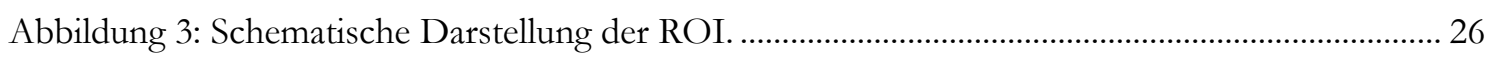

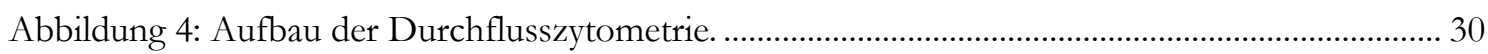

Abbildung 5: Eotaxin-1 hat keinen Einfluss auf den akuten Gewebeschaden in adoleszenten

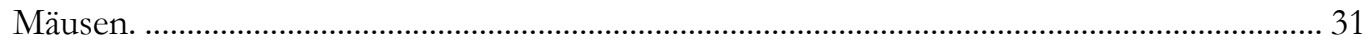

Abbildung 6: Qualitative Analyse des Aktivierungszustandes von Mikroglia...................................... 32

Abbildung 7: Eotaxin-1 induziert eine Aggravation des akuten post-ischämischen Gewebeschadens in adulten Mäusen........................................................................................ 33

Abbildung 8: Eotaxin-1 beeinträchtigt die funktionale Erholung nach zerebraler Ischämie der

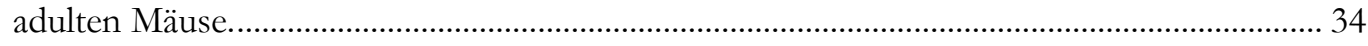

Abbildung 9: Eotaxin-1 hat keinen Einfluss auf den chronischen Gewebeschaden der adulten Mäuse.

Abbildung 10: Eotaxin-1 hat keinen Einfluss auf den chronischen Gewebeschaden der adoleszenten Mäuse.

Abbildung 11: Eotaxin-1 stimuliert die post-ischämische Zellproliferation in adoleszenten Mäusen.

Abbildung 12: Eotaxin-1 stimuliert die endogene post-ischämische Neurogenese in adoleszenten Mäusen.

Abbildung 13: Eotaxin-1 hemmt die Neurogenese in adulten Mäusen............................................... 39

Abbildung 14: Eotaxin-1 fördert die Gliogenese in adoleszenten Mäusen............................................ 40

Abbildung 15: Eotaxin-1 beeinflusst nicht die post-ischämische Gliogenese in adulten Mäusen..... 41

Abbildung 16: Eotaxin-1 modifiziert die subakute zentrale Immunantwort in adoleszenten Mäusen.

Abbildung 17: Eotaxin-1 modifiziert die subakute periphere Immunantwort in adoleszenten Mäusen.

Abbildung 18: Eotaxin-1 modifiziert die subakute zentrale Immunantwort in adulten Mäusen. ..... 44

Abbildung 19: Eotaxin-1 modifiziert die subakute periphere Immunantwort in adulten Mäusen.... 45

Abbildung 20: Eotaxin-1 hat keinen Einfluss auf die Expression des Mannoserezeptors................. 46

Abbildung 21: Eotaxin-1 hat keinen Einfluss auf die Expression von s100b. ......................................... 47

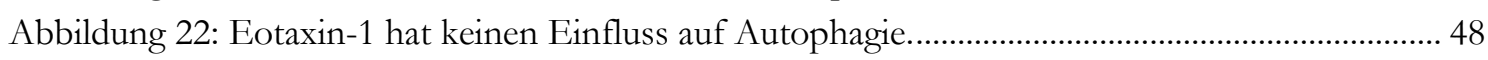

Abbildung 23: Eotaxin-1 wirkt unabhängig von pro-apoptotischen Signalwegen............................... 49

Abbildung 24: SB297006 hat keinen Einfluss auf den akuten Gewebeschaden in adoleszenten

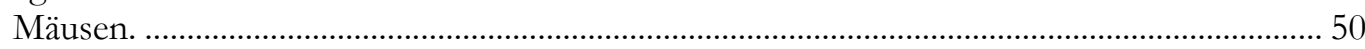

Abbildung 25: SB297006 inhibiert die Verschlechterung des akuten Gewebeschadens in adulten Mäusen.

Abbildung 26: SB297006 hat keinen Einfluss auf die funktionale Erholung nach zerebraler Ischämie der Maus

Abbildung 27: SB297006 beeinflusst nicht den chronischen Gewebeschaden der adoleszenten Mäuse.

Abbildung 28: SB297006 beeinflusst nicht den chronischen Gewebeschaden der adulten Mäuse... 54

Abbildung 29: SB297006 hemmt die Zellproliferation der adoleszenten Mäuse.................................. 55

Abbildung 30: SB297006 inhibiert die Neurogenese in adoleszenten Mäusen. ..................................... 56

Abbildung 31: SB297006 beeinflusst nicht die Neurogenese in adulten Mäusen.................................. 57

Abbildung 32: SB297006 hemmt die Gliogenese in adoleszenten Mäusen. ............................................ 58

Abbildung 33: SB297006 beeinflusst nicht die Gliogenese der adulten Mäuse..................................... 59 


\section{Tabellenverzeichnis}

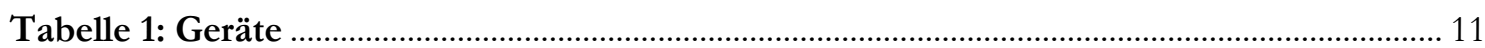

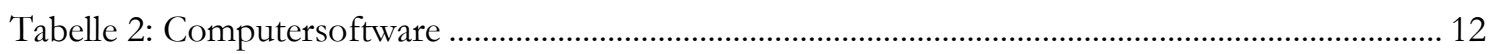

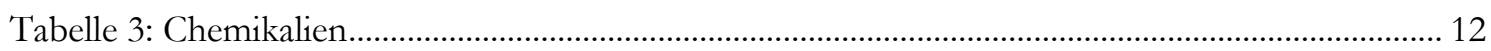

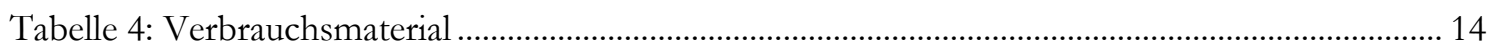

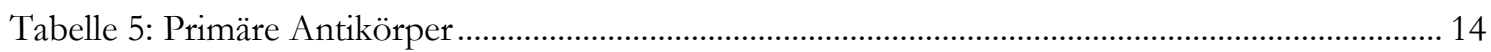

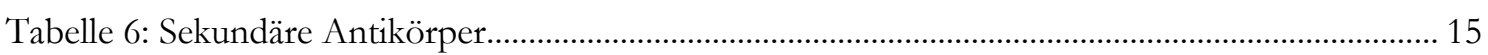

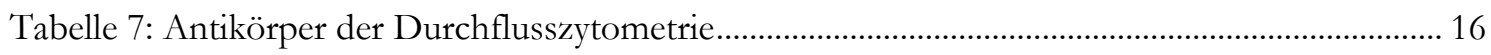

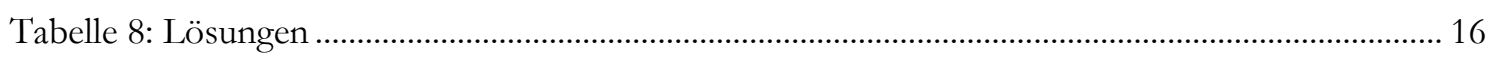

Tabelle 9: Anzahl der adoleszenten Versuchstiere mit Eotaxin-1- oder PBS-Behandlung ............... 20

Tabelle 10: Anzahl der adulten Versuchstiere mit Eotaxin-1- oder PBS-Behandlung ...................... 21

Tabelle 11: Anzahl der Versuchstiere mit SB297006- oder DMSO-Behandlung ............................... 21

Tabelle 12: Oberflächenmarker der Durchflusszytometrie ............................................................... 28 


\section{Abkürzungsverzeichnis}

ATP

BHS

BrdU

BSA

CCA

CCL11

CCR3

CDK5

DAPI

Dcx

DEGAM

DGN

DMSO

ECA

FACS

FCS

GFAP

IBA1

ICA

IL

LC3

MCA

MCAO

$\mathrm{NeuN}$

NF-kB

NPCs

PBS

PFA

PMSF

PVDF

RIPA

ROI

ROS

S100b

SDS

SVZ

TBS-(T)

TGF- $\beta$

TNF- $\alpha$

Tris
Adenosintriphosphat

Blut-Hirn-Schranke

Bromdesoxyuridin

Bovines Serumalbumin

Arteria carotis communis

Eotaxin-1

CC-Chemokinrezeptor Typ 3

Zyklin-abhängige-Kinase 5

Diamidinpheylinodil

Doublecortin

Deutsche Gesellschaft für Allgemeinmedizin und Familienmedizin

Deutsche Gesellschaft für Neurologie

Dimethylsulfoxid

Arteria carotis externa

Fluorescence activated cell sorting

Fetales Kälberserum

Saures Gliafaserprotein

Ionisiertes kalziumbindendes Adapter-Molekül

Arteria carotis interna

Interleukin

Mikrotubuli-assoziiertes Protein 1A/1B-leichte Kette 3

Arteria cerebri media

Okklusion der Arteria cerebri media

Neuronal nuclei

Nuclear factor kappa B

Neuronal progenitor cell(s)

Phosphatgepufferte Salzlösung

Paraformaldehyd

Phenylmethylsulfonylfluorid

Polyvinylidenfluorid

Radioimmunopräzipitation

Region of interest

Reaktive Sauerstoffspezies

Kalziumbindendes Protein b

Sodiumdodecylsulfat

Subventrikularzone

Tris-gepufferte Salzlösung (+ Tween 20)

Transforming growth factor $-\beta$

Tumornekrosefaktor- $\alpha$

Tris(hydroxymethyl)-aminomethan 
TTC

ZNS
Triphenyltetrazoliumchlorid

Zentrales Nervensystem 


\section{$1 \quad$ Einleitung}

\subsection{Ischämischer Schlaganfall}

\subsubsection{Definition, Epidemiologie und Therapie}

Der Schlaganfall ist definiert als ein ,akutes fokal-neurologisches Defizit aufgrund einer umschriebenen Durchblutungsstörung des Gehirns“ (DGN 2012). Man unterscheidet ätiologisch den ischämischen Schlaganfall (ca. 78 \%) vom hämorrhagischen Schlaganfall (ca. $13 \%$ ). Die übrigen Entitäten fallen auf Subarachnoidalblutungen bzw. sind unklarer Genese (DEGAM 2012). Schwerpunkt der hier vorliegenden Dissertation ist der ischämische Schlaganfall. Dieser entsteht durch die Okklusion des zerebralen Blutflusses und der daraus resultierenden Minderversorgung nachgeschalteter Hirnareale, welche zu der Entwicklung eines fokal-neurologischen Defizites führen kann.

Der Schlaganfall gehört zu den häufigsten Todesursachen weltweit, in Deutschland liegt die jährliche Anzahl an Neuerkrankungen bei 150.000 pro Jahr (DEGAM 2012). Überdies steigt die Inzidenz mit höherem Erwachsenenalter. Über 80 \% der Patienten sind über 60 Jahre alt, und aufgrund des demographischen Wandels in den Industrieländern ist sowohl von einer weiter steigenden Inzidenz als auch Prävalenz auszugehen (DEGAM 2012). Die Mortalität liegt üblicherweise bei 40 \% innerhalb der ersten zwölf Monate (DEGAM 2012), während bei $65 \%$ der Patienten auch nach einem Jahr noch immer von einer bleibenden Behinderung auszugehen ist. In Folge dessen hat der Schlaganfall nicht nur für den Betroffenen selbst weitreichende Folgen, sondern ist zudem auch von hoher sozioökonomischer Relevanz.

Die typischen Symptome eines ischämischen Schlaganfalls richten sich primär nach dem betroffenen Stromgebiet und der Akuität der Okklusion des Gefäßes. Es sind dies u. a. die Entwicklung einer sensomotorischen Hemiparese, Aphasie, Dysarthrie, Hirnnervenausfälle, Gesichtsfelddefekte, Störungen der Vigilanz und eine Affektion der Psychomotorik. Ursächlich ist in diesem Zusammenhang vornehmlich eine Arteriosklerose hirnversorgender Gefäße mit Entwicklung von Thromben bzw. Emboli sowie thrombembolische Ereignisse durch das Vorhandensein einer kardialen Emboliequelle, zum Beispiel aufgrund von Vorhofflimmern (Leppälä 1999). Seltene Faktoren wie beispielsweise das Vorliegen einer Gerinnungsstörung sollen an dieser Stelle unerwähnt bleiben. Typische Risikofaktoren für die Entwicklung eines ischämischen Hirninfarktes sind die arterielle Hypertonie, das Rauchen, der Diabetes mellitus, ein hohes Alter, eine Dyslipoproteinämie, ein 
Vorhofflimmern sowie eine positive Familienanamnese für das Auftreten kardiovaskulärer Ereignisse.

Der Schlaganfall ist ein neurologischer Notfall, der eine schnellstmögliche Einleitung einer Therapie erfordert. Der Rettungsdienst sollte alarmiert werden und Patienten mit Schlaganfallsymptomen bestenfalls in eine Abteilung bringen, die sich auf die Therapie des Schlaganfalls spezialisiert hat (so genannte Stroke Unit) (Psychogios et al. 2019; Venkatasubba Rao und Suarez 2018). Die kausale Therapie beinhaltet rekanalisierende Maßnahmen zur Wiederherstellung der normalen Blutversorgung des Gehirnes. Diese Maßnahmen inkludieren die systemische Thrombolyse mittels rt-PA (rekombinanter gewebespezifischer Plasminogenaktivator) innerhalb eines zugelassenen Zeitfensters von 4,5 Stunden sowie die mechanische Thrombektomie. Wenngleich elementare Fortschritte in der Behandlung des ischämischen Schlaganfalls erzielt werden konnten, insbesondere durch die Etablierung kathetergestützter Verfahren (Thomalla und Gerloff 2019), bleibt einer großen Zahl von Patienten aufgrund von engem Zeitfenster und möglicher Nebenwirklungen bzw. Kontraindikationen diese Therapie vorenthalten. In Folge dessen ist die Entwicklung neuer, adjuvanter Therapien zur Behandlung des ischämischen Schlaganfalls essentiell.

\subsubsection{Pathophysiologie des Schlaganfalls}

Die Entwicklung adjuvanter Therapien bedarf des Verständnisses über die Pathophysiologie des ischämischen Schlaganfalls. Die akute zerebrale Ischämie beruht, wie bereits erwähnt, auf einer Minderversorgung des Gewebes mit Blut und daraus resultierend einem Mangel an energiereichen Phosphaten wie Adenosintriphosphat (ATP) (Dirnagl 1999). Die zerebrale Ischämie aktiviert Mechanismen der Exzitotoxizität, Inflammation und Apoptose (Dirnagl 1999), wobei sich das Infarktgebiet in verschiedene metabolische Zonen einteilen lässt. Diese beinhalten den Infarktkern, also das bereits irreversibel zerstörte Gewebe, und die Penumbra, also das potentiell reversibel geschädigte Areal (Dirnagl 1999).

Im Infarktkern kommt es zum Erliegen der ATP-abhängigen $\mathrm{Na}^{+} / \mathrm{K}^{+}$-Pumpe, die das Membranpotential aufrechterhält (Khoshnam et al. 2017). Der Elektrolythaushalt der Zelle verschiebt sich nach intrazellulär, und Wasser strömt nach intrazellulär. Zusätzlich steigt die extrazelluläre Glutamatkonzentration im Gewebe an, welche sekundär zu einem Kalziumeinstrom in die Zelle führt (Khoshnam et al. 2017). Dies führt im weiteren Verlauf $\mathrm{zu}$ einer Depolarisation der Zelle und $\mathrm{zu}$ einem Zusammenbruch des Ruhemembranpotentials. Durch die Veränderung des Membranpotentials steigt sekundär 
die extrazelluläre Glutamatkonzentration weiter an und trägt so zu der Entwicklung eines zytotoxischen Ödems bei. Zeitgleich kommt es zu einer Aktivierung von Transkriptionsfaktoren, Endonukleasen, Phospholipasen und Proteasen, die die intrazelluläre Signalübertragung stören und die Zellfunktion sowie die strukturelle Integrität der Zelle beeinträchtigen (Khoshnam et al. 2017). Im kurzen Verlauf werden zusätzlich spannungsabhängige Kalziumkanäle aktiviert, so dass Kalzium weiter einströmt und es in letzter Konsequenz zum Zelltod kommt. Die Akkumulation von Glutamat extrazellulär wirkt des Weiteren direkt neurotoxisch und führt seinerseits zusätzlich zum Zelltod.

Die Penumbra, das vom Kollateralfluss kritisch unterversorgte Gebiet, wird prinzipiell noch mit Energie beliefert, ist jedoch vulnerabel für Periinfarkt-Depolarisationen (Lo 2008). Auch hier unterschreitet der zerebrale Blutfluss einen kritischen Schwellenwert der Ischämiegrenze (Baron 2001). Das Gewebe ist nicht ausreichend perfundiert, kann aber durch die Diffusion von Nährstoffen aus umliegenden Gefäßen zumindest temporär versorgt werden. In diesem Areal können sich ebenfalls depolarisierte Zellen nachweisen lassen. Gleichwohl ist dieser Prozess, eine rechtzeitige Wiederherstellung des Blutflusses vorausgesetzt, reversible und die Zellen können sich unter Umständen wieder repolarisieren und ihren Elektrolythaushalt aufrechterhalten. Bei Ausbleiben einer zeitigen Reperfusion im ehemals okkludierten Gefäß geht die Penumbra in den Infarktkern über, und es tritt auch hier der Zelltod ein (Khoshnam et al. 2017). Dieser unterscheidet sich allgemein in nekrotischem und apoptotischem Zelltod, wobei Übergänge fließend und neue Formen des Zelltodes Gegenstand aktueller Forschungsarbeiten sind. Entscheidend in diesem Zusammenhang ist die zeitliche Auflösung, d. h. die Dauer der zerebralen Ischämie, die Phase des Zellzyklus und der Zelltyp selbst. Der akute Zelltod im Rahmen der zuvor skizzierten Exzitotoxizität geht primär mit einem nekrotischen Zelltod einher, während der im Verlauf von Tagen und Wochen auftretende sekundäre Zelltod vornehmlich zu einem apoptotischen Zelltod führen kann, wie er nicht selten Folge pro-inflammatorischer Signalkaskaden ist (Iadecola und Anrather 2011).

Das Wiederherstellen des zerebralen Blutflusses, die Reperfusion, ist nicht automatisch mit einem besseren funktionellen Ergebnis des ehemals ischämischen Gewebes verbunden, selbst wenn diese zeitig erfolgt. Die Reperfusion kann zu einer so genannten Reenergetisierung durch Wiederversorgung mit Sauerstoff, ATP und Glukose der zuvor ischämischen Neuronen- und Gliazellverbände führen. Maßgeblich verantwortlich für den Reperfusionsschaden ist in diesem Zusammenhang der Zustand des Mitochondriums der Zelle bzw. der mitochondriale Schaden (Granger und Kvietys 2015). Ein ausgeprägter 
mitochondrialer Schaden bewirkt das Freisetzen von pro-apoptotischen Proteinen aus dem mitochondrialen Intermembranraum und induziert die apoptotische Signalkaskade, die letztlich zum Zelltod führt. Durch den Energiemangel unter der zerebralen Ischämie entsteht die zuvor erwähnte Erhöhung der intrazellulären Kalziumkonzentration, welche ihrerseits ebenfalls zum Verlust der mitochondrialen Integrität und zum irreversiblen Untergang der Zelle führt. Mit der mitochondrialen Dysfunktion geht auch die Bildung von reaktiver Sauerstoffspezies (ROS) sowie eine weitere Überladung der Zelle mit Kalzium und eine Induktion der Inflammation einher (Pundik 2012).

Die inflammatorische Immunantwort auf die zerebrale Ischämie beginnt bereits intravasal nach Eintritt des Energiemangels durch die Aktivierung von Komplementsystem, Thrombozyten und Endothel (Chamorro et al. 2012). Sterbende Neurone setzen „Gefahrensignale“, so genannte „damage associated molecular pattern (DAMPS)“ frei, die von Mikrogliazellen über Pathogenerkennungsrezeptoren wie beispielsweise dem Toll-like-Rezeptor (TLR) erkannt werden und zur Aktivierung der residenten Mikrogliazellen führt. Nachgeschaltet werden entzündliche Signalkaskaden über beispielsweise den nuclear factor kappa B (NF-kB) Signalweg und den mitogenaktivierten Protein (MAP)-Kinasewege ausgelöst und senden innerhalb von Minuten pro-inflammatorische Mediatoren, wie Interleukin-1 (IL-1), Interleukin-6 (IL-6), Tumornekrosefaktor- $\alpha$ (TNF- $\alpha$ ), Chemokine und deren Rezeptoren, Integrine und Adhäsionsmoleküle aus (Shim und Wong 2016). Mikrogliazellen sind ortsansässige Immunzellen des angeborenen Immunsystems im zentralen Nervensystem (ZNS). Die Aktivierung dieser Zellen führt zu einer frühen Inflammation im ischämischen Gewebe. Die Produktion der genannten pro-inflammatorischen Moleküle löst ihrerseits die Rekrutierung peripherer Immunzellen aus (Shim und Wong 2016). Die Infiltration peripherer Leukozyten kann schlussendlich zu einer weiteren Aggravation des Zell- und Gewebeschadens beitragen, in dem die infiltrierten Leukozyten die direkte und indirekte Zellschädigung durch die Sekretion von Chemokinen und auch phagozytären Mechanismen verstärken. Andererseits können Mikrogliazellen neben pro-inflammatorischen Mediatoren auch eine Reihe von Neurotransmittern und anderen Botenstoffen sezernieren, die einer Entzündungsreaktion des Gewebes entgegenwirken (Iadecola und Anrather 2011). Die genaue Rolle der Mikroglia ist in diesem Kontext jedoch weiterhin nicht geklärt.

Perakut führt das pro-inflammatorische Milieu zur Infiltration von neutrophilen Granulozyten (Neumann et al. 2015). Die Aktivierung der Leukozyten induziert einen zusätzlichen oxidativen Stress durch die Bildung von ROS, der die Permeabilität der 
Blut-Hirn-Schranke (BHS) fördert (Yilmaz und Granger 2010). Subakut setzen Leukozyten zudem Matrix-Metalloproteasen frei, die ihrerseits die Integrität der BHS reduzieren und so die Chemotaxis von Leukozyten erleichtern. Insbesondere finden sich in diesem Zusammenhang Makrophagen, Lymphozyten und Monozyten (Iadecola und Anrather 2011). Mit Einwandern von Monozyten und Makrophagen beginnt neben der Initiierung der adaptiven Immunantwort auch die Freisetzung anti-inflammatorischer Mediatoren und die Aktivierung von Gewebereparaturmechanismen. Mikrogliazellen und infiltrierte Makrophagen phagozytieren die abgestorbenen Zellen. Die Phagozytose fördert die Produktion von transforming growth factor- $\beta$ (TGF- $\beta$ ) und Interleukin-10 (IL-10), pleiotrope immunregulatorische Zytokine, die das entzündungshemmende Milieu einleiten (Iadecola und Anrather 2011). Zudem kann TGF- $\beta$ die zelluläre Immunreaktion hemmen und fördert so die Mediation von Wachstumsfaktoren (Taylor et al. 2006). Die post-ischämische Produktion von Wachstumsfaktoren durch Immunzellen, Neurone und Gliazellen fördert die Gewebereparatur durch die Stimulation der endogenen Neurogliogenese und Angiogenese sowie der Reorganisation der Matrix (Hermann und Chopp 2012). Folgerichtig ist also die post-ischämische Inflammation differenziert zu betrachten, insofern als dass sie sowohl die Entwicklung des Gewebeschadens fördern ihr aber auch gleichzeitig entgegenwirken kann.

Gleichzeitig zur zentralen (zerebralen) Immunreaktion zeigt sich auch eine systemische (periphere) Immunreaktion (Chamorro et al. 2012). In der akuten Phase, Stunden nach dem Schlaganfall, findet man Veränderungen der Blutzusammensetzung zugunsten von Leukozyten, C-reaktivem Protein (CRP), IL-6 und pro-inflammatorischen Zytokinen (Iadecola und Anrather 2011). Dieser akuten Phase folgt eine ausgeprägte Immunsuppression mit Lymphopenie, eingeschränkter funktioneller Aktivität von Monozyten und entzündungshemmendem Milieu (Iadecola und Anrather 2011). Diese neuronale Steuerung der Immunität wird durch die Hypothalamus-NebennierenrindenAchse und das sympathische Nervensystem erklärt. Die zerebrale Inflammation wird von der Hypophyse registriert und führt zu einer Freisetzung von Glucocorticoiden, Stresshormonen, aus der Nebennierentinde und zu einer Aktivierung des Sympathikus (Chamorro et al. 2012). Die Immunsuppression führt ihrerseits zu einer Begünstigung von Infektionen, beispielsweise der Atemwege oder der Harnwege, und tragen zu einer erhöhten Morbidität und Mortalität nach dem Schlaganfall bei (Chamorro et al. 2012).

Die komplexe Modulation der Inflammation bietet sich somit als ein Angriffspunkt für therapeutische Interventionen an. Die Manipulation derselben kann in diesem Kontext 
äußerst komplexe Immunantworten im Zielorgan und den peripheren Geweben hervorrufen, die es in präklinischen Untersuchungen zu analysieren gilt.

\subsubsection{Regenerationsmechanismen nach zerebraler Ischämie}

Das Gehirn kann nach einer Schädigung wie der zerebralen Ischämie auf endogene Regenerationsmechanismen bzw. Gewebereparaturmechanismen zurückgreifen. Diese umfassen u. a. die Neurogenese, die Gliogenese und die Angiogenese. Die adulte Neurogenese ist ein endogener Regenerationsmechanismus nach neuronalem Zelluntergang und persistiert auch im adulten Gehirn (Guillemot 2007). Tatsächlich findet man in sogenannten neurogenen Nischen wie der subventrikulären Zone (SVZ) der Seitenventrikel oder der subgranulären Zone des Hippocampus astrozytenartige neurale Vorläuferzellen, so genannte neurale Progenitorzellen (NPCs) (Guillemot 2007). Von dort aus wandern NPCs über den rostralen Migrationsstrom zu den Zellschichten des Bulbus olfactorius und des Dentatusgranulates. Die bloße Induktion einer zerebralen Ischämie ist in der Lage die zuvor skizzierte endogene Neurogenese zu stimulieren. Nach zerebraler Ischämie proliferieren, migrieren und differenzieren NPCs im Infarktareal, weisen jedoch nur geringe Überlebensund Differenzierungsraten auf (Doeppner et al. 2011); das Gros der sich im Infarktgewebe befindenden NPCs mündet in den Zelltod. Wenngleich Einige wenige neues Gewebe bilden, reicht die endogene Neurogenese nicht zur post-ischämischen, neurologischen Erholung aus (Doeppner et al. 2011).

Im post-ischämischen Gewebe entsteht durch endogene Stimuli eine reaktive Gliose, die sogenannte Glianarbe. Das Narbengewebe besteht größten Teils aus reaktiven Astrozyten, die namensgebend für die Glianarbe stehen, und aus einem fibrotischen Anteil. Diese Astrozyten entstammen sowohl von einwandernden neuronalen Vorläuferzellen, also Zellen der Neurogliogenese, als auch von sich teilenden residenten Astrozyten (Frisen 2016). In der embryonalen Entwicklung differenzieren sich die glialen Vorläufer ebenfalls aus den neuralen Vorstufen zu Astrozyten und zu oligodendroglialen Zellen, wobei dies zeitgleich zur Neurogenese auftritt (Guillemot 2007). Die Gliogenese ist wichtig für die Aufrechterhaltung der zerebralen Homöostase und Erschaffung eines Mikromilieu zur Umgestaltung des Gewebes.

Neuro- und Gliogenese sind keine für sich selbst stehenden Prozesse. Tatsächlich beeinflussen sie sich gegenseitig und stehen aber auch mit der Angiogenese im ischämischen Gewebe in Zusammenhang (Hermann und Chopp 2012). Die Sekretion angiogener Faktoren aus Neuronen und Astrozyten stimuliert das mikrovaskuläre Wachstum, während neu 
gebildete Endothelzellen ihrerseits sowohl die Neurogenese als auch die Gliogenese begünstigen (Hermann und Chopp 2012).

\subsection{Eotaxin-1 (CCL11)}

\subsubsection{Funktion und Wirkung}

Eotaxin-1 oder auch CCL11 genannt ist ein Chemokin der CC-Chemokinfamilie. Chemokine sind Zytokine, die chemotaktisch Leukozyten zur Entzündung und Verletzung locken (Chen et al. 2018). Die Rekrutierung der eosinophilen Granulozyten ist namensgebend für das Chemokin. Die Rolle von Eotaxin-1 wurde zunächst im peripheren Immunsystem beschrieben und untersucht. Es zeigte sich, dass Eotaxin-1 chemotaktisch eosinophile Granulozyten anlockt und die Gewebeeosinophilie im Zusammenhang mit allergischen Entzündungen wie Asthma, Atopien und Parasiteninfektionen vermittelt (Garcia-Zepeda 1996). Anschließende Berichte verdeutlichten eine wichtige Rolle von Eotaxin-1 in gastrointestinalen Erkrankungen wie der Colitis Ulcerosa oder dem Morbus Crohn (Mir et al. 2002). Eotaxin-1 ist ein Schlüsselregulator inflammatorischer Prozesse im Gastrointestinaltrakt, der Leber, der Lunge und der Haut (Garcia-Zepeda 1996). Es bindet unter anderem am CC-Chemokinrezeptor Typ 3 (CCR3), einem G-Protein gekoppelten Rezeptor (Millard et al. 2014). Zudem reguliert Eotaxin-1 nicht nur die Migration und Aktivierung von eosinophilen Granulozyten, sondern auch von T-Zellen, Mastzellen und basophilen Granulozyten (Huber et al. 2018). Der zelluläre Ursprung von Eotaxin-1, als Mediator des angeborenen Immunsystems, findet sich in der Lunge, im Darm und in der Haut. Es wird von Makrophagen, eosinophilen Granulozyten, Lymphozyten, Fibroblasten, Perizyten und glatten Muskelzellen produziert und sezerniert (Huber et al. 2018). Die Synthese wird durch pro-inflammatorische Mediatoren wie zum Beispiel Interleukin-4 (IL-4) und TNF- $\alpha$ hochreguliert und von anti-inflammatorischen Zytokinen wie IL-10 und Interferon- $\gamma($ IFN- $\gamma$ ) herunterreguliert (Huber et al. 2018). Neben der inflammatorischen Expression fördert Eotaxin-1 durch eine konstitutive Expression die Migration von oligodendroglialen Progenitorzellen und glatten Muskelzellen, welche beide in Regenerationsmechanismen involviert sind (Kodali et al. 2004; Maysami et al. 2006).

\subsubsection{Wirkungen von Eotaxin-1 im ZNS}

Im ZNS wird die Wirkung von Zytokinen divers diskutiert. Generell kann angenommen werden, dass pro-inflammatorische Zytokine neurotoxisch und anti-inflammatorische 
Zytokine neuroprotektiv wirken (Allan 2001), wenngleich auch diese vereinfachte Darstellung im Einzelfall der Realität nicht immer entspricht. Im ischämischen Gewebe werden Zytokine überwiegend von Astrozyten, Mikrogliazellen und von infiltrierenden Immunzellen produziert. Rezeptoren für Chemokine finden sich vor allem auf ortsständigen Immunzellen des Gehirns, den Mikrogliazellen (Chen et al. 2018). Die Leukozyteninfiltration und deren Aktivierung kann akut zu einer unverhältnismäßigen Entzündung führen. Andererseits fördern Zytokine, zu einem späteren Zeitpunkt, die Migration von nicht immunen, unreifen Zellen, wie neuralen Stammzellen, NPCs und Endothelzellen, die die Neuroregeneration nach zerebraler Ischämie fördern (Chen et al. 2018). Letzteres beschreibt die bereits oben erwähnte konstitutive Funktion von Chemokinen.

Eotaxin-1 ist bluthirnschrankengängig und findet sich auf Rezeptoren von NPCs, Astrozyten und vor allem auf Mikrogliazellen (Erickson et al. 2014; Huber et al. 2018). Die Integrität der BHS spielt eine Rolle in der Regulierung der Eotaxin-1-Spiegel im ZNS. Der Transport von Eotaxin-1 über die BHS findet in regional unterschiedlichen Transportraten (hohe Raten im Striatum im Vergleich $\mathrm{zu}$ anderen Hirnregionen) statt und wird durch die zelluläre Blutzusammensetzung beeinflusst (Erickson et al. 2014). Eine pro-inflammatorische Blutzusammensetzung begünstigt das Überwinden der BHS (Erickson et al. 2014). Zentral sind aktivierte Astrozyten die Hauptquelle für Eotaxin-1, und Mikrogliazellen sind vorwiegend sensitiv für dieses (Parajuli et al. 2015).

Die Plasma- und Liquorkonzentration von Eotaxin-1 in Menschen und Mäusen steigt physiologisch im Alter an und ist mit degenerativen Prozessen im ZNS vergesellschaftet (Villeda et al. 2011). Villeda und Kollegen (2011) haben in einem Parabioseexpermiment, in dem sie jungen Mäusen Serum von gealterten Mäusen und alten Mäusen Serum von jungen Tieren injiziert haben, herausgefunden, dass blutübertragene Faktoren des gealterten Milieus die adulte, hippocampale Neurogenese hemmen und die synaptische Plastizität sowie die Lern- und Gedächtnisfunktion stören. Die Autoren haben u. a. Eotaxin-1 als Auslöser dieser Effekte identifiziert und daraufhin durch ektope Applikation von Eotaxin-1 die periphere Konzentration desselben in jungen Tieren erhöht. Sie stellten fest, dass Eotaxin-1 die adulte Neurogenese und die Lern- sowie Gedächtnisfunktion der jungen Tiere signifikant hemmt (Villeda et al. 2011). Diese Effekte auf die Neurogenese und des Alterns lassen sich durch intrazerebroventrikuläre Injektion eines Antikörpers aufheben. Die Parabiose eines jungen Tieres auf ein altes Tier reicht jedoch nicht aus um die Auswirkungen von Eotaxin-1 auf das Altern umzukehren (Villeda et al. 2011). Das Phänomen der altersabhängigen immunologisch getriggerten Neurodegeneration lässt sich unteranderem dadurch erklären, 
dass der Plexus choroideus die neuroimmunologische Schnittstelle des Gehirns ist. Im Alter wird dieser durch systemische und auch zentraler Faktoren beeinflusst und führt durch die Leukozytenrekrutierung zur Umwandlung von einer Neuroinflammation zu einer Neurodegeneration (Baruch et al. 2014). Eotaxin-1 ist ein nachgeschalteter Mediator des Entzündungszustandes des Plexus choroideus und dieser Entzündungsprozess begünstigt den negativen Einfluss auf die hippocampale Neurogenese und auf das hippocampusabhängige Lernen und Gedächtnis (Baruch et al. 2013). Die Eotaxin-1Expression mit dem Alter scheint somit durch systemische und zentrale Mediatoren gesteuert zu sein (Baruch et al. 2013).

Die Effekte von Eotaxin-1 auf die Funktion des Hippocampus haben eine hohe Relevanz für psychiatrische Störungen wie beispielsweise depressive Störungen oder Demenzen (Stuart et al. 2015). Erhöhte Level an Eotaxin-1 im Blut und im Liquor findet man bei verschiedenen neurodegenerativen Erkrankungen wie zum Beispiel der Demenz vom Alzheimer Typ und der leichten kognitiven Gedächtnisstörung (Choi 2008). Positiv korrelieren erhöhte Level an Eotaxin-1 mit der Ausprägung der Chorea Huntington (Wild et al. 2011). Ebenso fand man in der chronisch-traumatischen Enzephalopathie, einer progressiv neurodegenerativen Erkrankung nach repetitiven Schädel-Hirn-Traumen, erhöhte Konzentrationen von Eotaxin-1 (Cherry et al. 2017). Interessanterweise ist bei der amyotrophen Lateralsklerose (ALS) Eotaxin-1 ebenfalls hochreguliert. Jedoch korreliert hier die Eotaxin-1-Konzentration invers mit der Krankheitsprogression (Furukawa et al. 2015). Vermutlich sind in diesem Zusammenhang ätiologisch neuroinflammatorische Prozesse ursächlich für den neurodegenerativen Umbau. Tatsächlich übernimmt Eotaxin-1 in neuroinflammatorischen Erkrankungen eine regulierende Rolle. In einem Rattenmodell der Multiplen Sklerose (MS) moduliert Eotaxin-1 die Immunantwort zugunsten einer Hemmung der Demyelinisierung und reduziert so die kumulative mikrogliale Aktivierung. Die durch Eotaxin-1 modifizierte Immunantwort führt sodann zu einem milderen Verlauf der Erkrankung (Adzemovic et al. 2012). Darüber hinaus fördert Eotaxin-1 im pro-inflammatorischen Milieu die Migration von Mikrogliazellen und führt durch Aktivierung von ROS zu oxidativem Stress. Dieser potenziert den exzitatorisch neuronalen Zelltod in vitro (Parajuli et al. 2015).

Betrachtet man neuroregenerative Prozesse scheint Eotaxin-1 einen negativen Effekt auf die adulte Neurogenese zu entfalten, wie bereits von Villeda und Kollegen (2011) zuvor beschrieben. Es zeigte sich ebenfalls ein hemmender Einfluss von Eotaxin-1 auf die Neuroregeneration in einem Tierversuch zu Malaria. Die hierbei im Tiermodell induzierte 
zerebrale Malaria geht mit einer Enzephalitis einher und führt zu kognitiven Störungen und epileptischen Anfällen bis hin zum Koma (de Miranda et al. 2015). Unter diesen Bedingungen fand sich eine erhöhte Expression von Eotaxin-1, und diese ging mit einer gehemmten Neurogenese im Gyrus dentatus einher (de Miranda et al. 2015). Interessanterweise findet man im Gegensatz dazu unter ischämischen Bedingungen im neonatalen Mäusegehirn erhöhte Level von Eotaxin-1 (Wang et al. 2017). Diese scheinen mit einer Stimulation der Migration von NPCs aus der SVZ und somit einer erhöhten Neurogenese vergesellschaftet zu sein (Wang et al. 2017). In vitro Daten suggerieren, dass diese Effekte erfolgreich durch die Applikation eines CCR3-Inhibitors zu blockieren sind (Wang et al. 2017). Zusammenfassend lässt sich festhalten, dass die Effekte von Eotaxin-1 auf das ZNS heterogener Natur sind und dabei u. a. von den pathophysiologischen Gegebenheiten, der Eotaxin-1-Konzentration selbst aber auch von den anatomischen Strukturen abhängig sind.

\subsection{Zielsetzung der Dissertation}

Vor dem Hintergrund der äußerst heterogenen Funktionen von Eotaxin-1 und der lediglich im neonatalen Maushirn vorliegenden Datenlage stellt sich die Frage, inwiefern Eotaxin-1 eine Rolle bei der zerebralen Ischämie der adulten Maus spielt. In diesem Zusammenhang sind von besonderem Interesse etwaige Effekte im Hinblick auf Neuroprotektion, Inflammation und Neuroregeneration.

In der hier vorliegenden Arbeit wird daher die akute Neuroprotektion anhand des Infarktvolumens, des neuronalen Verlustes sowie der mikroglialen Immunantwort bewertet. Im subakuten Stadium des Schlaganfalls liegt der Schwerpunkt auf möglichen Eotaxin-1 vermittelten Signalwegen und der systemischen sowie der zentralen Inflammation. Im Langzeitversuch liegt der Fokus auf den Gewebereparaturmechanismen, dargestellt durch proliferierende Zellen. Der chronische Gewebeschaden wird durch eine immunhistochemische Analyse der neuronalen Dichte und der mikroglialen Immunantwort erneut überprüft. Die funktionale Erholung der Versuchstiere wird mittels Verhaltenstest an ausgewählten Tagen ausgewertet.

Im Hinblick auf therapeutische Konsequenzen ist es von Bedeutung die vermeintliche Rolle von Eotaxin-1 mittels des Rezeptorantagonisten SB297006 zu bekräftigen. Diese Inhibition des Eotaxin-1-Signalweges wird im Kurzzeitversuch und Langzeitversuch angewandt. 


\section{$2 \quad$ Material und Methoden}

\subsection{Material}

Tabelle 1: Geräte

Gerät, Typ
Autoklave, VX-65

Hersteller, Land

Systec, Deutschland

Blotkammer, Mini Trans-Blot Cell

Bio Rad, USA

Chemi-Doc, XRS+

Bio Rad, USA

CryoStat, CM3050S

Leica, Deutschland

Durchflusszytometer, LSRFortessa

BD Bioscience, USA

Epifluoreszenzmikroskop, Axioplan 2

Zeiss, Deutschland

imaging

Feinwaage, BL210S

Sartorius, Deutschland

Gelelektrophoresekammer, Mini-Protean

Bio Rad, USA

Tetra Cell

Heizplatte, Homeothermic Control Unit

Homogenisator, Tissue Lyser LT

Laser-Doppler, PeriFlux System 5000

Lichtmikroskop, Axiostar Plus

Mikroskopkamera, AxioCamMRc

pH-Meter, P20

Photometer, Sunrise

Reinstwassersystem, Arium pro

Rota-Rod, Acceler Rota-Rod for mice 7650

Thermocycler, Cyclone 25

Trockenschrank, UT 20

Ultrazentrifuge, $5415 \mathrm{R}$

Harvard Apperatus, USA

Qiagen, Deutschland

Perimed, Schweden

Zeiss, Deutschland

Zeiss, Deutschland

Sartorius, Deutschland

Tecan, Schweiz

Sartorius, Deutschland

TSE Systems, Deutschland

Peqlab, Deutschland

Heraeus, Deutschland

Eppendorf, Deutschland

Zentrifuge, 5810R

Eppendorf, Deutschland 
Tabelle 2: Computersoftware

\begin{tabular}{l} 
Computersoftware \\
\hline AxioVision Software \\
EvolutionCapt Software \\
FlowJo Software \\
GraphPad Prism 7 Software \\
ImageJ Software
\end{tabular}

\section{Internetadresse}

https://www.micro-shop.zeiss.com/de/

http://www.vilber.de/

https://www.flowjo.com/

https://www.graphpad.com/

https://imagej.nih.gov/ij/

Tabelle 3: Chemikalien

\begin{tabular}{|c|c|}
\hline Chemikalie & Hersteller, Land \\
\hline 10x Elektrophorese-Puffer & Bio Rad, USA \\
\hline 4x Laemmli-Puffer & Roth, Deutschland \\
\hline Ammoniumpersulfat & Sigma Aldrich, USA \\
\hline Bepanthen & Bayer, Deutschland \\
\hline Bicinchoninsäure-Protein-Kit & Thermo Scientific, USA \\
\hline Bovines Serumalbumin (BSA) & Sigma Aldrich, USA \\
\hline Bromodesoxyuridin (BrdU) & Sigma Aldrich, USA \\
\hline Buprenorphin & Schering-Plough, Deutschland \\
\hline Diamidinphenylindol (DAPI) & AppliChem GmbH, Deutschland \\
\hline Dimethylsulfoxid (DMSO) & Sigma Aldrich, USA \\
\hline DNAse & Roche, Schweiz \\
\hline Enhanced-Chemoluminescence-Lösung & Cell Signaling Technology, USA \\
\hline Eotaxin-1 (CCL11) & R\&D Systems, USA \\
\hline Erythrozyten-Lyse & BD Biosciences, USA \\
\hline Eselserum & Merck Millipore, USA \\
\hline Ethylendiamintetraacetat (EDTA) & Promega, USA \\
\hline Fetales Kälberserum (FCS) & Merck Millipore, USA \\
\hline Glucose & Merck Millipore, USA \\
\hline
\end{tabular}




\section{Chemikalie}

Glycin

Isofluran

Kaliumchlorid ( $\mathrm{KCl})$

Kaliumdihydrogenphosphat $\left(\mathrm{KH}_{2} \mathrm{PO}_{4}\right)$

Methanol

Milchpulver

Natriumchlorid $(\mathrm{NaCl})$

Natriumdihydrogenphosphat $\left(\mathrm{Na}_{2} \mathrm{HPO}_{4}\right)$

Paraformaldehyd (PFA)

Percoll

Phenylmethylsulfonylfluorid (PMSF)

Polyacrylamid

Polysorbat 20 (Tween 20)

Precision-Plus-Protein-Kaleidoscop

Radioimmunopräzipitations (RIPA)-

Arbeitslösung

Salzsäure (HCL)

SB297006

Sodiumdodecylsulfat (SDS)

Tetramethlethylenediamine (TEMED)

Triphenyltetrazoliumchlorid (TTC)

Tris-aminomethan (Tris)

Triton X-100

Zitronensäure-Monohydrat
Hersteller, Land

Merck Millipore, USA

AbbVie, USA

Merck Millipore, USA

Sigma Aldrich, USA

Merck Millipore, USA

Sigma Aldrich, USA

Merck Millipore, USA

Merck Millipore, USA

Roth, Deutschland

GE Healthcare, Schweden

Cell Signaling Technology, USA

Roth, Deutschland

Merck Millipore, USA

Bio Rad, USA

Cell Signaling Technology, USA

Merck Millipore, USA

Sigma Aldrich, USA

Merck Millipore, USA

Sigma Aldrich, USA

Roth, Deutschland

Merck Millipore, USA

Sigma Aldrich, USA

Merck Millipore, USA 
Tabelle 4: Verbrauchsmaterial

\begin{tabular}{l|l} 
Verbrauchsmaterial & Hersteller, Land \\
\hline Cryomatrix & Thermo Fisher Scientific, USA \\
15 und 50 ml Falcons & Sarstedt, Deutschland \\
Fettstift Dako-Pen & Dako Agilent, USA \\
Immu-Mount-Eindeckmedium & Thermo Scientific, USA \\
Nadel & Braun, Deutschland \\
Objektträger & Menzel-Gläser, Deutschland \\
Objektträger-Deckglas & Menzel-Gläser, Deutschland \\
Petrischale & Sarstedt, Deutschland \\
Pipette & Eppendorf, Deutschland \\
Pipettenspitze & Sarstedt, Deutschland \\
Polyvinylidenfluorid (PVDF)-Membran & Merck Millipore, USA \\
Spritze & BD Plastipak, Deutschland \\
Tubes (verschiedener Größen) & Eppendorf, Deutschland \\
Whatman-Papier & Bio Rad, USA \\
Faden 3-0 & Eochicon, USA \\
Seidenfaden 5-0 & Docol Corporation, USA \\
Silikonbeschichtetes Monofilament 6-0 &
\end{tabular}

Tabelle 5: Primäre Antikörper

\begin{tabular}{l|l} 
Antikörper & Hersteller, Land \\
\hline $\begin{array}{l}\text { Monoklonaler Antikörper Kaninchen anti- } \\
\text { kalziumbindendes Protein b (s100b; 1:500 }\end{array}$ & Abcam, England \\
Immunhistochemie; 1:2000 Western-Blot) & \\
$\begin{array}{l}\text { Monoklonaler Antikörper Maus anti- } \\
\text { Doublecortin (Dcx; 1:500) }\end{array}$ & Abcam, England \\
$\begin{array}{l}\text { Monoklonaler Antikörper Maus anti- } \alpha- \\
\text { Tubulin (1:10.000) }\end{array}$ & Gene'Tex, USA
\end{tabular}




\section{Antikörper}

Monoklonaler Antikörper Ratte anti-BrdU $(1: 250)$

Polyklonaler Antikörper Huhn anti-saures

Gliafaserprotein (GFAP; 1:1000)

Polyklonaler Antikörper Kaninchen anti-

Zyklin-abhängige-Kinase 5 (CDK5;

$1: 1000)$

Polyklonaler Antikörper Kaninchen antiionisiertes kalziumbindendes Adapter-

Molekül (IBA1; 1:500)

Polyklonaler Antikörper Kaninchen anti-

Mikrotubuli-assoziiertes Protein 1A/1B-

leichte Kette 3 (LC3; 1:1000)

Polyklonaler Antikörper Kaninchen anti-

Mannoserezeptor (1:500)

Polyklonaler Antikörper Kaninchen anti-

neuronal nuclei (NeuN; 1:1000)

Polyklonaler Antikörper Kaninchen antip35 (1:1000)

\section{Hersteller, Land}

Bio Rad, USA

Merck Millipore, USA

SantaCruz, USA

WAKO, USA

Abcam, England

Abcam, England

Abcam, England

SantaCruz, USA

Tabelle 6: Sekundäre Antikörper

\begin{tabular}{l} 
Antikörper \\
\hline AlexaFlour488-Esel anti Ratte-IgG \\
(1:250) \\
AlexaFlour488-Ziege anti-Huhn-IgG \\
(1:250) \\
Cy3-Esel anti-Kaninchen-IgG (1:250) \\
Cy3-Esel anti-Maus-IgG (1:250) \\
Cy3-Esel anti-Ratte-IgG (1:250)
\end{tabular}

Antikörper

(1:250)

AlexaFlour488-Ziege anti-Huhn-IgG

Cy3-Esel anti-Maus-IgG (1:250)

-Esel anti-Ratte-IgG (1:250)

\section{Hersteller, Land}

JacksonImmunoResearch, England

JacksonImmunoResearch, England

JacksonImmunoResearch, England

JacksonImmunoResearch, England

JacksonImmunoResearch, England 


\begin{tabular}{l|l} 
Antikörper & Hersteller, Land \\
\hline $\begin{array}{l}\text { HRP-konjugierter polyklonaler Antikörper } \\
\text { Ziege anti-Kaninchen-IgG }(1: 10.000)\end{array}$ & Abcam, England \\
$\begin{array}{l}\text { HRP-konjugierter polyklonaler Antikörper } \\
\text { Ziege anti-Maus-IgG (1:10.000) }\end{array}$ & Abcam, England
\end{tabular}

Tabelle 7: Antikörper der Durchflusszytometrie

\begin{tabular}{l|l} 
Antikörper & Hersteller/ Land \\
\hline $\begin{array}{l}\text { CD11b Ratte anti-Maus-IgG-PE-Cy7 } \\
(1: 50)\end{array}$ & eBioscience, USA \\
CD16/32 FcX Ratte anti-Maus-IgG (1:50) & BioLegend, USA \\
CD19 Ratte anti-Maus-IgG-APC (1:50) & Becton Dickinson, USA \\
CD3 Ratte anti-Maus-IgG-PE (1:50) & Becton Dickinson, USA \\
CD45 Ratte anti-Maus-IgG-BV 510 (1:50) & Becton Dickinson, USA \\
Ly6C Ratte anti-Maus-IgG-V450 (1:50) & Becton Dickinson, USA \\
Ly6G Ratte anti-Maus-IgG-FITC (1:50) & Becton Dickinson, USA
\end{tabular}

Tabelle 8: Lösungen

\begin{tabular}{|c|c|}
\hline Lösung, Gel, Puffer & Zusammensetzung \\
\hline \multirow{3}{*}{$\begin{array}{l}\text { 1x Tris-gepufferte Salzlösung (TBS, pH } \\
7,4)\end{array}$} & 8,8 g $150 \mathrm{mM} \mathrm{NaCl}$ \\
\hline & 2,4 g $20 \mathrm{mM}$ Tris \\
\hline & $800 \mathrm{ml} \mathrm{dH_{2 } \mathrm { O }}$ \\
\hline \multirow{5}{*}{$\begin{array}{l}\text { 1x Phosphatgepufferte Salzlösung (PBS, } \\
\text { pH 7,4) }\end{array}$} & $8 \mathrm{~g} 137 \mathrm{mM} \mathrm{NaCl}$ \\
\hline & $0,2 \mathrm{~g} 2,7 \mathrm{mM} \mathrm{KCl}$ \\
\hline & 2,16 g $10 \mathrm{mM} \mathrm{Na}_{2} \mathrm{HPO}_{4}$ \\
\hline & $0,2 \mathrm{~g} 1,8 \mathrm{mM} \mathrm{KH}_{2} \mathrm{PO}_{4}$ \\
\hline & $800 \mathrm{ml} \mathrm{dH_{2 } \mathrm { O }}$ \\
\hline
\end{tabular}




\begin{tabular}{|c|c|}
\hline Lösung, Gel, Puffer & Zusammensetzung \\
\hline \multirow[t]{2}{*}{4 \% PFA Fixierlösung } & 40 g Paraformaldehyd \\
\hline & $1 \mathrm{~L} \mathrm{PBS}$ \\
\hline \multirow[t]{2}{*}{ Zitratpuffer (pH 6,0) } & 6 g 0,2\%iges Zitronensäure-Monohydrat \\
\hline & $3 \mathrm{~L} \mathrm{dH}_{2} \mathrm{O}$ \\
\hline \multirow[t]{4}{*}{ Blockpuffer (Immunhistochemie) } & TBS \\
\hline & $2 \%$ iges BSA (in TBS) \\
\hline & 10\%iges Eselserum \\
\hline & 0,25\%iges Triton X-100 \\
\hline \multirow[t]{6}{*}{ Trenn- und Sammelgel } & $30 \%$ iges Polyacrylamid \\
\hline & $1 \mathrm{M}$ Tris + SDS (pH 6,8) \\
\hline & 1,5 M Tris + SDS (pH 8,8) \\
\hline & $10 \%$ iges Ammoniumpersulfat (in $\mathrm{dH}_{2} \mathrm{O}$ ) \\
\hline & TEMED \\
\hline & $\mathrm{dH}_{2} \mathrm{O}$ \\
\hline \multirow[t]{3}{*}{ 1x Tris-HCL/SDS (pH 6,8) } & 12,1 g 0,1 M Tris \\
\hline & $0,4 \mathrm{~g} 1,4 \mathrm{mM}$ SDS \\
\hline & $100 \mathrm{ml} \mathrm{dH}{ }_{2} \mathrm{O}$ \\
\hline \multirow[t]{3}{*}{ 1,5x Tris-HCL/SDS (pH 8,8) } & $91 \mathrm{~g} 0,8 \mathrm{M}$ Tris \\
\hline & $2 \mathrm{~g} 7 \mathrm{mM}$ SDS \\
\hline & $500 \mathrm{ml} \mathrm{dH_{2 }} \mathrm{O}$ \\
\hline \multirow[t]{4}{*}{ 10x Elektrophorese-Puffer } & $15,12 \mathrm{~g} 250 \mathrm{mM}$ Tris \\
\hline & 71,25 g 1,9 M Glycin \\
\hline & $5 \mathrm{~g} 1 \%$ iges SDS \\
\hline & $500 \mathrm{ml} \mathrm{d} \mathrm{H}_{2} \mathrm{O}$ \\
\hline \multirow[t]{2}{*}{ 1x Elektrophorese-Puffer } & $100 \mathrm{ml}$ Stocklösung \\
\hline & $900 \mathrm{ml} \mathrm{dH}{ }_{2} \mathrm{O}$ \\
\hline \multirow[t]{3}{*}{ 10x Transferpuffer } & $30,25 \mathrm{~g} 25 \mathrm{mM}$ Tris \\
\hline & 144 g 192 mM Glycin \\
\hline & 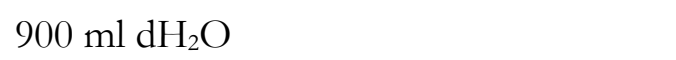 \\
\hline
\end{tabular}


Lösung, Gel, Puffer

1x Transferpuffer

10x TBS-T

1x TBS-T

$5 \%$ Milchlösung

Verdauungspuffer

Percoll-Verdünnugspuffer ( $\mathrm{pH} 7,0)$

Percoll-Gradient

FACS-Puffer

Erythrozytenlyse-Puffer

\section{Zusammensetzung}

$100 \mathrm{ml}$ Stocklösung

$200 \mathrm{ml}$ Methanol (100 \%)

$700 \mathrm{ml} \mathrm{dH}_{2} \mathrm{O}$

24,2 g 0,2 M Tris

80 g $1,5 \mathrm{M} \mathrm{NaCl}$

$10 \mathrm{ml}$ 1\%iges Tween 20

$900 \mathrm{ml} \mathrm{dH}_{2} \mathrm{O}$

$100 \mathrm{ml}$ 10x Stocklösung

$900 \mathrm{ml} \mathrm{dH_{2 } \mathrm { O }}$

Milchpulver

TBS-T

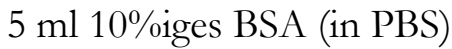

$5 \mathrm{~g}$ Glucose

$5 \mathrm{ml}$ DNAse $\left(10 \mathrm{mg} / \mathrm{ml} \mathrm{dH}_{2} \mathrm{O}\right)$

$500 \mathrm{ml}$ PBS

$100 \mathrm{ml} 10 \mathrm{x}$ PBS

$300 \mathrm{ml} \mathrm{dH}_{2} \mathrm{O}$

$20 \mathrm{ml}$ Resuspensionspuffer

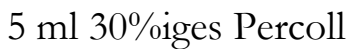

$4 \mathrm{ml}$ 45\%iges Percoll

$2 \mathrm{ml} \mathrm{70 \% iges} \mathrm{Percoll}$

$100 \mathrm{ml}$ Fluorescence activated cell sorting

(FACS)-Puffer

$3 \mathrm{ml} \mathrm{FCS}$

$97 \mathrm{ml}$ PBS

$1 \mathrm{ml}$ Erylyse Solution

$10 \mathrm{ml} \mathrm{dH_{2 } \mathrm { O }}$ 


\subsection{Methoden}

Die Experimente dieser Arbeit wurden in der Arbeitsgruppe für Translationale Schlaganfallforschung in der Klinik für Neurologie der Universitätsmedizin Göttingen unter der Leitung von Herrn Prof. Dr. med. Thorsten R. Döppner und der Betreuung durch Frau Dr. phil. nat. Bozena Zechmeister durchgeführt. Diese führte freundlicherweise sämtliche Tieroperationen und die standardisierten Verhaltenstests durch.

\subsubsection{Versuchstierhaltung}

Für die hier vorliegende Studie wurden männliche C57BL6/J-Mäuse (Charles River Laboratorien, Deutschland) mit einem Alter von sechs Wochen bis sieben Monaten und einem Gewicht von 22-25 g bei zirkadianer Tagesrhythmik mit freiem Zugang zu Wasser und Futter gemäß Verordnungen der örtlichen Behörden im Tierstall des Universitätsklinikums Göttingen gehalten. Die Versuchstiere wurden randomisiert und streng zufällig den Experimental- und Kontrollgruppen zugeteilt. Die Experimente und Analysen erfolgten verblindet. Die Experimentalgruppe ist definiert durch die Behandlung mit Eotaxin-1 oder dem Rezeptorantagonisten SB297006, indessen die Kontrollgruppe eine Trägersubstanz erhielt. Als Trägersubstanzen wurde eine phosphatgepufferte Salzlösung (PBS) oder Dimethylsulfoxid (DMSO) verwendet.

\subsubsection{Experimentelle Gruppen}

Am Tag null des experimentellen Aufbaus wurden die Mäuse der Okklusion der Arteria cererbri media (MCAO) zugeführt, und es wurden verschiedene Endpunkte, d. h. nach 24 Stunden (Kurzzeitversuch), sieben Tagen (Intermediärversuch) und 28 Tagen (Langzeitversuch), definiert. Alle Versuchstiere erhielten im Anschluss an die Operation die erste Gabe von $10 \mu \mathrm{g}$ pro kg KG Eotaxin-1 oder $100 \mu \mathrm{l}$ PBS intraperitoneal. Während bei den Kurzzeitversuchen keine weiteren Injektionen durchgeführt wurden, wurde bei den Intermediär- und Langzeitversuchen (7 und 28 Tage) in der ersten Woche täglich eine intraperitoneale Injektion von Eotaxin-1 bzw. PBS injiziert. In der Überlebensgruppe mit 28 Tagen Beobachtungszeit wurde den Tieren vom achten bis 18. Tag zusätzlich $50 \mathrm{mg}$ pro kg KG Bromdesoxyuridin (BrdU, ein Proliferationsmarker) gespritzt. Der Versuchsaufbau ist exemplarisch in Abb. 1 dargestellt. 


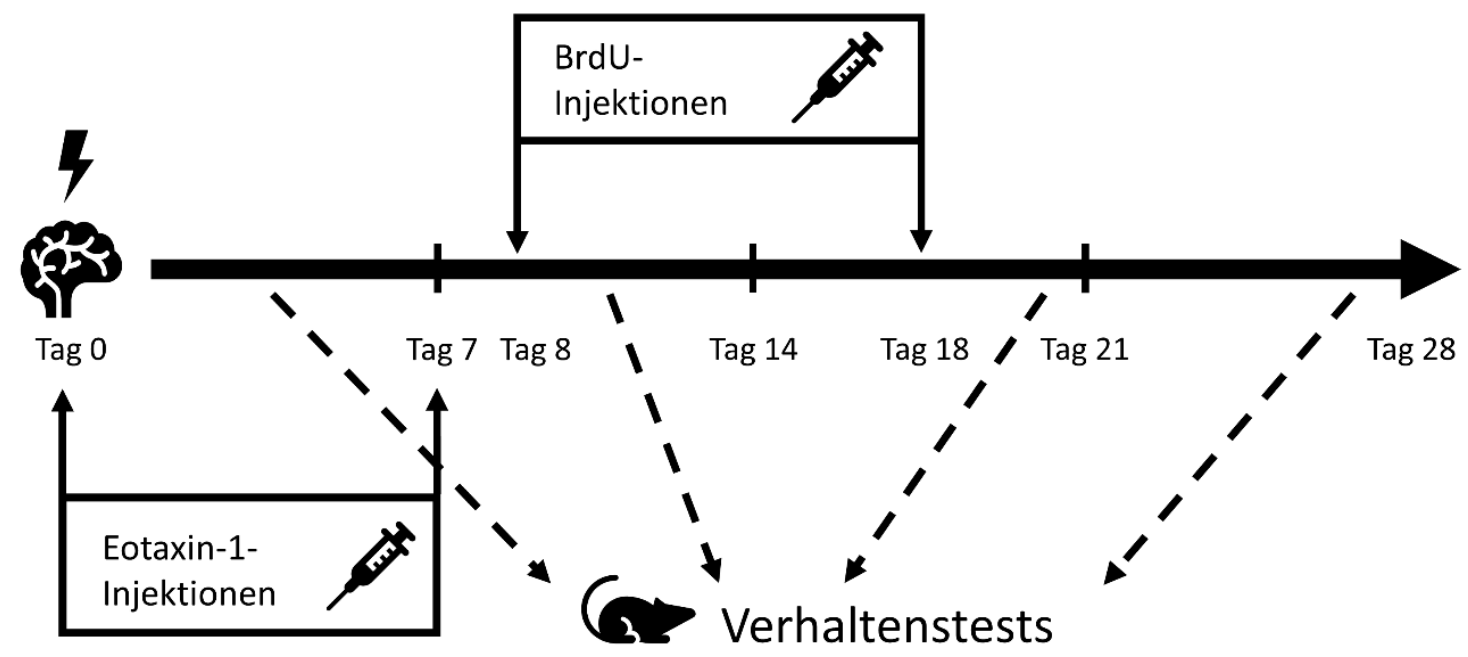

Abbildung 1: Versuchsaufbau des Langzeitversuches mit Eotaxin-1. C57BL6-Mäuse erhielten an Tag null nach 45-minütiger zerebraler Ischämie mit Beginn der Reperfusion und an den folgenden sieben Tagen täglich intraperitoneal $10 \mu \mathrm{g}$ pro kg KG Eotaxin-1 oder $100 \mu \mathrm{l}$ PBS als Kontrolle. An den Tagen 8-18 wurde BrdU intraperitoneal verabreicht. An ausgewählten Tagen wurden distinkte Verhaltenstests durchgeführt. Die Tiere wurden nach 28 Tagen euthanasiert.

Die Versuche wurden an zwei verschiedenen Altersgruppen durchgeführt. Dies sind zum einen sechs Wochen alte Tiere (adoleszente Mäuse) und zum anderen sechs Monate alte Tiere (adulte Mäuse). Es wurden bei den Kurzzeitversuchen der akute Gewebeschaden und die akute Immunantwort untersucht, während im subakuten Stadium des Schlaganfalls vornehmlich die periphere und die zentrale post-ischämische Inflammation betrachtet und mögliche Signalwege analysiert wurden. Im Langzeitversuch wurde die funktionale Erholung anhand von standardisierten Verhaltenstests in einem Beobachtungszeitraum von bis zu 28 Tagen untersucht, der chronische Gewebeschaden und die Neuro- bzw. Gliogenese analysiert. In den Tabellen 9-11 sind die Methoden und die jeweilige Anzahl der Versuchstiere aufgelistet.

Tabelle 9: Anzahl der adoleszenten Versuchstiere mit Eotaxin-1- oder PBS-Behandlung

\begin{tabular}{l|l|l|l} 
Analyse & 24 Stunden & 7 Tage & 28 Tage \\
\hline TTC-Färbung & $\mathrm{n}=20$ & & \\
Immunfluoreszenz & $\mathrm{n}=20$ & $\mathrm{n}=18$ \\
Western-Blot & & $\mathrm{n}=9$ & \\
Durchflusszytometrie & &
\end{tabular}




\begin{tabular}{l|l|l|l} 
Analyse & 24 Stunden & 7 Tage & 28 Tage \\
\hline Verhaltenstests & & & $\mathrm{n}=18$
\end{tabular}

Tabelle 10: Anzahl der adulten Versuchstiere mit Eotaxin-1- oder PBS-Behandlung

\begin{tabular}{l|l|l|l} 
Analyse & 24 Stunden & 7 Tage & 28 Tage \\
\hline TTC-Färbung & $\mathrm{n}=15$ & & \\
$\begin{array}{l}\text { Immunfluoreszenz } \\
\text { Western-Blot }\end{array}$ & $\mathrm{n}=15$ & $\mathrm{n}=8$ & \\
Durchflusszytometrie & & $\mathrm{n}=8$ & \\
Verhaltenstests & & & $\mathrm{n}=13$
\end{tabular}

Zur Bestätigung der aus den Ergebnissen gebildeten Hypothesen wurden die Mäuse beider Altersgruppen mit dem Rezeptorantagonisten SB297006 oder mit DMSO als Kontrolle im Kurz- und Langzeitversuch behandelt.

Tabelle 11: Anzahl der Versuchstiere mit SB297006- oder DMSO-Behandlung

\begin{tabular}{l|ll|ll} 
Analyse & $\mathbf{3}$ Tage & & $\mathbf{2 8}$ Tage & \\
& Adoleszent & Adult & Adoleszent & Adult \\
\hline TTC-Färbung & $\mathrm{n}=19$ & $\mathrm{n}=20$ & & \\
Immunfluoreszenz & $\mathrm{n}=19$ & $\mathrm{n}=20$ & $\mathrm{n}=18$ & $\mathrm{n}=15$ \\
Verhaltenstests & & & $\mathrm{n}=18$ & $\mathrm{n}=15$
\end{tabular}

Die Tiere erhielten im Anschluss an die Induktion der zerebralen Ischämie die erste intraperitoneale Injektion von $1 \mathrm{mg}$ pro $\mathrm{kg} \mathrm{KG} \mathrm{SB297006} \mathrm{oder} 50 \mu \mathrm{l}$ DMSO und folgend tägliche Gaben über drei Tage. Das Gewebe wurde mittels Triphenyltetrazoliumchlorid (TTC)-Färbung und einer Immunfluoreszenzfärbung untersucht. Im Langzeitversuch erhielten die Tiere analog zum Versuchsaufbau mit Eotaxin-1 vom achten bis 18. Tag $50 \mathrm{mg}$ pro kg KG BrdU und täglich den Antagonisten oder DMSO über sieben Tage. Die 
Verhaltenstests wurden an ausgewählten Tagen durchgeführt, und das Gewebe wurde immunhistochemisch untersucht (Abb. 2).

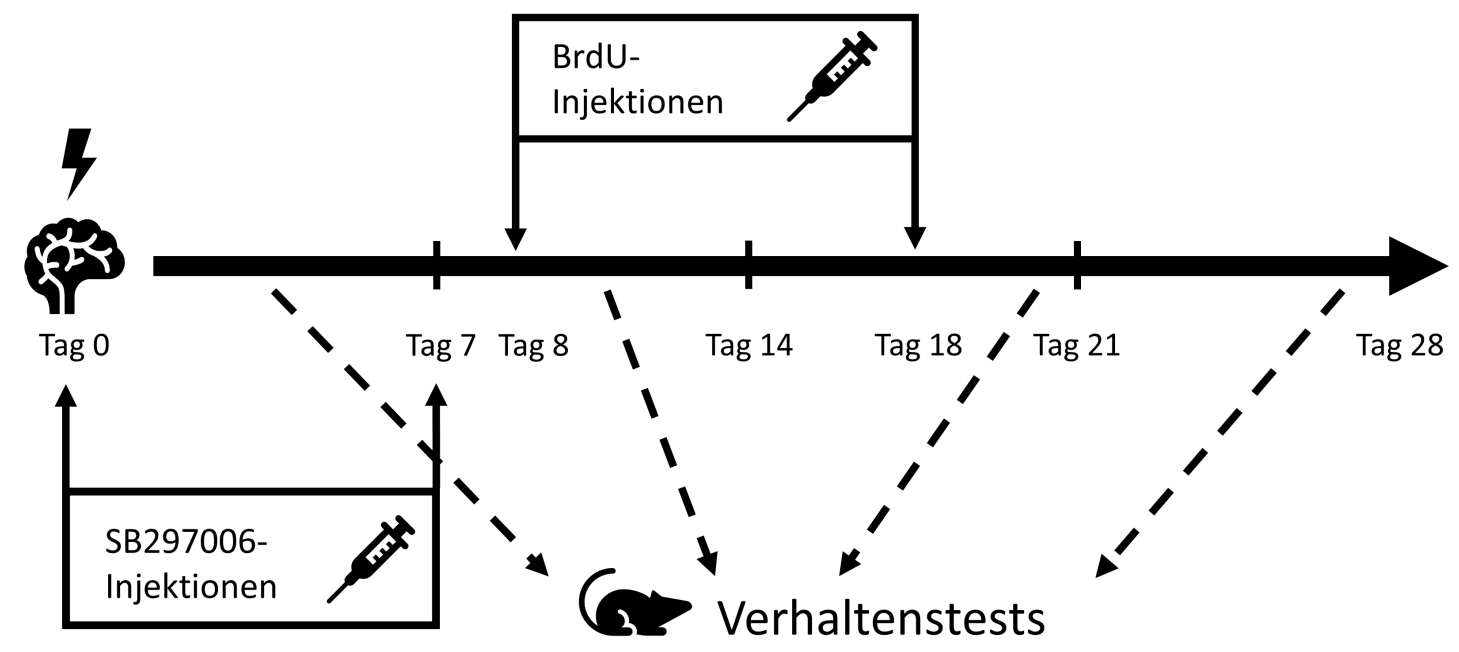

Abbildung 2: Versuchsaufbau des Langzeitversuches mit SB297006. C57BL6-Mäuse erhielten an Tag null nach 45-minütiger zerebraler Ischämie mit Beginn der Reperfusion und an den folgenden sieben Tagen täglich intraperitoneal $1 \mathrm{mg}$ pro kg KG SB297006 oder $50 \mu \mathrm{l}$ DMSO als Kontrolle. An den Tagen 8-18 wurde BrdU intraperitoneal verabreicht. An ausgewählten Tagen wurden distinkte Verhaltenstests durchgeführt. Die Tiere wurden nach 28 Tagen euthanasiert.

\subsubsection{Okklusion der Arteria cerebri media (MCAO)}

Die Induktion der zerebralen Ischämie wurde über das Fadenokklusionsmodell der Maus erreicht, bei dem es zu einem funktionellen Verschluss der Arteria cerebri media (MCA) kommt. Diese Methode ist reliabel und in der Arbeitsgruppe seit vielen Jahren standardisiert (Doeppner et al. 2017). Die Tiere wurde mit einem 2\%igem Isofluran-Frischluft-Gasgemisch narkotisiert und es wurde ein Schlaganfall im rechten Stromgebiet der MCA gesetzt. Zu Beginn wurde Buprenorphin (0,1 mg pro kg KG) als Analgetikum subkutan injiziert und Bepanthen, zum Schutz der Augen vor dem Austrocknen aufgetragen. Während der Operation wurde der Blutfluss mittels Laser-Doppler gemessen. Die Mäuse wurden auf einer Heizplatte platziert, und die Körpertemperatur der Versuchstiere unter der Narkose wurde konstant über ein rektales Feedbackthermometer gemessen. Die Halsregion wurde mit 70\%igem Ethanol desinfiziert, und ein Hautschnitt wurde im lateralen Halsdreieck gesetzt. Die Arteria carotis communis (CCA) und die Arteria carotis externa (ECA) wurden frei präpariert. Diese wurden mit einem 5-0 Seidenfaden jeweils proximal permanent verschlossen. Ein neurochirurgischer Gefäßclip wurde transient auf den proximalen Abgang der Arteria carotis interna (ICA) gesetzt, so dass eine vorübergehende Blutleere in der CCA zwischen proximaler Ligatur, Verschluss der proximalen ECA und der proximalen ICA 
herrscht. Ein mit Silikon beschichtetes Mikrofilament wurde über einen kleinen Einschnitt in der CCA installiert, das Filament bis zum geschlossenen Clip vorgeschoben und letzterer dann entfernt. Sodann wurde das Filament über die nun offene ICA bis zum proximalen Abgang der rechten MCA vorgeschoben. Das verblieb dort für $45 \mathrm{~min}$ in situ, um eine transiente fokale zerebrale Ischämie zu induzieren. Im Anschluss an diese erfolgte die Retraktion des Fadens und der Verschluss der Wunden einschließlich einer adäquaten Hautnaht mit einem 3-0 Faden. Die Reperfusionszeit betrug - wie oben dargelegt - 24 Stunden, 7 Tage oder 28 Tage.

Postoperativ wurde auf eine ausreichende Flüssigkeitssubstitution mit $1 \mathrm{ml} \mathrm{NaCl}$ subkutan geachtet, und es wurde eine adäquate Analgesie (siehe oben) durchgeführt. Zusätzlich wurden die Tiere nach einem Score bewertet. Dieser umfasste das Körpergewicht, den Allgemeinzustand, das Spontanverhalten, die Wundheilung und die Motorik bzw. Koordination. Das Überschreiten eines bestimmten Scorewertes erforderte die Einleitung einer tierärztlichen Notfalltherapie oder das sofortige schmerzlose Töten des Tieres. Abbruchkriterien waren zerebrale Anfälle, die mehr als 10 Minuten oder wiederholt innerhalb von 24 Stunden auftreten, 24 Stunden keine Nahrungs- oder Flüssigkeitsaufnahme und somit ein Gewichtsverlust von mehr als 20 \% des Körpergewichts, das Auftreten einer Biot'schen Atemstörung und fehlendes Erwachen des Tieres nach der Operation. Traf eines dieser Kriterien zu, erfolgt die sofortige schmerzlose Tötung des Tieres.

\subsubsection{Darstellung der post-ischämischen Zellproliferation mittels BrdU}

BrdU ist ein chemisch synthetisiertes Analogon der Nukleinbase Thymidin. Es wird im Zellzyklus während der S-Phase der semikonservativen Replikation der Desoxyribonukleinsäure (DNA) eingebaut. BrdU ist somit ein Indikator für die Zellproliferation, welche zum Zeitpunkt der BrdU-Applikation (hier: Tag 8 bis 18) stattgefunden hat. Gleichwohl sei angemerkt, dass BrdU-Inkorporationen unter Umständen auch nach Zellreparaturprozessen ohne das Vorhandensein einer Zellproliferation auftreten können (Taupin 2007). Die Zellproliferation wurde immunhistochemisch, mittels einer Doppelfärbung gegen BrdU und gegen den Zellkern untersucht. Die Zellkernfärbung erfolgte gegen Diamidinphenylindol (DAPI). Das Ansetzen und Aufziehen der BrdU-Lösung fand stets unter Lichtschutz statt, und die Injektion erfolgte intraperitoneal in einer Dosis von $50 \mathrm{mg}$ pro $\mathrm{kg} \mathrm{KG.}$ 


\subsubsection{Verhaltenstests}

Um Aussagen über die funktionelle Erholung, das Gedächtnis und die motorisch-sensiblen Fähigkeiten zu treffen, wurden distinkte Verhaltenstests durchgeführt. Die ausgewählten Verhaltenstests sind in unserer Arbeitsgruppe etabliert und werden regelmäßig durchgeführt (Doeppner et al. 2014). Die Tiere wurden ein bis zwei Tage vor der Induktion der Ischämie mit den Geräten und Tests vertraut gemacht und trainiert. Im Rahmen dieser Dissertation wurden der Rota-Rod-Test und der Corner-Turn-Test durchgeführt. Diese Tests wurden am 1., 3., 5., 7., 14., 21. und 28. Tag nach dem Schlaganfall ausgeführt.

\subsubsection{Rota-Rod-Test}

Mit diesem Test prüfte man die motorisch-sensiblen Fähigkeiten der Versuchstiere. Das Tier saß auf einem rotierenden Zylinder. Dieser drehte sich mit 4 bis zu $40 \mathrm{rpm}$ und erreichte seine maximale Geschwindigkeit nach 260 Sekunden. Es wurde die Zeit bis zum Herunterfallen des Tieres vom rotierenden Zylinder gemessen. Der Test wurde spätestens nach 300 Sekunden beendet. Die Tiere durchliefen drei Testversuche, und es wurde der Mittelwert bestimmt.

\subsubsection{Corner-Turn-Test}

Bei diesem Verfahren wurden sensomotorische Defizite und die posturale Instabilität nach dem Schlaganfall betrachtet. Es wurden zwei vertikale Platten in einem Winkel von $30^{\circ}$ zueinander aufgestellt, so dass sie eine Ecke (den sogenannten „Corner“) bildeten. Das Tier wurde nun in diesen Corner platziert und bewegte sich auf diesen zu. Sobald die Vibrissen eine der beiden Platten berührten, verlässt die Maus unter physiologischen Bedingungen streng zufällig den Corner. Schlaganfallmäuse präferieren aufgrund der vorhandenen sensomotorischen Hemiparese die nicht-paretische Körperseite. In diesem Fall neigen die Schlaganfallmäuse also dazu die Ecke über die rechte (gesunde) Körperseite zu verlassen. Es wurden zehn Testdurchläufe durchgeführt und aus diesen der Lateralitätsindex ((Anzahl Linksdrehungen - Anzahl Rechtsdrehungen) / Anzahl der Durchläufe) errechnet. Bei gesunden Tieren betrug dieser Score ca. 0,5. Ein starkes sensomotorisches Defizit spiegelte sich durch einen approximativen Wert von 1 wider.

\subsubsection{Darstellung des post-ischämischen Gewebeschadens mittels TTC-Färbung}

Die TTC-Färbung ist eine etablierte Methode zur Darstellung und Quantifizierung des Infarktareals. TTC ist ein Redox-Farbstoff, der sich oxidiert farblos und reduziert rot färbt. In vitalem Gewebe reduzieren die mitochondrialen Enzyme das TTC, was zu einer 
Rotfärbung führt. Enzymatisch inaktives Gewebe hingegen kann den Farbstoff nicht reduzieren, folglich stellt sich das geschädigte Gewebe farblos bzw. weiß dar. Für die TTC-Färbung wurden die Tiere in eine tiefe Narkose mit 5\%igem Isofluran und Sauerstoff gelegt und durch eine schmerzlose zervikale Dislokation euthanasiert. Der Kopf wurde abgetrennt und das Gehirn entnommen. Dieses wurde in einer Gehirnmatrix fixiert und in $2 \mathrm{~mm}$ dicke koronare Schnitte geschnitten. Es folgte die Färbung mit dem TTC für zehn Minuten im Dunklen. Die Schnitte wurden von beiden Seiten eingescannt und mittels ImageJ Software ausgewertet, indem das Infarktvolumen mit dem gesunden Gewebe verrechnet wurde.

\subsubsection{Immunhistochemische Analyse}

\subsubsection{Immunhistochemische Färbung nach 24 Stunden}

Zur Darstellung des akuten Gewebeschadens und der post-ischämischen Immunantwort nach 24 Stunden wurde eine Immunfluoreszenz mit einem maturen neuronalen Marker neuronal nuclei $(\mathrm{NeuN})$ und einem Marker, der Mikrogliazellen anfärbt, ionisiertes kalziumbindendes Adapter-Molekül (IBA1) angefertigt. Zur Herstellung der immunhistochemischen Schnitte wurde eine transkardiale Perfusion durchgeführt. Diese erfolgte unter Narkose durch eine Inzision in der linken Herzkammer und dem rechten Vorhof und Spülung mit zunächst PBS, gefolgt von 4\%igem Paraformaldehyd (PFA). Anschließend wurde das Gehirn entnommen und in $2 \mathrm{~mm}$ dicke Schnitte geschnitten. Das Gewebe wurde in 4\%iges PFA für 24 Stunden und darauffolgend in Saccharose für weitere 24 Stunden gelegt bevor es in Cryomatrix fixiert und bei $-80^{\circ} \mathrm{C}$ gelagert wurde. Der nun gefrorene Block wurde in einen Cryostat eingespannt, und es wurden bei $-20{ }^{\circ} \mathrm{C} 12 \mu \mathrm{m}$ dicke Schnitte geschnitten, die auf Objektträger übertragen wurden. Die Objektträger wurden bis zur Färbung bei $-20^{\circ} \mathrm{C}$ aufbewahrt. Die immunhistochemische Färbung wurde mit den oben genannten Chemikalien, Lösungen und Verbrauchsmaterialien durchgeführt (Tab. 3-6 und 8). Die Schnitte wurden nach kurzer Erwärmung auf Raumtemperatur in Zitratpuffer ( $\mathrm{pH}$ 6,0) aufgekocht. Es folgten Waschschritte mit einer tris-gepufferten Salzlösung (TBS). Der Hintergrund wurde mit einem Blockpuffer aus 2\%igem bovinen Serumalbumin (BSA), 0,25\%igem Triton X-100, 10\%igem Eselserum und TBS geblockt. Anschließend inkubierten die primären Antikörper gelöst im Blockpuffer über Nacht in einer Feuchtkammer. Am zweiten Tag folgten nach einigen Waschschritten in TBS die Inkubation des sekundären Antikörpers über eine Stunde in der Feuchtkammer. Die DAPI-Färbung erfolgte für 10 Minuten im Dunklen zum Anfärben der Zellkerne. Im letzten Schritt wurden die 
Objektträger mit wenigen Tropfen eines Eindeckmediums bedeckt und die Deckgläser auf den Objektträgern fixiert.

\subsubsection{Immunhistochemische Färbung nach 28 Tagen}

Nach 28 Tagen erfolgte eine Doppelfärbung gegen BrdU und einem der folgenden Antikörper: NeuN, Doublecortin (Dcx, immaturer neuronaler Marker), kalziumbindendes Protein b (s100b) und saures Gliafaserprotein (GFAP) nach dem oben beschriebenen Protokoll. Zudem wurde der chronische Gewebeschaden und die post-ischämische Immunantwort mittels NeuN- und IBA1-Färbung erneut betrachtet.

Die Analyse der Zellen wurde an einem Epifluoreszenzmikroskop in den sogenannten „regions of interest“ (ROI) mit Hilfe der AxioVision Software ausgezählt. Die ROI umfassten die Subventrikulärzone (SVZ) und die Stammganglien. Die stereotaktischen Koordinaten der SVZ befanden sich 0,14 $\mathrm{mm}$ anterior, $1,25 \mathrm{~mm}$ lateral und $2 \mathrm{~mm}$ ventral des Bregmas. Die quantitative Zellanalyse in den Stammganglien erfolgte 0,14 mm anterior, $2 \mathrm{~mm}$ lateral und $3 \mathrm{~mm}$ ventral. Nach 24 Stunden wurden die absolute Anzahl der als positiv gewerteten Zellen der Kontrollgruppe mit der Experimentalgruppe verglichen. In der Doppelfärbung erfolgte die Auszählung anhand der Kolokalisation von BrdU, DAPI und entsprechendem Differenzierungsprotein.

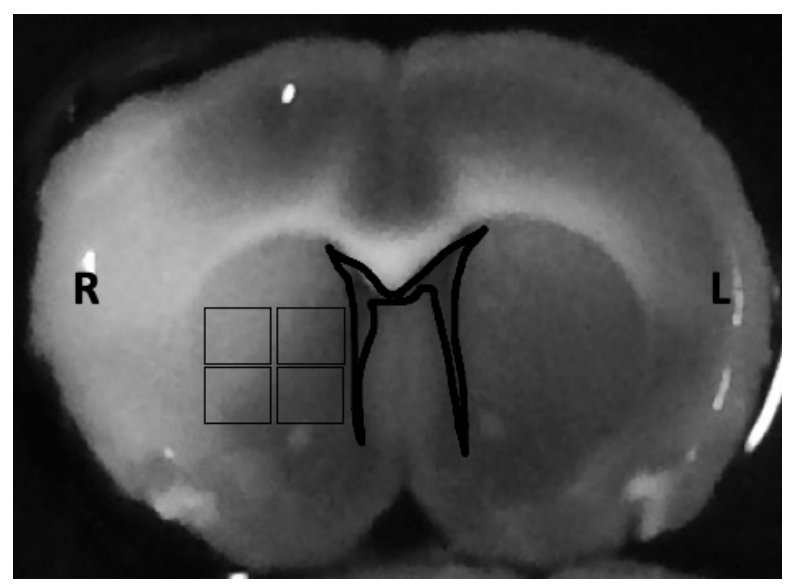

Abbildung 3: Schematische Darstellung der ROI. Darstellung eines Koronarschnittes des murinen Gehirns. Die Kästchen stellen exemplarisch die vier ROI im rechten, ischämischen Striatum der Maus dar, Schwarz markiert ist das Ventrikelsystem zur Orientierung im Bild und die Bezeichnungen für rechts (R) und links (L). 


\subsubsection{Western-Blot}

Eine etablierte Methode zur quantitativen Bestimmung von exprimierten Proteinen im Gewebe ist der Western-Blot. Die Analyse erfolgte an Gehirnlysaten. Die Gehirne wurden nach der schmerzlosen Tötung des Tieres in Stickstoff schockgefrostet und bis zur Verarbeitung in $-80^{\circ} \mathrm{C}$ aufbewahrt. Zunächst wurde das Gehirn in die Hemisphären getrennt und im Homogenisator (50 $\mathrm{Hz}$ Oszillationen) mit einem Lysepuffer aus einem Radioimmunopräzipitation (RIPA)-Puffer und dem Protease-Inhibitor Phenylmethylsulfonylfluorid (PMSF) lysiert. Anschließend wurde mit Hilfe eines Bicinchoninsäure-Kits photometrisch der Proteingehalt bestimmt. Das Herstellen der Gele erfolgte mit den in den Tabellen 3-6 und 8 aufgeführten Chemikalien und Puffern. Als erstes wurde das Trenngel aufgegossen und mit Isopropanol bis zur vollständigen Polymerisierung bedeckt. Danach wurde das Sammelgel aufgefüllt und ein 10-well-Kamm installiert. Die Proben mit einem Gehalt von 30 oder $40 \mu \mathrm{g}$ Protein, versetzt mit 4x Laemmli und bei $95{ }^{\circ} \mathrm{C}$ circa fünf Minuten denaturiert, wurden auf das Sodiumdodecylsulfat (SDS)-Gel (10, 12 oder $15 \%$ ) beladen. In die erste Geltasche wurde ein Markerprotein gesetzt, das den Standard abbildete. Anschließend startete die Elektrophorese, bei der die Proteine nach ihrer Größe aufgetrennt wurden, mit 45 Volt für das Sammelgel und 95 Volt für das Trenngel im Elektrophoreselauf-Puffer.

Es folgte das eigentliche „Blotten“. Dabei wurden die Proteine vom Gel auf eine Polyvinylidenfluorid (PVDF)-Membran übertragen. Der Transfer der Proteine vom Gel auf die Membran erfolgte durch das Übereinanderschichten dieser zu einem Blotsandwich und das Einspannen in ein elektrisches Feld, so dass die negativ geladenen Proteine zur Anode wanderten. Vor dem Transfer inkubierte man die PVDF-Membran in Methanol für eine Minute. Der Transfer wurde bei $4{ }^{\circ} \mathrm{C}$ durchgeführt. Danach blockten die Membranen für eine Stunde in einer 5\% igen Milchlösung (Milchpulver in 1x TBS-T). Die Membranen mit den primären Antikörpern inkubierten über Nacht, gelöst in einer 5\%igen Milchlösung bei $4{ }^{\circ} \mathrm{C}$ auf einem Schüttler. Verwendet wurden s100b und der Mannoserezeptor als Mikrogliazellmarker. Zur Detektion von Signalwegen der Autophagie oder der Apoptose wurden das Mikrotubuli-assoziiertes Protein 1A/1B-leichte Kette 3 (LC3) und die Zyklinabhängige-Kinase 5 (CDK5) sowie p35/p25 verwendet.

Am nächsten Tag folgte das Inkubieren des entsprechenden sekundären Antikörpers bei Raumtemperatur in $10 \mathrm{ml}$ 5\%iger Milchlösung nachdem die Membranen in 1x TBS-T gewaschen wurden. Zur Darstellung der Banden wurden die Membranen mit einer Enhanced-Chemoluminescence-Lösung inkubiert und im Chemi-Doc entwickelt. 
Softwaregestützt folgte die densitometrisch quantitative Auswertung durch EvolutionCapt. Dabei setzte man den Antikörper ins Verhältnis zu der zugehörigen Ladekontrolle mit $\alpha$-Tubulin.

\subsubsection{Durchflusszytometrie}

Die Durchflusszytometrie ist ein Messverfahren zur Analyse von Zellen nach ihrer Größe und Granularität. Dabei werden die einzelnen Zellen durch ein Licht bzw. einen Laserstrahl geführt und streuen bzw. emitieren das Licht unterschiedlich, welches von einem Detektor gemessen wird. Das Vorwärtsstreulicht (FSC) gibt Auskunft über die Größe der Zelle, während das Seitwärtsstreulicht (SSC) ein Maß für die Granularität der Zelle ist. Das Durchflusszytometer kann zudem Fluoreszenzfarben messen, und somit wurden Antikörper gegen zellspezifische Marker fluoreszenzmarkiert. Zur Bewertung der systemischen Immunantwort wurde das Blut der Tiere nach sieben Tagen untersucht. Die Analyse der zentralen Immunantwort erfolgte ebenfalls nach sieben Tagen durch die Untersuchung der ischämischen Hemisphäre der Gehirne. Die Blutentnahme erfolgte unter tiefer Narkose transkardial aus der linken Herzkammer. Es wurden drei Tropfen Blut in ein Röhrchen mit Ethylendiamintetraacetat (EDTA) abgenommen, damit das Blut nicht gerinnt. Anschließend wurde die Maus mit PBS perfundiert, dekapitiert und das Gehirn entnommen.

Das Blut wurde bei $4{ }^{\circ} \mathrm{C}$ und $3000 \mathrm{rpm}$ für fünf Minuten zentrifugiert und mit PBS zur Fixierung der Zellen gewaschen. Die Zellsuspensionen aus dem Blut wurden mit einem Fc-Block (1:50, CD16/32 Ratte anti-Maus-IgG) für zehn Minuten im Dunkeln auf Eis inkubiert, um unspezifische Bindungen zu vermeiden. Anschließend inkubierte der Antikörpermix (1:50) für zwanzig Minuten im Dunkeln auf Eis. Es wurden folgende Antikörper gegen die Oberflächenmarker verschiedener Zellen verwendet:

Tabelle 12: Oberflächenmarker der Durchflusszytometrie

\begin{tabular}{l|l} 
Oberflächenmarker & Zellen \\
\hline CD3 & T-Zellen \\
CD11b & Monozyten \\
CD19 & B-Zellen \\
CD45 & Leukozyten, Mikroglia
\end{tabular}




\begin{tabular}{l|l} 
Oberflächenmarker & Zellen \\
\hline Ly6G & $\begin{array}{l}\text { polymorphe neutrophile Granulozyten } \\
\text { Monozyten, Makrophagen, dendritische } \\
\text { Ly6C }\end{array}$ \\
\hline Zellen
\end{tabular}

Die Erythrozyten wurden durch eine Erythrozytenlyse aufgelöst, so dass die weißen Blutzellen deutlicher detektiert werden, indem $350 \mu$ l Erythrozytenlyse zu den Zellsuspensionen hinzugegeben wurde. Die Resuspension erfolgte unter Sicht bis die Zellsuspension klar erschien. Die Erythrozytenlyse wurde mit $750 \mu \mathrm{l}$ mit einem fluorescence activated cell sorting (FACS)-Puffer abgestoppt, und es folgten Zentrifugationen für sechs Minuten bei $4{ }^{\circ} \mathrm{C}$ und $1250 \mathrm{rpm}$ mit Waschritten im FACS-Puffer.

Das Gehirn wurde nach der transkardialen Perfusion mit PBS direkt weiterverarbeitet. Die ischämische Hemisphäre wurde in einer Petrischale zerkleinert. Das nun manuell homogenisierte Gewebe wurde in einen Verdauungspuffer aufgenommen und anschließend zentrifugiert bei $1600 \mathrm{rpm}$ und $4{ }^{\circ} \mathrm{C}$ für zehn Minuten. Der Überstand wurde verworfen und das Zellpellet in 30\%igem Percoll-Puffer gelöst. Es wurde ein Percoll-Gradient (drei Phasen) hergestellt und die Zellsuspension aufgeladen. Diese wurde für 20 Minuten bei $2300 \mathrm{rpm}$ und $4{ }^{\circ} \mathrm{C}$ zentrifugiert. Dabei setzte sich das Myelin ab, und die Leukozyten sammelten sich in der mittleren Phase. Nun wurde die mittlere Phase mit den Leukozyten abgenommen und in FACS-Puffer gelöst. Der Überstand wurde verworfen, und es folgten Zentrifugationen für zehn Minuten bei $4{ }^{\circ} \mathrm{C}$, und $1600 \mathrm{rpm}$ mit Waschritten im FACS-Puffer. Es folgte die Inkubation mit Fc-Block (1:50) für zehn Minuten im Dunkeln auf Eis und anschließend die Färbung des Antikörpermix (1:50) mit den oben genannten Antikörpern für 20 Minuten im Dunklen auf Eis. Nun folgten Waschschritte mit dem FACS-Puffer und die Messung der Zellsuspensionen am FACS-Gerät. Die Proben wurden nach der Kompensation der Antikörper-Färbung eingespeist und nach gezeigtem Schema „gegated“ (Abb. 4). 

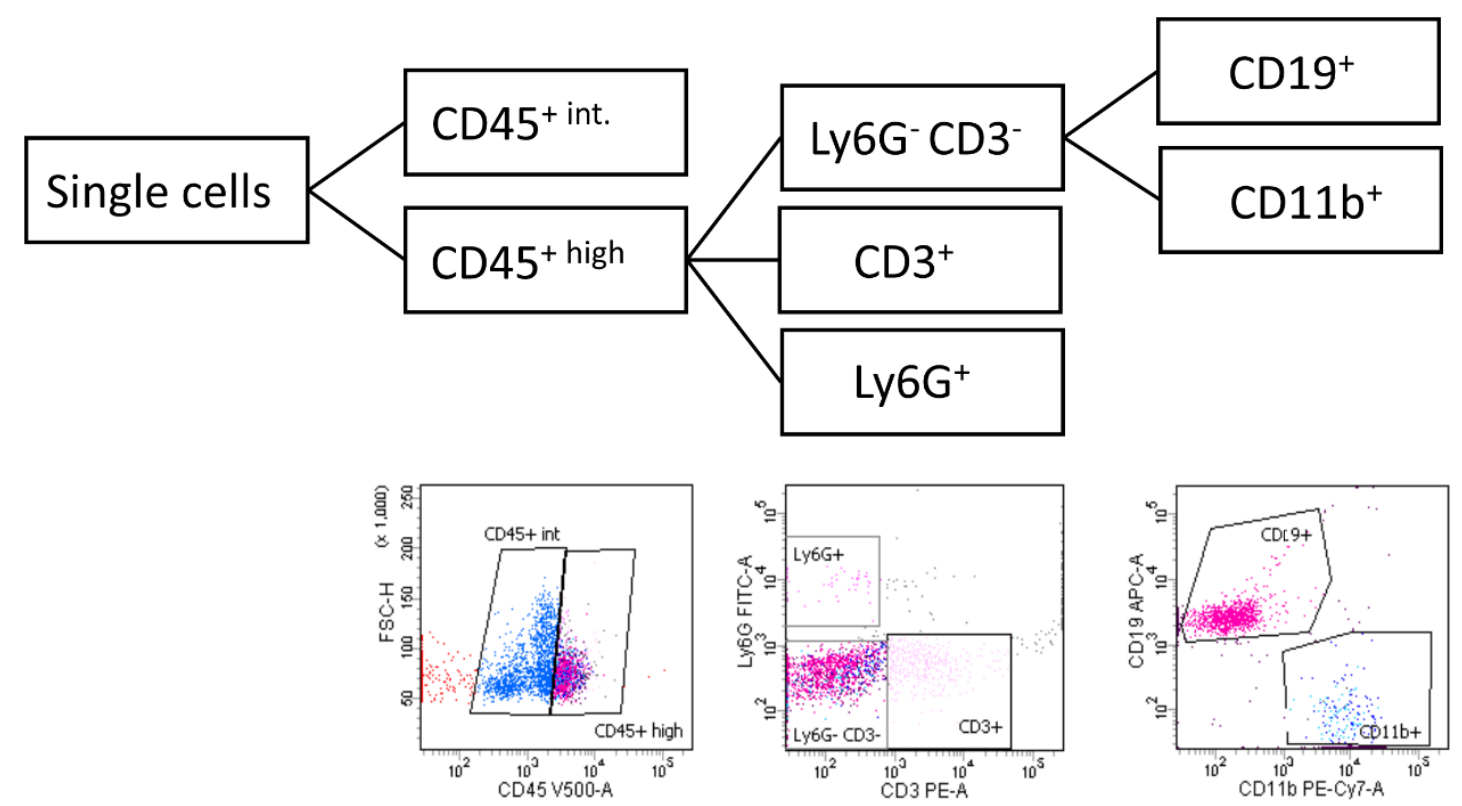

Abbildung 4: Aufbau der Durchflusszytometrie. Die Zellsuspension wurde mit CD45 gefärbt und zwischen CD45 int.-Mikrogliazellen und CD45 high_Leukozyten unterschieden. Die Subpopulation der CD45high-Leukozyten wurde weiter aufgeteilt in $\mathrm{CD}_{4} 5^{\text {high }} \mathrm{CD}^{+}$-T-Zellen, CD45high Ly6G ${ }^{+}$-neutrophile Granulozyten, CD45 highLy6G-CD3-CD19+-B-Zellen und CD45ighLy6G-CD3-CD11b+-dendritische Zellen. Unterhalb des Flussdiagramms abgebildet sind repräsentative Streudiagramme der jeweiligen Phase der GatingStrategie.

Die Analyse erfolge softwareunterstützt durch FlowJo. Zunächst wurde die Kompensation überprüft und gegebenenfalls angepasst. Anschließend wurden die Gates gesetzt. Die Population der Leukozyten $\left(\mathrm{CD} 45^{+}\right)$wurde weiter aufgeschlüsselt in Mikrogliazellen $\left(\mathrm{CD} 45^{\text {int. }}\right)$, T-Zellen $\left(\mathrm{CD} 45^{\text {high }} \mathrm{CD}^{+}\right)$, neutrophile Granulozyten $\left(\mathrm{CD} 45^{\text {high }} \mathrm{Ly} 6 \mathrm{G}^{+}\right)$, B-Zellen (CD45 ${ }^{\text {high }}$ Ly6G-CD3-CD19 ${ }^{+}$) und dendritische Zellen (CD45 ${ }^{\text {high }}$ Ly6G-CD3-CD11 b ${ }^{+}$).

\subsection{Statistik}

Die Ergebnisse dieser Arbeit wurden mittels GraphPad Prism 7 Software analysiert und als Mittelwerte und Standardabweichung dargestellt. Der Vergleich zweier Gruppen miteinander erfolgte nicht-parametrisch anhand des Mann-Whitney-U-Testes. Für den Vergleich mehrere Gruppen wurde eine zweifach Multivarianzanalyse (ANOVA) durchgeführt. Dieser folgten Sidaks-multiple-Vergleich-Teste für die einzelnen Testtage. P-Werte von $<0,05$ wurden als statistisch signifikant gewertet. 


\section{Ergebnisse}

Zur besseren Lesbarkeit wurde in dieser hier vorliegenden Arbeit Eotaxin-1 im Fließtext ausgewählt. In den folgenden Abbildungen wird das Synonym CCL11 für Eotaxin-1 verwendet, da dieses sich in der aktuellen Fachliteratur häufiger wiederfindet.

\subsection{Eotaxin-1 führt zu einer Zunahme des akuten post-ischämischen Gewebeschadens in adulten Mäusen}

Zunächst wurde untersucht, ob Eotaxin-1 eine akute Neuroprotektion nach zerebraler Ischämie induziert. Nach TTC-gestützter Infarktvolumetrie zeigte sich jedoch, dass Eotaxin-1 keinen Einfluss auf die Größe des Infarktvolumens in den adoleszenten Tieren hat (Abb. 5 A).

A
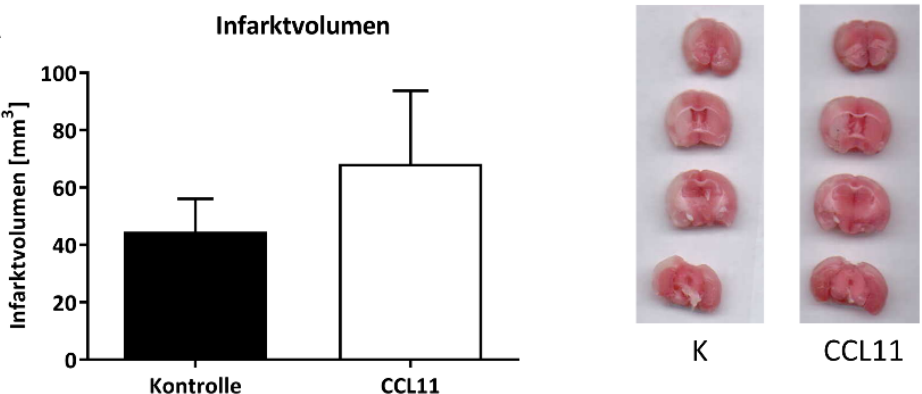

B
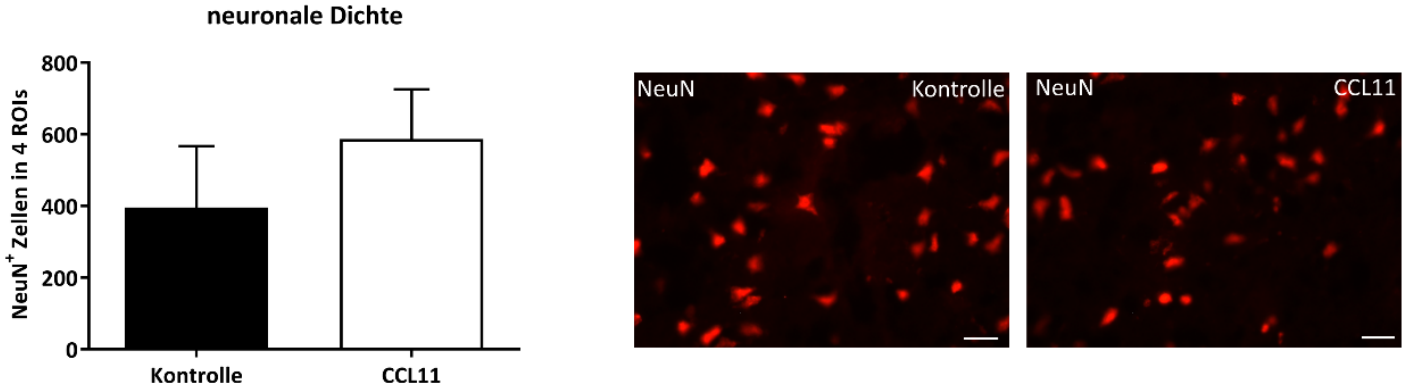

C mikrogliale Aktivierung
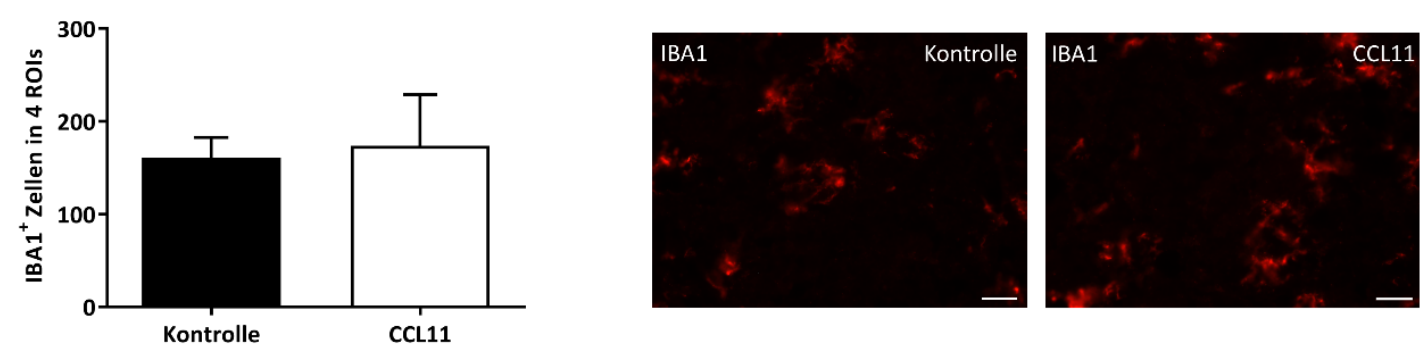

Abbildung 5: Eotaxin-1 hat keinen Einfluss auf den akuten Gewebeschaden in adoleszenten Mäusen. C57BL6-Mäuse erhielten nach 45-minütiger zerebraler Ischämie mit Beginn der Reperfusion intraperitoneal 10 
$\mu \mathrm{g}$ pro kg KG Eotaxin-1 oder $100 \mu \mathrm{l}$ PBS als Kontrolle. Nach 24 Stunden Überleben wurde in (A) das Infarktvolumen mittels TTC-Färbung gemessen, die neuronale Dichte anhand von NeuN-Färbung (B) und die mikrogliale Aktivität anhand des Markers IBA1 (C) bestimmt. Repräsentative Bilder der T'TC-Färbung und der Immunhistochemie sind neben den Graphen abgebildet. Die Ergebnisse sind dargestellt als Mittelwerte \pm Standardabweichung, Abkürzung: $\mathrm{K}=$ Kontrolle, Maßstab $10 \mu \mathrm{m}$.

Gleichsam fand sich kein Unterschied im Hinblick auf die neuronale Dichte (Abb. 5 B). Eotaxin-1 hatte unter diesen experimentellen Bedingungen auch keinen Effekt auf die mikrogliale Aktivierung, welche mittels IBA1-Färbung bestimmt wurde (Abb. 5 C).

Mikrogliazellen liegen physiologischerweise in zwei Zuständen vor; in inaktivem oder aktivem Zustand. Die zerebrale Ischämie selbst führt zu einer Aktivierung von Mikroglia im ischämischen Gewebe. Im Rahmen dieses Prozesses kommt es zu einer Differenzierung von M1- und M2-Mikrogliazellen, welche jeweils einen distinkten Phänotyp aufweisen (Abb. 6).
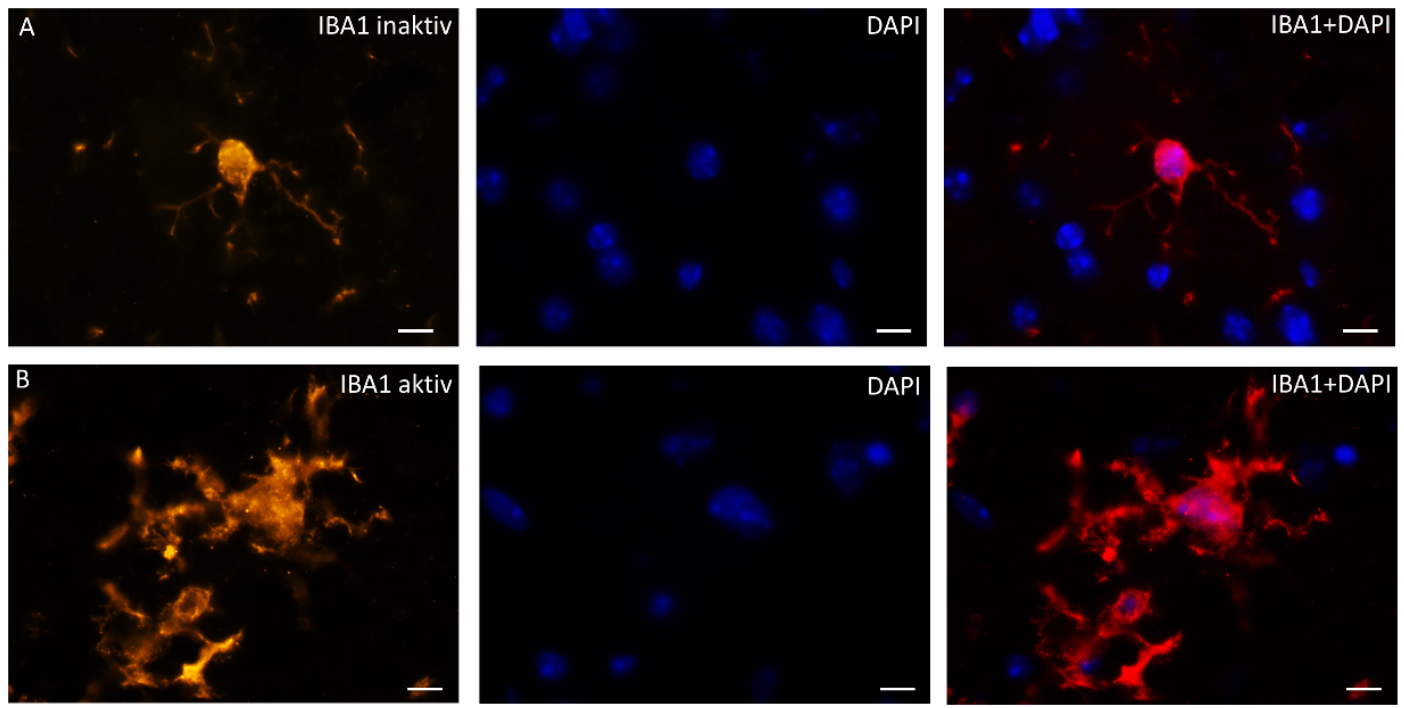

Abbildung 6: Qualitative Analyse des Aktivierungszustandes von Mikroglia. C57BL6-Mäuse wurden einer 45-minütiger zerebralen Ischämie unterzogen. Die Tiere wurden 24 Stunden nach dieser schmerzlos getötet, und es wurde eine Mikrogliafärbung anhand von IBA1 zur morphologischen Beurteilung von Mikroglia durchgeführt. Dargestellt sind repräsentative Aufnahmen von inaktiven (A) respektive aktiven (B) Mikrogliazellen. Der Maßstab ist $5 \mu \mathrm{m}$.

Während Eotaxin-1 also keinen Effekt im Hinblick auf die zuvor genannten Parameter in den adoleszenten Mäusen hatte, stellte sich in den adulten Tieren ein anderes Bild ein. In der Experimentalgruppe der adulten Tiere fand man signifikant größere Infarktvolumina im 
Vergleich zur Kontrollgruppe (Abb. 7 A). Die größeren Schlaganfallvolumina nach Gabe von Eotaxin-1 führten auch zu einer Abnahme der neuronalen Dichte in dieser Versuchsgruppe 24 Stunden nach Induktion der zerebralen Ischämie (Abb. 7 B). Überraschenderweise kam es in diesem Zusammenhang nicht zu einer erwarteten Zunahme der mikroglialen Aktivierung, sondern vielmehr zu einer Reduktion der post-ischämischen Mikrogliaaktivierung durch Eotaxin-1 (Abb. 7 C).

A

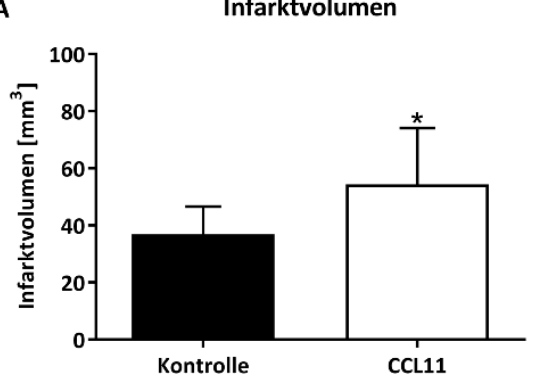

B

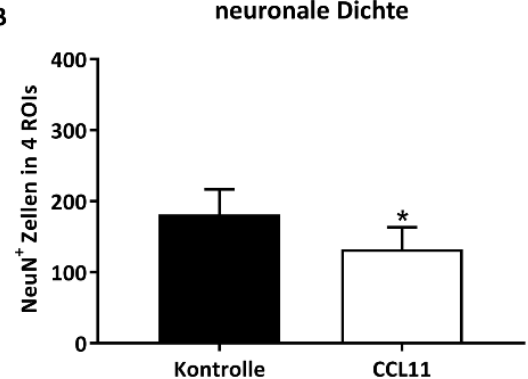

C

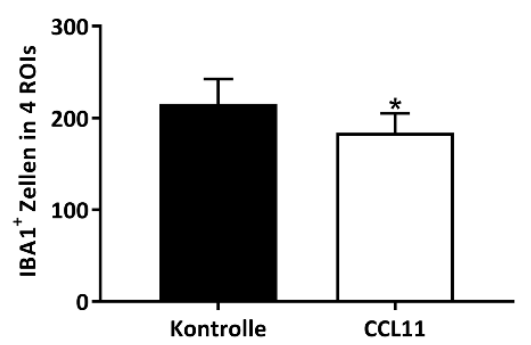

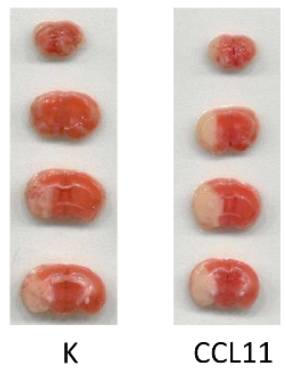
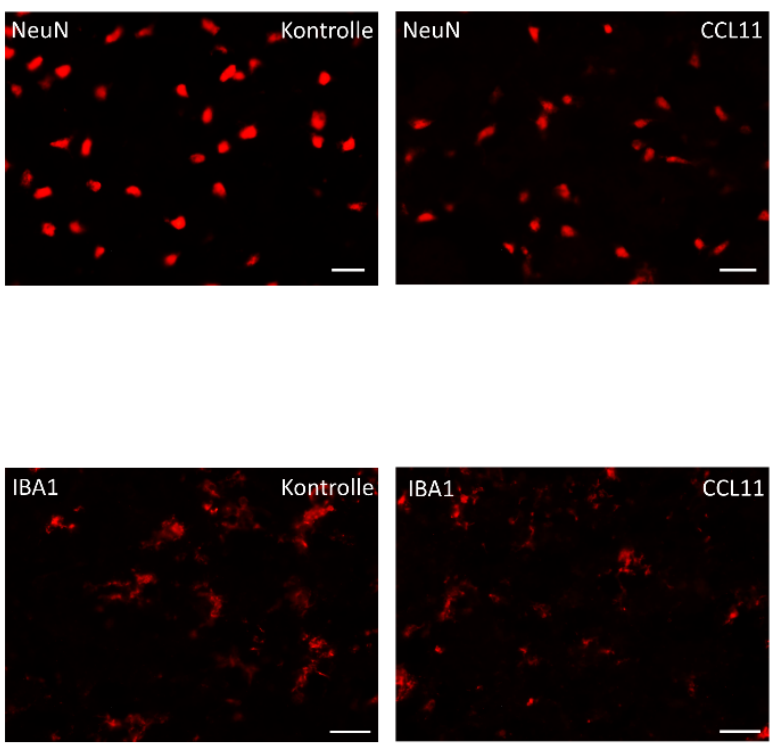

Abbildung 7: Eotaxin-1 induziert eine Aggravation des akuten post-ischämischen Gewebeschadens in adulten Mäusen. C57BL6-Mäuse erhielten nach 45-minütiger zerebraler Ischämie mit Beginn der Reperfusion intraperitoneal $10 \mu \mathrm{g}$ pro kg KG Eotaxin-1 oder $100 \mu \mathrm{l}$ PBS als Kontrolle. Nach 24 Stunden Überleben wurde in (A) das Infarktvolumen mittels T'TC-Färbung gemessen und eine Immunhistochemie des Gewebes gegen den neuronalen Marker NeuN (B) bzw. gegen den mikroglialen Marker IBA1 (C) angefertigt. Repräsentative Bilder der TTC-Färbung und der Immunhistochemie sind neben den Graphen abgebildet. Die Ergebnisse sind dargestellt als Mittelwerte \pm Standardabweichung. *Signifikant unterschiedlich zur Kontrollgruppe, $\mathrm{p}<0,05$, Abkürzung: $\mathrm{K}=$ Kontrolle, Maßstab $10 \mu \mathrm{m}$. 


\subsection{Eotaxin-1 moduliert die post-ischämische neurologische Erholung in adulten Mäusen}

Im Langzeitversuch der Studie betrug das Gesamtüberleben der Versuchstiere 28 Tage. Man führte an ausgewählten Tagen etablierte Verhaltenstests durch mit der Frage, ob Eotaxin-1 die funktionale Regeneration beeinflusst. Nach täglicher intraperitonealer Applikation von Eotaxin-1 während der ersten sieben Tage nach Ischämie fand sich bei adoleszenten Tieren kein signifikanter Einfluss von Eotaxin-1 auf die funktionelle Erholung (Abb. 8 A, B).

Im Gegensatz zu den an adoleszenten Tieren erhobenen Daten fand sich in den mit Eotaxin-1 behandelten adulten Mäusen eine transiente, signifikante Verschlechterung sowohl im Rota-Rod-Test wie auch im Corner-Turn-Test (Abb. 8 C, D). Diese Veränderungen ließen sich innerhalb der ersten drei Tage nach Induktion der zerebralen Ischämie beobachten. Jenseits dieses Beobachtungszeitraumes näherten sich die Testergebnisse von Experimental- und Kontrollgruppe an.

A

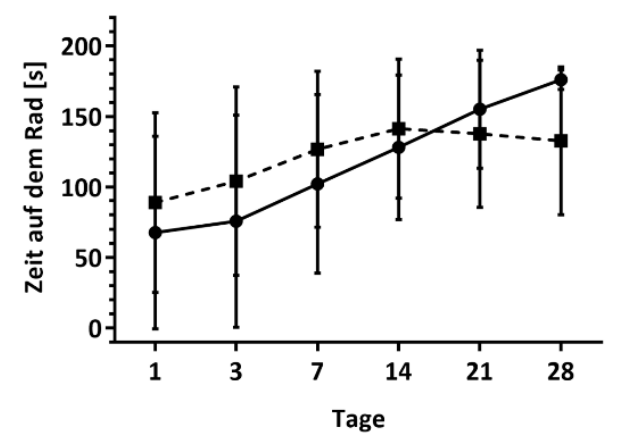

C

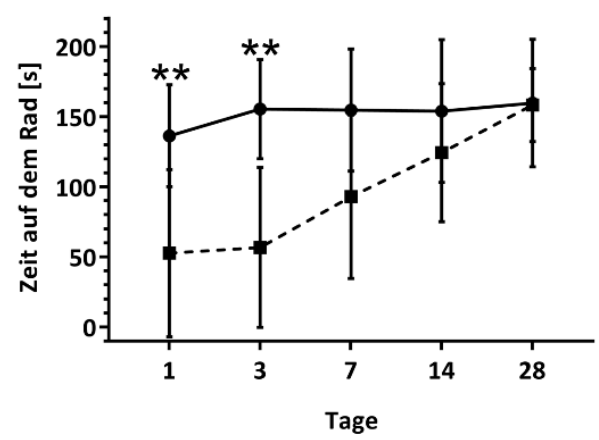

B

6 Wochen alt

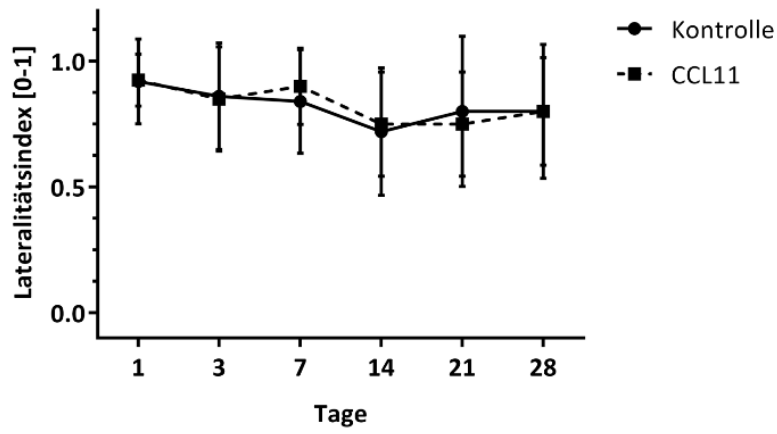

D

6 Monate alt

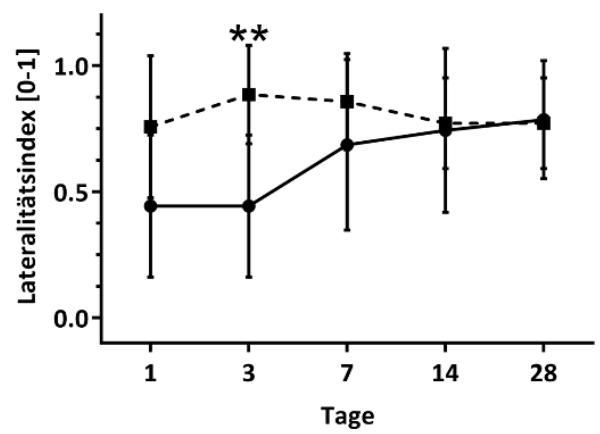

Abbildung 8: Eotaxin-1 beeinträchtigt die funktionale Erholung nach zerebraler Ischämie der adulten Mäuse. C57BL6-Mäuse erhielten nach 45-minütiger zerebraler Ischämie mit Beginn der Reperfusion und an den folgenden sieben Tagen täglich intraperitoneal $10 \mu \mathrm{g}$ pro kg KG Eotaxin-1 oder $100 \mu \mathrm{l}$ PBS als Kontrolle. Die Tiere wurden nach 28 Tagen euthanasiert. Die Verhaltenstests wurden an Tag 1, 3, 7, 14 ,21 und 28 nach 
der zerebralen Ischämie durchgeführt. Der Rota-Rod-Test und der Corner-Turn-Test wurden jeweils an adoleszenten (A, B) und adulten (C, D) Tieren durchgeführt. Die Ergebnisse sind dargestellt als Mittelwerte \pm Standardabweichung, **Signifikant unterschiedlich zur Kontrollgruppe, $\mathrm{p}<0,01$.

Die funktionelle neurologische Erholung geht nicht notwendigerweise mit Veränderungen des Gewebeschadens selbst einher. Tatsächlich zeigte sich nach Eotaxin-1-Behandlung der adulten Mäuse kein Effekt auf die neuronale Dichte oder auf das Ausmaß der mikroglialen Aktivierung (Abb. 9).

A
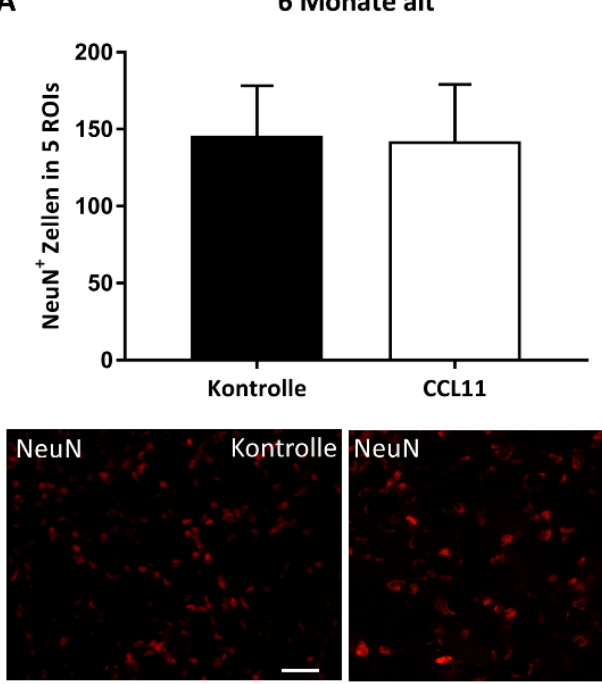

B
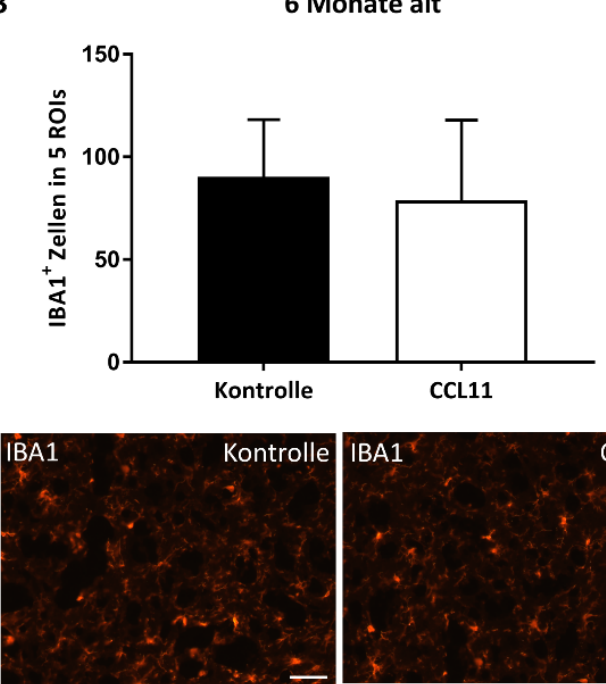

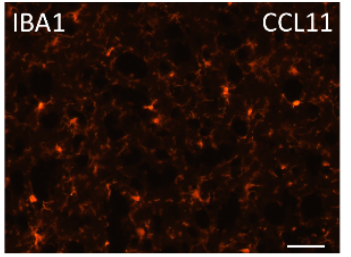

Abbildung 9: Eotaxin-1 hat keinen Einfluss auf den chronischen Gewebeschaden der adulten Mäuse. C57BL6-Mäuse erhielten nach 45-minütiger zerebraler Ischämie mit Beginn der Reperfusion und an den folgenden sieben Tagen täglich intraperitoneal $10 \mu \mathrm{g}$ pro kg KG Eotaxin-1 oder $100 \mu \mathrm{l}$ PBS als Kontrolle. Die Tiere wurden nach 28 Tagen euthanasiert. Es wurden am Tag 28 sowohl die neuronale Dichte (A) als auch das Ausmaß der mikroglialen Aktivierung (B) analysiert. Repräsentative Bilder der quantitativen Analyse finden sich jeweils unterhalb der Diagramme. Die Ergebnisse sind dargestellt als Mittelwerte \pm Standardabweichung, Maßstab $20 \mu \mathrm{m}$.

Ebenso fanden sich keine signifikanten Unterschiede im Hinblick auf die zuvor genannten Parameter bei adoleszenten Tieren (Abb. 10). Diese Ergebnisse sind damit kohärent zu den fehlenden Effekten durch Eotaxin-1 im adoleszenten Tier in den Verhaltenstests (Abb. 8 A, B). 
A
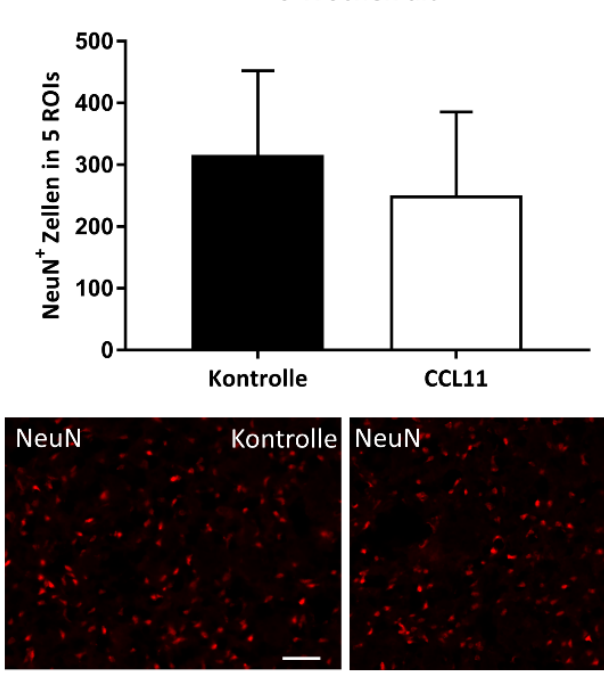

B

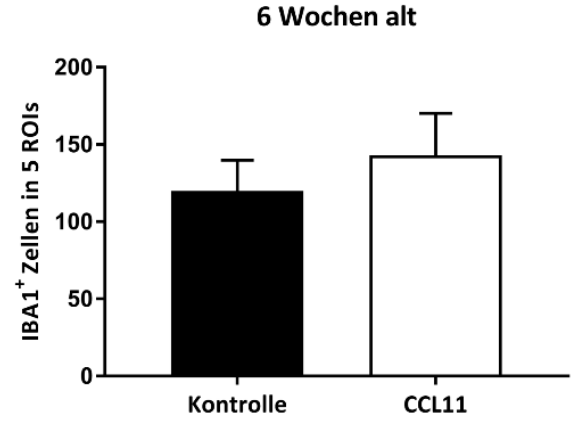

Abbildung 10: Eotaxin-1 hat keinen Einfluss auf den chronischen Gewebeschaden der adoleszenten Mäuse. C57BL6-Mäuse erhielten nach 45-minütiger zerebraler Ischämie mit Beginn der Reperfusion und an den folgenden sieben Tagen täglich intraperitoneal $10 \mu \mathrm{g}$ pro kg KG Eotaxin-1 oder $100 \mu \mathrm{l}$ PBS als Kontrolle. Die Tiere wurden nach 28 Tagen euthanasiert. Es wurden am Tag 28 sowohl die neuronale Dichte (A) als auch das Ausmaß der mikroglialen Aktivierung (B) analysiert. Repräsentative Bilder der quantitativen Analyse finden sich jeweils unterhalb der Diagramme. Die Ergebnisse sind dargestellt als Mittelwerte \pm Standardabweichung, Maßstab $20 \mu \mathrm{m}$.

\subsection{Eotaxin-1 fördert Regenerationsmechanismen in adoleszenten Mäusen und hemmt die Neurogenese in adulten Mäusen}

Im Hinblick auf die post-ischämische Neuroregeneration erhielten die Tiere an ausgewiesenen Tagen den Proliferationsmarker BrdU, so dass anhand einer Kofärbung mit Differenzierungsmarkern die post-ischämische Gliogenese und Neurogenese nach vier Wochen beurteilt werden konnte. Tatsächlich ließ sich durch die Applikation von Eotaxin-1 eine erhöhte endogene Zellproliferation in adoleszenten Tieren beobachten, wie anhand der quantitativen Analyse von BrdU ${ }^{+}$-Zellen dargestellt werden konnte (Abb. 11 A). Umgekehrt zeigte sich in den adulten Tieren kein Einfluss von Eotaxin-1 im Hinblick auf die Zellproliferation (Abb. 11 B). 
A

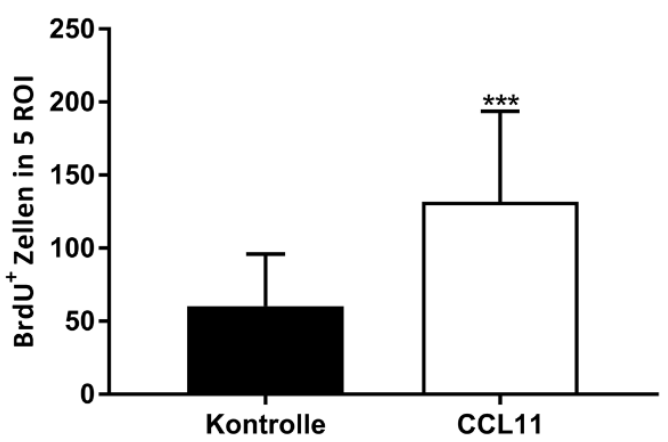

B

6 Monate alt

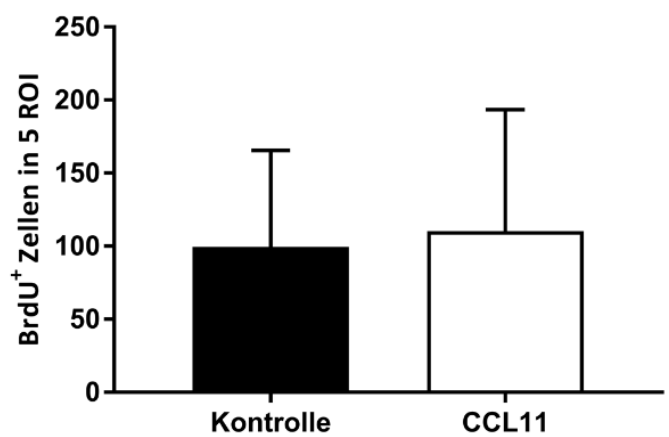

Abbildung 11: Eotaxin-1 stimuliert die post-ischämische Zellproliferation in adoleszenten Mäusen. C57BL6-Mäuse erhielten nach 45-minütiger zerebraler Ischämie mit Beginn der Reperfusion und an den folgenden sieben Tagen täglich intraperitoneal $10 \mu \mathrm{g}$ pro kg KG Eotaxin-1 oder $100 \mu \mathrm{l}$ PBS als Kontrolle. An den Tagen 8-18 wurde BrdU intraperitoneal verabreicht. Die Tiere wurden nach 28 Tagen euthanasiert. Die Zellproliferation wurde anhand BrdU+ ${ }^{+}$Zellen sowohl in adoleszenten (A) wie auch in adulten (B) Mäusen quantifiziert. Die Ergebnisse sind dargestellt als Mittelwerte \pm Standardabweichung, ***Signifikant unterschiedlich zur Kontrollgruppe, $\mathrm{p}<0,001$.

Im weiteren Verlauf dieser Arbeit wurde anhand der oben dargestellten BrdU-Markierung eine weitere Analyse des Phänotyps dieser Zellen durchgeführt, wie zuvor bereits dargestellt. In adoleszenten Tieren führte die Behandlung mit Eotaxin-1 zu einer Stimulation der endogenen post-ischämischen Neurogenese. Es fanden sich eine signifikant erhöhte Koexpression von BrdU ${ }^{+}$-Zellen mit dem immaturen neuronalen Marker Dcx (Abb. 12 A) und dem maturen neuronalen Marker NeuN (Abb. 12 B). 


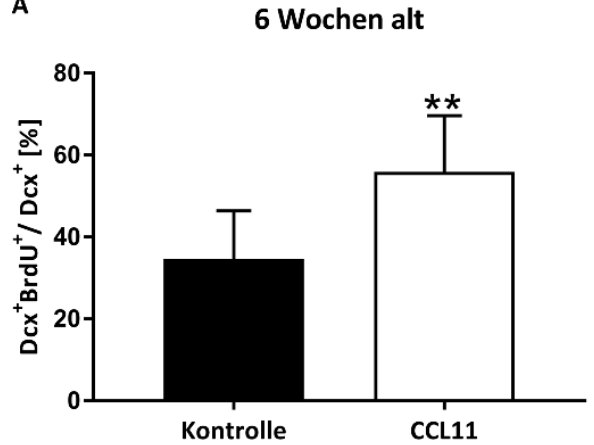

B

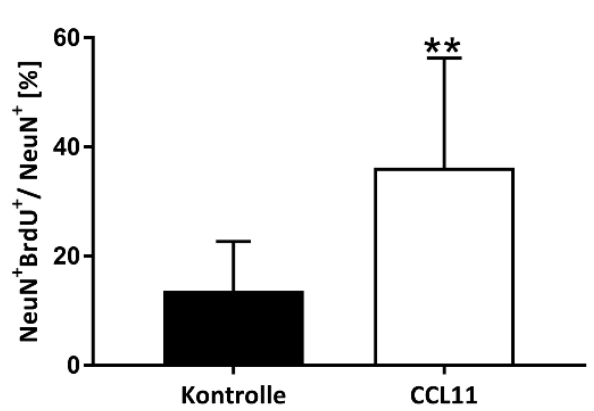

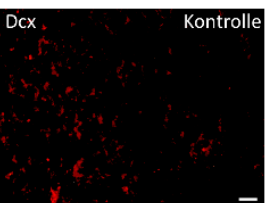
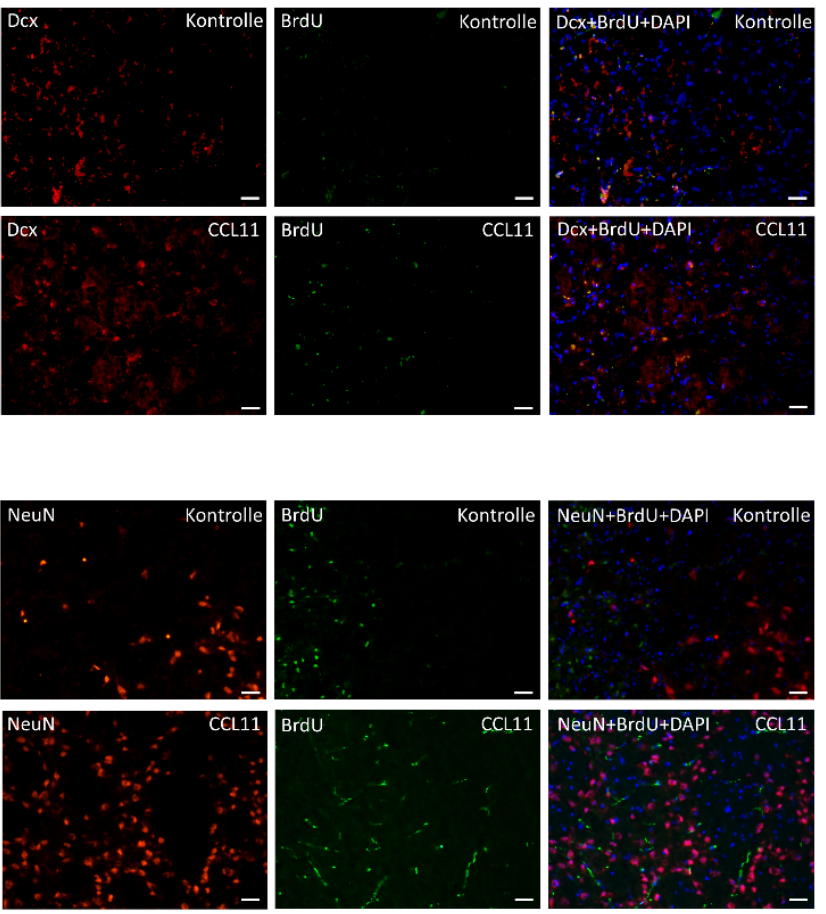

Abbildung 12: Eotaxin-1 stimuliert die endogene post-ischämische Neurogenese in adoleszenten Mäusen. C57BL6-Mäuse erhielten nach 45-minütiger zerebraler Ischämie mit Beginn der Reperfusion und an den folgenden sieben Tagen täglich intraperitoneal $10 \mu \mathrm{g}$ pro kg KG Eotaxin-1 oder $100 \mu \mathrm{l}$ PBS als Kontrolle. An den Tagen 8-18 BrdU intraperitoneal verabreicht. Die Tiere wurden nach 28 Tagen euthanasiert. Die Neurogenese in den adoleszenten Mäusen wurde anhand einer Doppelfärbung mit BrdU gegen den neuronalen Markern Dcx (A) und NeuN (B) evaluiert. Repräsentative Bilder der jeweiligen Färbung sind neben den Graphen abgebildet. Die Ergebnisse sind dargestellt als Mittelwerte \pm Standardabweichung, **Signifikant unterschiedlich zur Kontrollgruppe, $\mathrm{p}<0,01$, Maßstab $20 \mu \mathrm{m}$.

In den adulten Tieren zeigte sich hingegen nach Eotaxin-1-Behandlung eine signifikant verringerte Koexpression von BrdU und dem neuronalen Marker NeuN bei fehlendem Effekt auf die Koexpression von BrdU und Dcx (Abb. 13). Diese immunhistochemischen Daten spiegeln im Wesentlichen die Ergebnisse der zuvor geschilderten Verhaltenstests wider. 
A

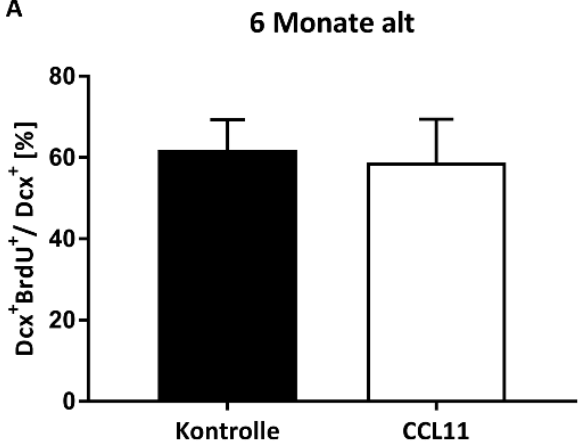

B

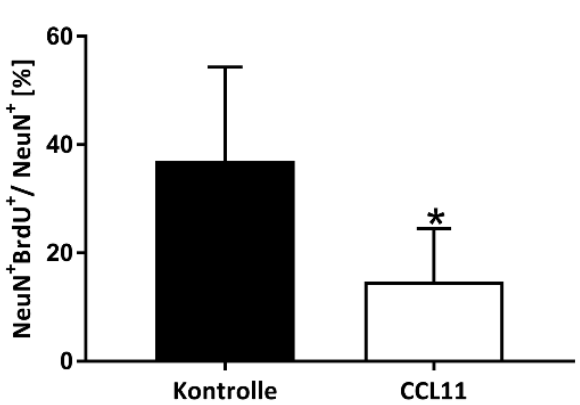

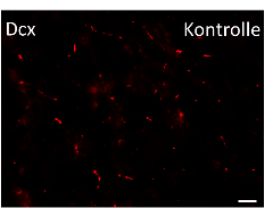
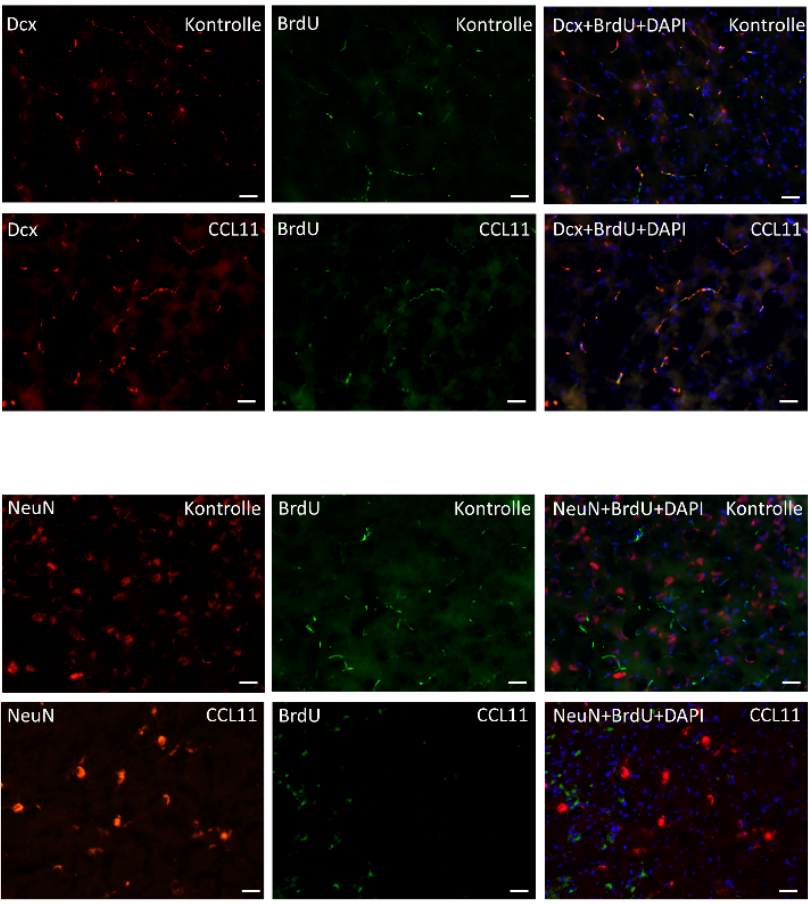

Abbildung 13: Eotaxin-1 hemmt die Neurogenese in adulten Mäusen. C57BL6-Mäuse erhielten nach 45minütiger zerebraler Ischämie mit Beginn der Reperfusion und an den folgenden sieben Tagen täglich intraperitoneal $10 \mu \mathrm{g}$ pro $\mathrm{kg}$ KG Eotaxin-1 oder $100 \mu \mathrm{l}$ PBS als Kontrolle. An Tag 8-18 wurde BrdU intraperitoneal verabreicht. Die Tiere wurden nach 28 Tagen euthanasiert. Die Neurogenese in den sechs Monate alten Tieren wurde anhand einer Doppelfärbung mit BrdU und den neuronalen Markern Dcx (A) und NeuN (B) evaluiert. Repräsentative Bilder der jeweiligen Färbung neben den Graphen abgebildet. Die Ergebnisse sind dargestellt als Mittelwerte \pm Standardabweichung, *Signifikant unterschiedlich zur Kontrollgruppe, $\mathrm{p}<0,05$, Maßstab $20 \mu \mathrm{m}$.

In Analogie zur Beurteilung der post-ischämischen Neurogenese wurde die Gliogenese durch Doppelfärbungen gegen BrdU und einen glialen Marker untersucht. Es waren dies die glialen Marker GFAP und s100b. Während GFAP ein bekannter Astrozytenmarker ist, kann s100b sowohl als Astro- wie auch Oligodendrozytenmarker dienen. In der Gliogenese wirkt s100b durch Aktivierung von Zielproteinen auf transkriptioneller Ebene während der Embyronalentwicklung in Mäusen (Hachem et al. 2007). In diesem Zusammenhang ging die Applikation von Eotaxin-1 mit einer Stimulation der Gliogenese in den adoleszenten Versuchstieren einher und unterstützte somit die Daten zur Neurogenese in diesen Tieren. Es fand sich also eine signifikant erhöhte Koexpression von $\mathrm{BrdU}^{+}$-Zellen mit GFAP (Abb. 14 A) bzw. s100b (Abb. 14 B) in der Experimentalgruppe im Vergleich zu der Kontrollgruppe der adoleszenten Mäuse. 


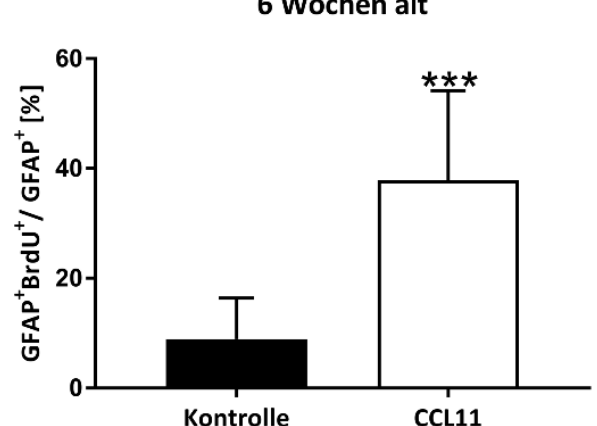

B

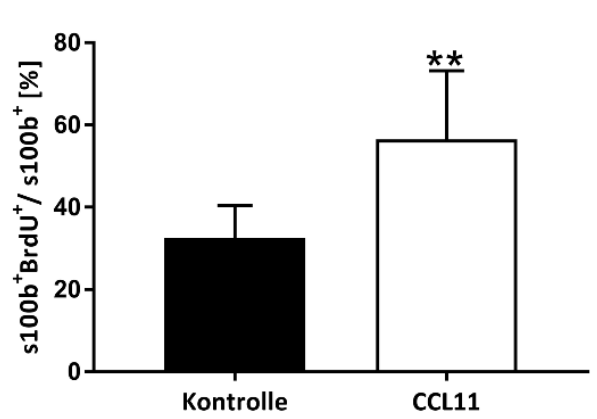

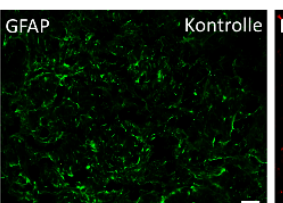
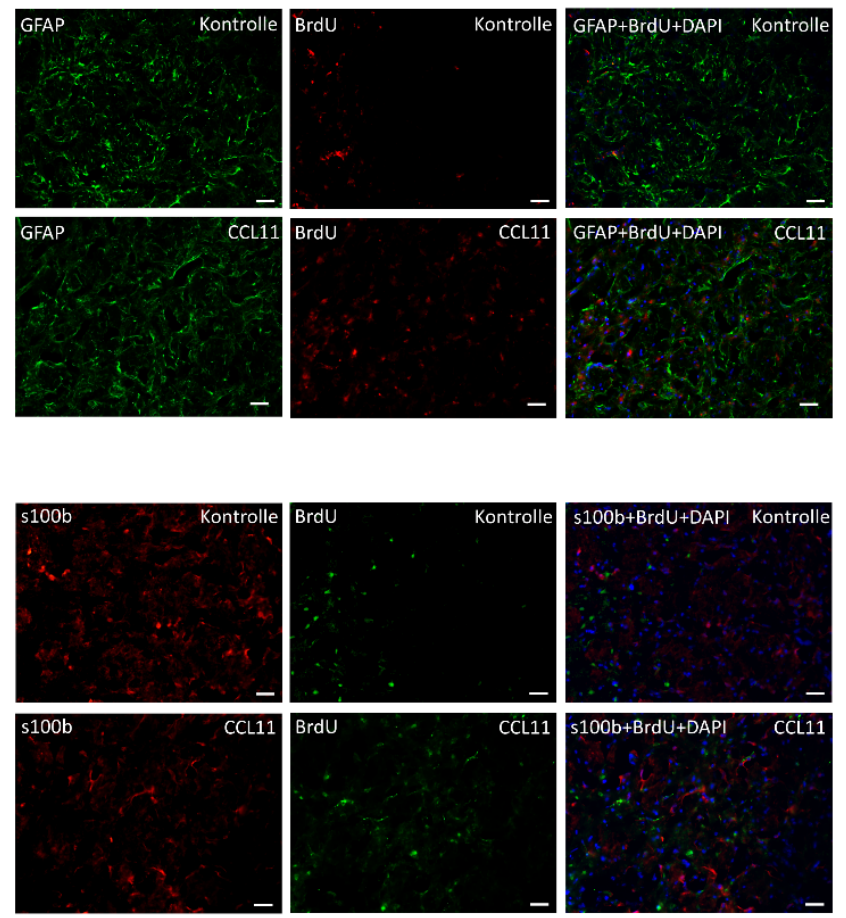

Abbildung 14: Eotaxin-1 fördert die Gliogenese in adoleszenten Mäusen. C57BL6-Mäuse erhielten nach 45-minütiger zerebraler Ischämie mit Beginn der Reperfusion und an den folgenden sieben Tagen täglich intraperitoneal $10 \mu \mathrm{g}$ pro kg KG Eotaxin-1 oder $100 \mu \mathrm{l}$ PBS als Kontrolle. An Tag 8-18 wurde BrdU intraperitoneal verabreicht. Die Tiere wurden nach 28 Tagen euthanasiert. Die Gliogenese in den sechs Wochen alten Tieren wurde anhand einer Doppelfärbung mit BrdU und den glialen Markern GFAP (A) und s100b (B) evaluiert. Repräsentative Bilder der jeweiligen Färbung sind neben den Graphen abgebildet. Die Ergebnisse sind dargestellt als Mittelwerte \pm Standardabweichung, **Signifikant unterschiedlich zur Kontrollgruppe, $\mathrm{p}<0,01, * * *$ Signifikant unterschiedlich zur Kontrollgruppe, $\mathrm{p}<0,001$, Maßstab $20 \mu \mathrm{m}$.

Betrachtete man die Gliogenese im chronischen Stadium des Schlaganfalls in der Gruppe der adulten Tiere, so fand man keinen Einfluss von Eotaxin-1 auf die Koexpression der zuvor genannten glialen Marker mit BrdU (Abb. 15 A, B). 
A

6 Monate alt
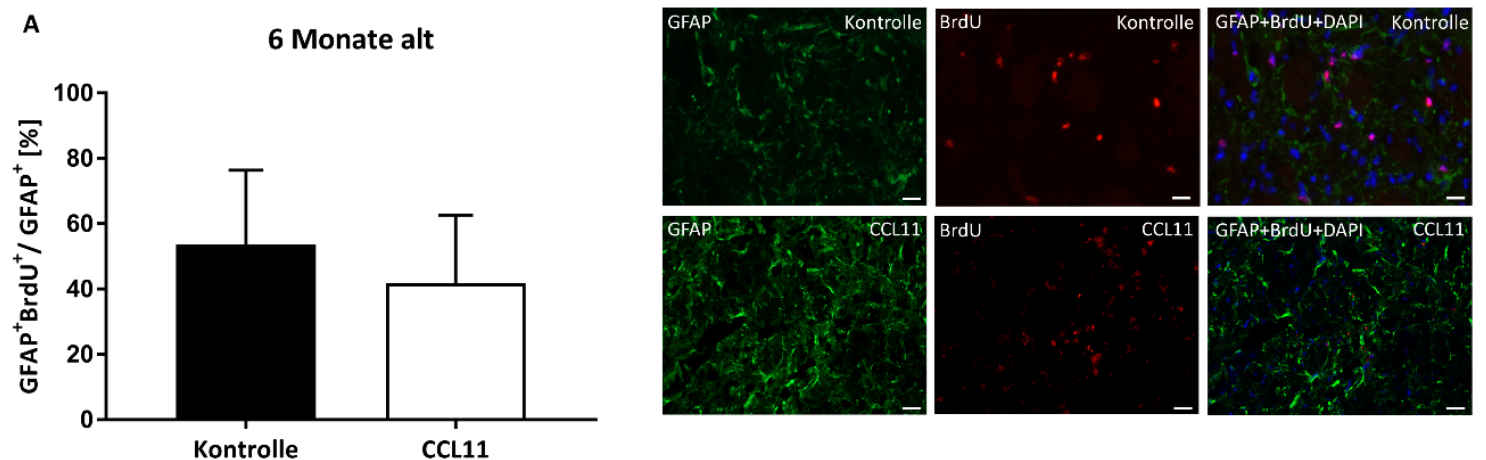

B

6 Monate alt
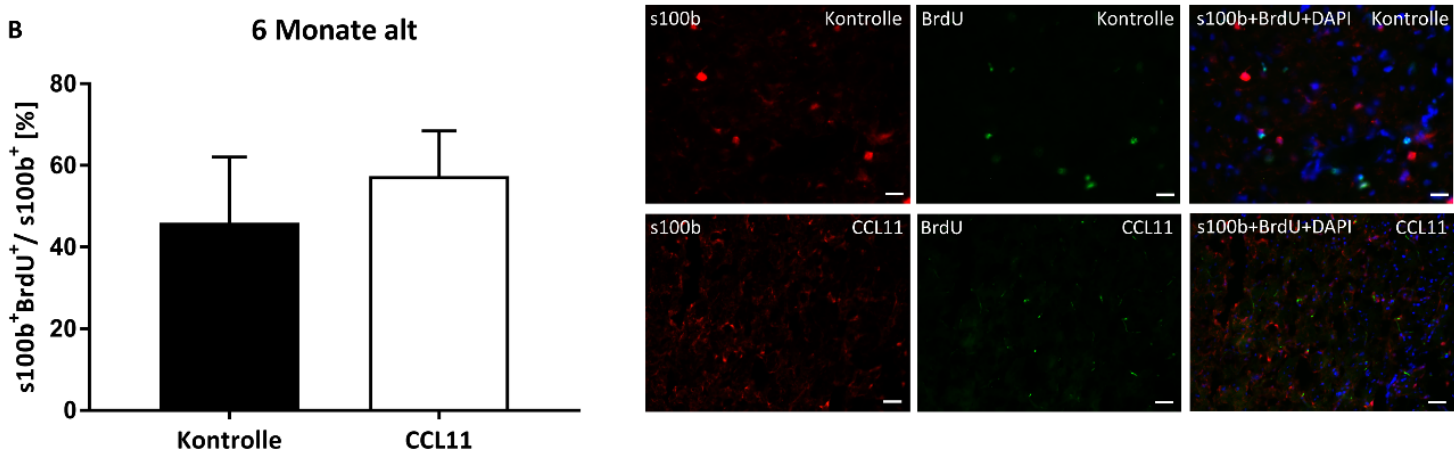

Abbildung 15: Eotaxin-1 beeinflusst nicht die post-ischämische Gliogenese in adulten Mäusen. C57BL6-Mäuse erhielten nach 45-minütiger zerebraler Ischämie mit Beginn der Reperfusion und an den folgenden sieben Tagen täglich intraperitoneal $10 \mu \mathrm{g}$ pro kg KG Eotaxin-1 oder $100 \mu \mathrm{l}$ PBS als Kontrolle. An Tag 8-18 wurde BrdU intraperitoneal verabreicht. Die Tiere wurden nach 28 Tagen euthanasiert. Die Gliogenese in den sechs Monate alten Tieren wurde anhand einer Doppelfärbung mit BrdU und den glialen Markern GFAP (A) und s100b (B) evaluiert. Repräsentative Bilder der jeweiligen Färbung sind neben den Graphen abgebildet. Die Ergebnisse sind dargestellt als Mittelwerte \pm Standardabweichung, Maßstab $20 \mu \mathrm{m}$.

\subsection{Eotaxin-1 modifiziert die post-ischämische periphere und zentrale Immunantwort}

Die zerebrale Ischämie des Gehirns betrifft nicht nur isoliert das Gehirn, sondern hat ebenso systemische Auswirkungen auf den gesamten Organismus. Folgerichtig wurde im weiteren Verlauf dieser Arbeit im subakuten Stadium des Schlaganfalls, d. h., sieben Tage nach zerebraler Ischämie, der Effekt von Eotaxin-1 auf die periphere und auf die zentrale Immunantwort in ischämischen adoleszenten und adulten Mäusen untersucht. Hierzu wurden umfangreiche durchflusszytometrische Analysen gegen Marker für Mikrogliazellen bzw. Monozyten, T- und B-Zellen, neutrophile Granulozyten und dendritische Zellen aus Blut- und Hirnproben durchgeführt. Unter diesen experimentellen Bedingungen zeigte sich, dass Eotaxin-1 die post-ischämische zentrale Immunantwort sieben Tage nach Induktion 
der zerebralen Ischämie in adoleszenten Tieren modulierte. Man fand eine signifikant erhöhte relative Anzahl an Mikrogliazellen, T-Zellen und B-Zellen (Abb.16 A, C, D).

\section{ZNS}

A

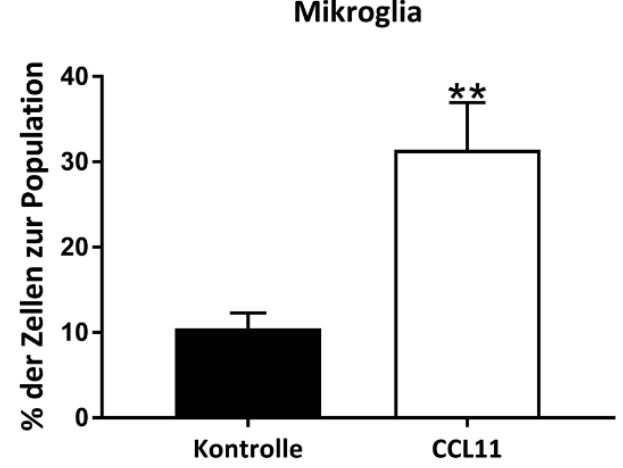

C

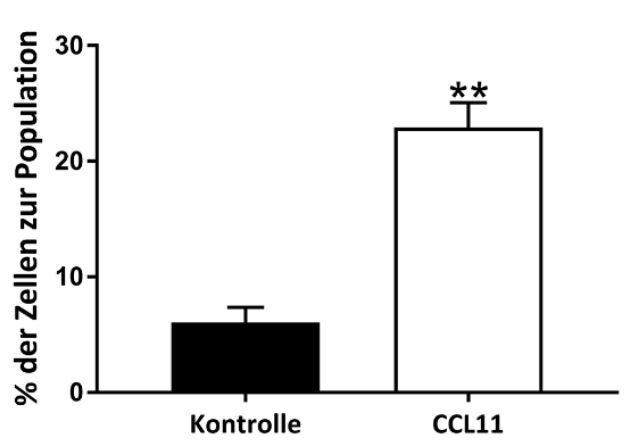

B

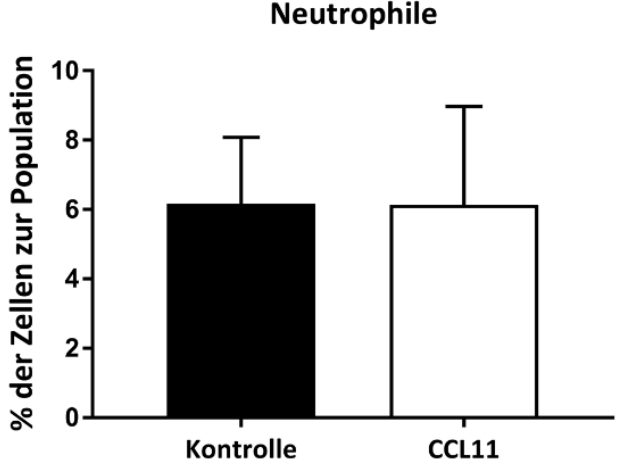

D

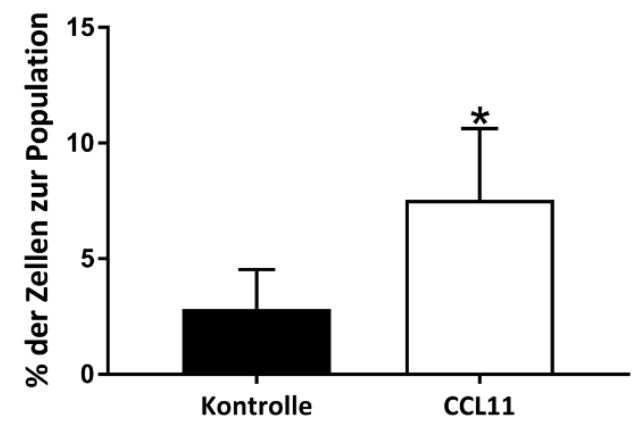

Abbildung 16: Eotaxin-1 modifiziert die subakute zentrale Immunantwort in adoleszenten Mäusen. C57BL6-Mäuse erhielten nach 45-minütiger zerebraler Ischämie mit Beginn der Reperfusion und an den folgenden sieben Tagen täglich intraperitoneal $10 \mu \mathrm{g}$ pro kg KG Eotaxin-1 oder $100 \mu \mathrm{l}$ PBS als Kontrolle. Die Analyse der Durchflusszytometrie erfolgte softwaregestützt mit FlowJo am siebten Tag nach zerebraler Ischämie. Gezeigt ist die quantitative Analyse der sechs Wochen alten Tiere. (A) CD45 ${ }^{+}$int.-, (B) CD45 ${ }^{+}$high-$_{-}$, (C) $\mathrm{CD}^{+}$- und (D) $\mathrm{CD}^{-} 9^{+}$-Zellen wurden in ZNS-Proben gemessen. Die Ergebnisse sind dargestellt als Mittelwerte \pm Standardabweichung, *Signifikant unterschiedlich zur Kontrollgruppe, $\mathrm{p}<0,05 * *$ Signifikant unterschiedlich zur Kontrollgruppe, $\mathrm{p}<0,01$.

Die durchflusszytometrische Analyse der Blutproben ergab eine modifizierte subakute systemische Immunantwort am siebten post-ischämischen Tag in den adoleszenten Mäusen. Es zeigte sich eine signifikant verringerte relative Anzahl an neutrophilen Granulozyten und signifikant erhöhter relativer Anteil an T- und B-Zellen in den adoleszenten Tieren (Abb.17 $\mathrm{B}, \mathrm{C}, \mathrm{D})$. 


\section{BLUT}

A

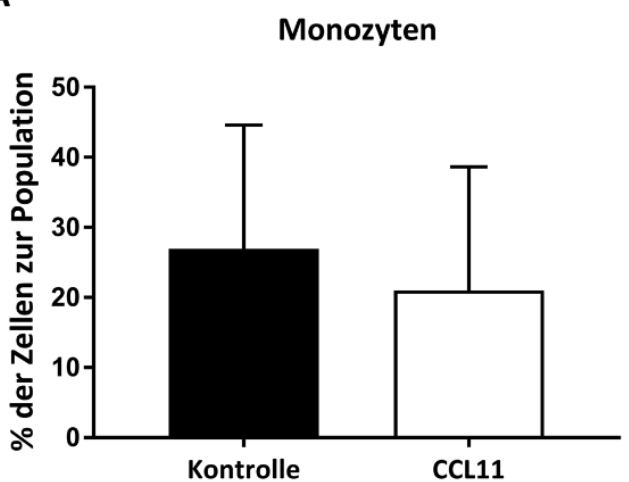

C

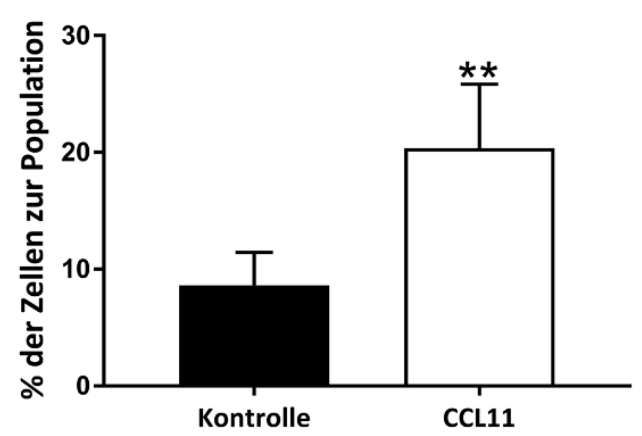

B

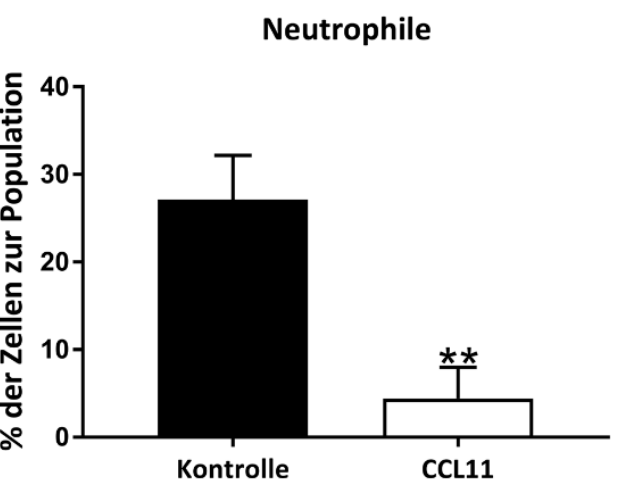

D

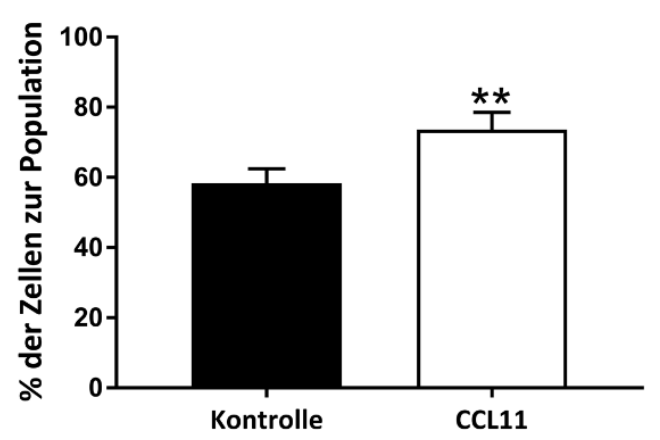

Abbildung 17: Eotaxin-1 modifiziert die subakute periphere Immunantwort in adoleszenten Mäusen. C57BL6-Mäuse erhielten nach 45-minütiger zerebraler Ischämie mit Reperfusion intraperitoneal $10 \mu \mathrm{g}$ pro $\mathrm{kg}$ KG Eotaxin-1 oder $100 \mu \mathrm{l}$ PBS als Kontrolle und alle 24 Stunden für sieben Tage. Die Analyse der Durchflusszytometrie erfolgte softwaregestützt mit Flowjo am siebten Tag nach zerebraler Ischämie. Gezeigt ist die quantitative Analyse der sechs Wochen alten Tiere. (A) CD45 ${ }^{+}$int.-, (B) $\mathrm{CD}^{+} 5^{+}$high $_{-}$, (C) $\mathrm{CD}^{+}$- und (D) $\mathrm{CD} 19^{+}$-Zellen im Blut gemessen. Die Ergebnisse sind dargestellt als Mittelwerte \pm Standardabweichung, **Signifikant unterschiedlich zur Kontrollgruppe, $\mathrm{p}<0,01$.

Im Gegensatz zu den Ergebnissen der adoleszenten Mäuse fand sich in den adulten Tieren durch die Applikation von Eotaxin-1 im Hinblick auf die zentrale Immunantwort lediglich ein erhöhter Anteil an B-Zellen (Abb. 18 D). Die nach 24 Stunden immunhistochemisch nachgewiesene Inhibierung von Mikrogliazellen durch Eotaxin-1 (Abb. 7 C), konnte nach sieben Tagen in der Durchflusszytometrie hingegen nicht beobachtet werden (Abb. 18 A). 


\section{ZNS}

A

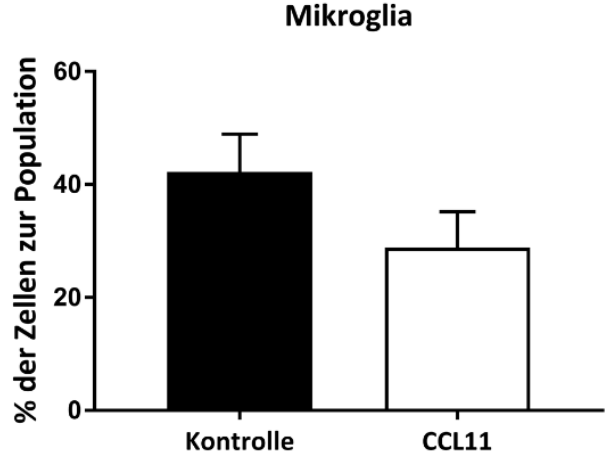

C

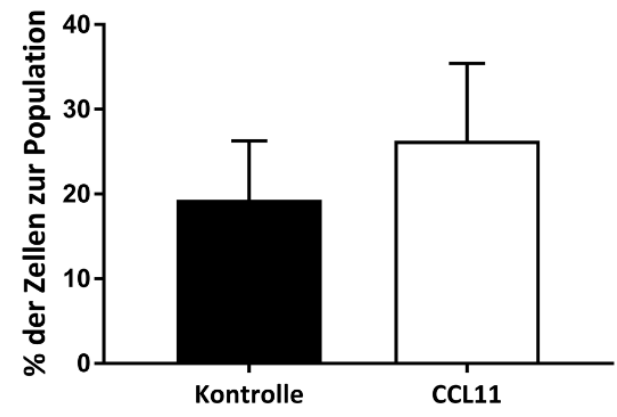

B

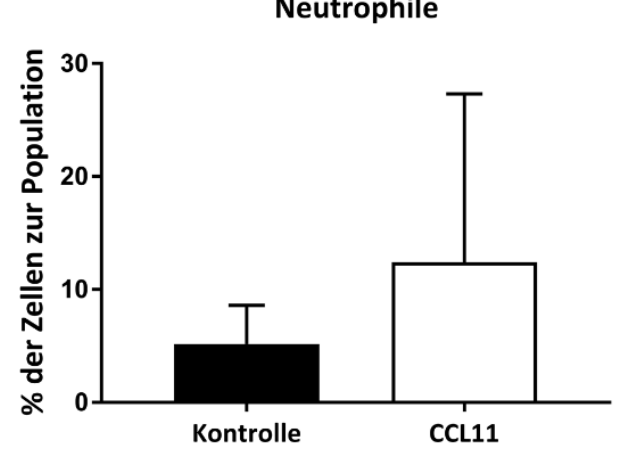

D

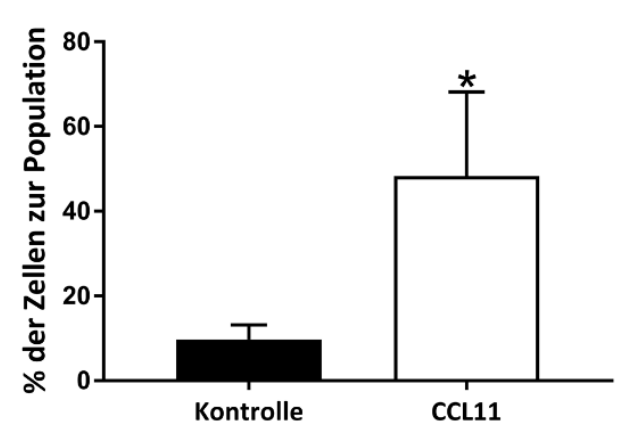

Abbildung 18: Eotaxin-1 modifiziert die subakute zentrale Immunantwort in adulten Mäusen. C57BL6-Mäuse erhielten nach 45-minütiger zerebraler Ischämie mit Beginn der Reperfusion und an den folgenden sieben Tagen täglich intraperitoneal $10 \mu \mathrm{g}$ pro kg KG Eotaxin-1 oder $100 \mu \mathrm{l}$ PBS als Kontrolle. Die Analyse der Durchflusszytometrie erfolgte softwaregestützt mit Flowjo am siebten Tag nach zerebraler Ischämie. Gezeigt ist die quantitative Analyse der sechs Monate alten Tiere. (A) CD45 $5^{+}$int.-, (B) CD45 ${ }^{+}$high-, $_{\text {, }}$ (C)

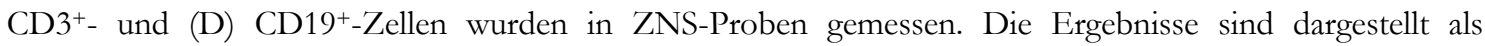
Mittelwerte \pm Standardabweichung, $*$ Signifikant unterschiedlich zur Kontrollgruppe, $\mathrm{p}<0,05$.

In der Peripherie fand sich eine durch Eotaxin-1 modulierte post-ischämische Immunantwort in den adulten Tieren. Im Blut fand man eine signifikante relative Reduktion der neutrophilen Granulozyten und eine signifikante relative Erhöhung der T- und B-Zellen (Abb.19 B, C, D). 


\section{BLUT}

A
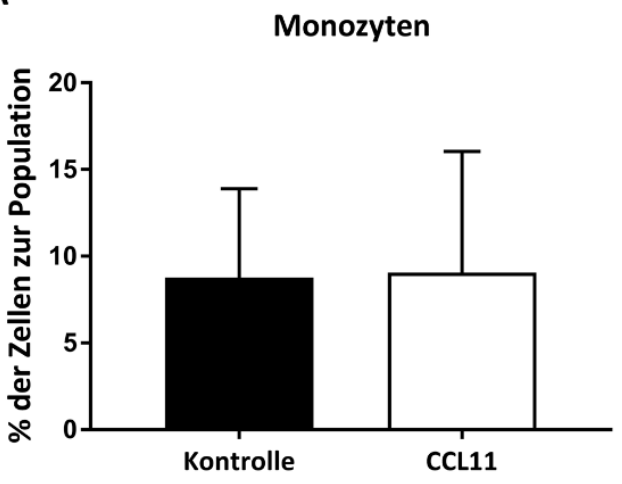

C

T-Zellen

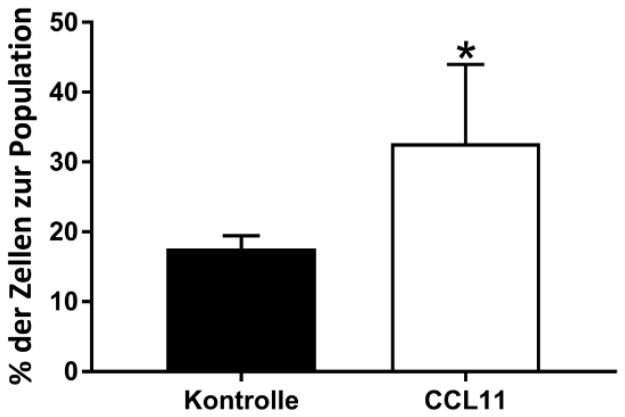

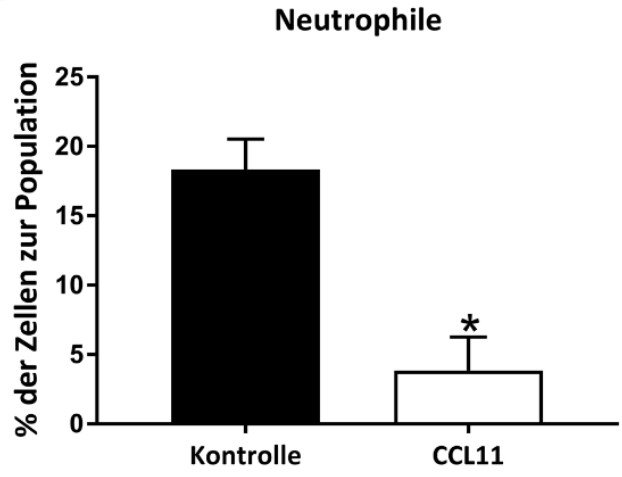

D

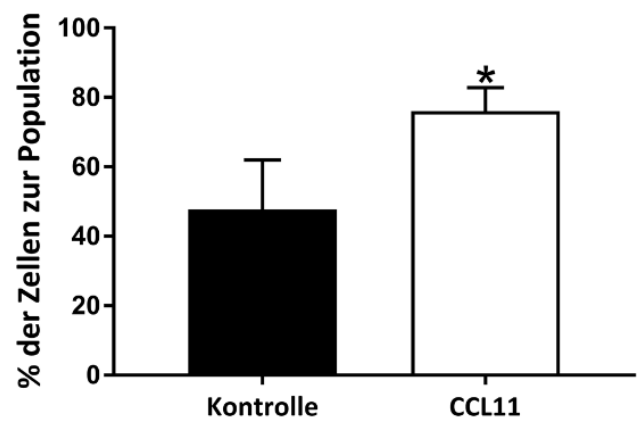

Abbildung 19: Eotaxin-1 modifiziert die subakute periphere Immunantwort in adulten Mäusen. C57BL6-Mäuse erhielten nach 45-minütiger zerebraler Ischämie mit Reperfusion intraperitoneal $10 \mu \mathrm{g}$ pro kg KG Eotaxin-1 oder $100 \mu \mathrm{l}$ PBS als Kontrolle und alle 24 Stunden für sieben Tage. Die Analyse der Durchflusszytometrie erfolgte softwaregestützt mit FlowJo am siebten Tag nach zerebraler Ischämie. Gezeigt

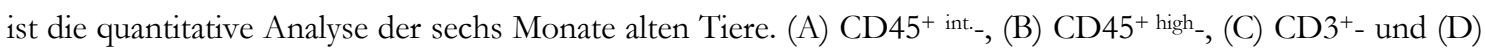
CD19+-Zellen im Blut gemessen. Die Ergebnisse sind dargestellt als Mittelwerte \pm Standardabweichung, *Signifikant unterschiedlich zur Kontrollgruppe, $\mathrm{p}<0,05$.

\subsection{Eotaxin-1 führt zu keiner Modulation von Autophagie oder pro- apoptotischer Signalwege}

Im folgenden experimentellen Teil der Studie wurden mögliche Signalwege mittels WesternBlot sieben Tage nach zerebraler Ischämie analysiert. Die Tiere wurden gleich der Tiere für die Durchflusszytometrie behandelt. Der Schwerpunkt der Analysen wurde auf die zelluläre Immunantwort (Mannoserezeptor und s100b), die Autophagie (LC3) und pro-apoptotische Signalkaskade (CDK5 und p35/p25) gelegt. 
Aktivierte Mikrogliazellen können je nach Zytokinmilieu und Expression von Oberflächenmarkern unterschiedlich aktiviert werden (Taylor und Sansing 2013). Diese Aktivierung erfolgt zum einen über den klassischen Aktivierungsweg, der proinflammatorische Zytokine ausschüttet und ROS aktiviert, man ordnet diesen zu M1-Mikrogliazellen zu. Zum anderen erfolgt die Aktivierung über einen alternativen Signalweg, der zu einer anti-inflammatorischen Immunantwort von M2-Mikrogliazellen führt. Die Aktivierung von M2-Mikrogliazellen kann durch Zytokine, wie zum Beispiel IL-4 und IL-10, erreicht werden. Ein Marker für M2-Mikrogliazellen ist der Mannoserezeptor. In dieser hier vorliegenden Studie konnte jedoch kein Einfluss von Eotaxin-1 auf das Expressionsmuster des Mannoserezeptors in beiden Altersgruppen festgestellt werden (Abb. 20).

A

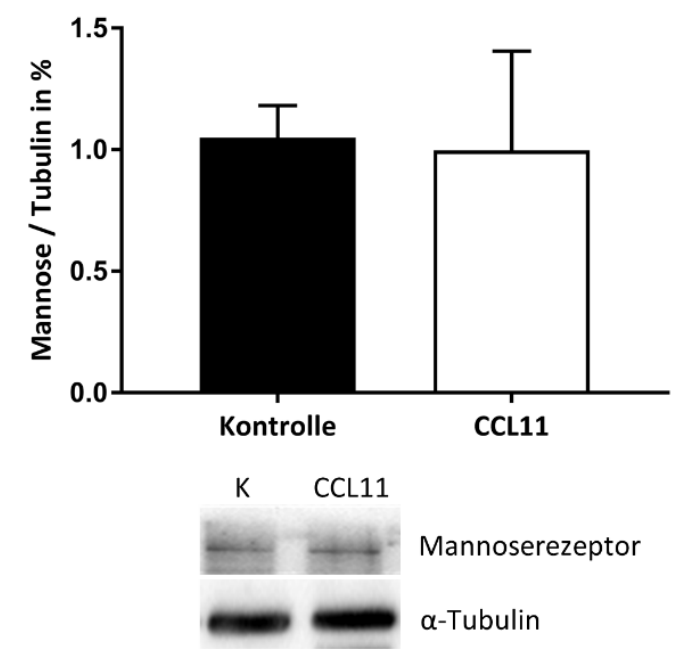

B

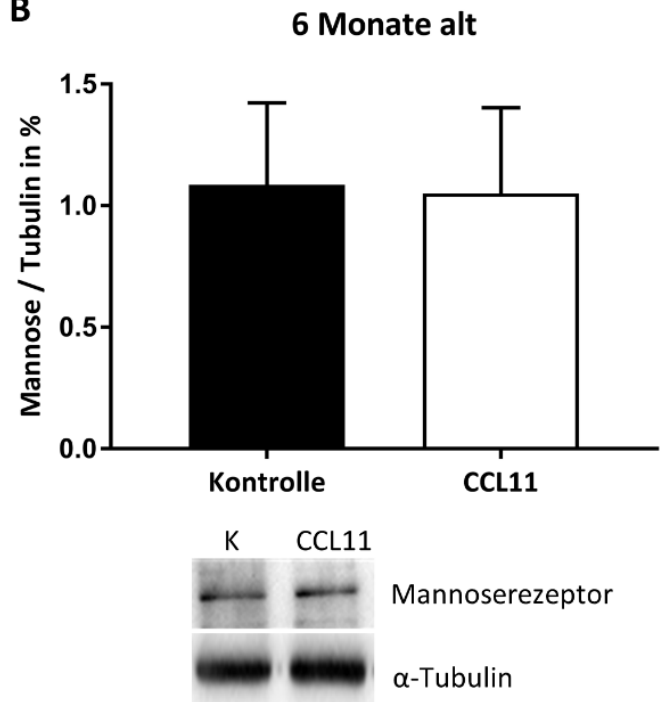

Abbildung 20: Eotaxin-1 hat keinen Einfluss auf die Expression des Mannoserezeptors. C57BL6-Mäuse erhielten nach 45-minütiger zerebraler Ischämie mit Beginn der Reperfusion und an den folgenden sieben Tagen täglich intraperitoneal $10 \mu \mathrm{g}$ pro kg KG Eotaxin-1 oder $100 \mu \mathrm{l}$ PBS als Kontrolle. Nach sieben Tagen wurde das Gewebe der mittels Western-Blot-Analyse untersucht. Gezeigt werden die densitometrisch quantitative Auswertung in (A) des Mannoserezeptors der sechs Wochen alten Tiere, und in (B) des Mannoserezeptors der sechs Monate alten Tiere ( $\alpha$-Tubulin wurde als Ladekontrolle verwendet, repräsentative Blots sind unterhalb der Graphen abgebildet). Die Ergebnisse sind dargestellt als Mittelwerte \pm Standardabweichung, Abkürzung: $\mathrm{K}=$ Kontrolle.

S100b ist ein kalziumbindendes Protein und wirkt dosisabhängig im ZNS auf diverse Weise als intra- und extrazellulärer Regulator (Donato et al. 2009). Zudem ist s100b ein Biomarker für den Schweregrad von Hirnschäden und ist nach ischämischem Insult prognostisch relevant (Foerch 2005; Sun 2013). S100b spielt eine Rolle in der Proliferation und 
Differenzierung von Gliazellen, kann Signalwege aktivieren, die die Apoptose hemmen und kann M1-Mikrogliazellen aktivieren und somit pro-inflammatorisch wirken (Zhou et al. 2018). In der hier vorliegenden Arbeit konnte jedoch kein Einfluss von Eotaxin-1 auf die Expression von bzw. Regulierung durch s100b in beiden Altersgruppen festgestellt werden (Abb. 21).
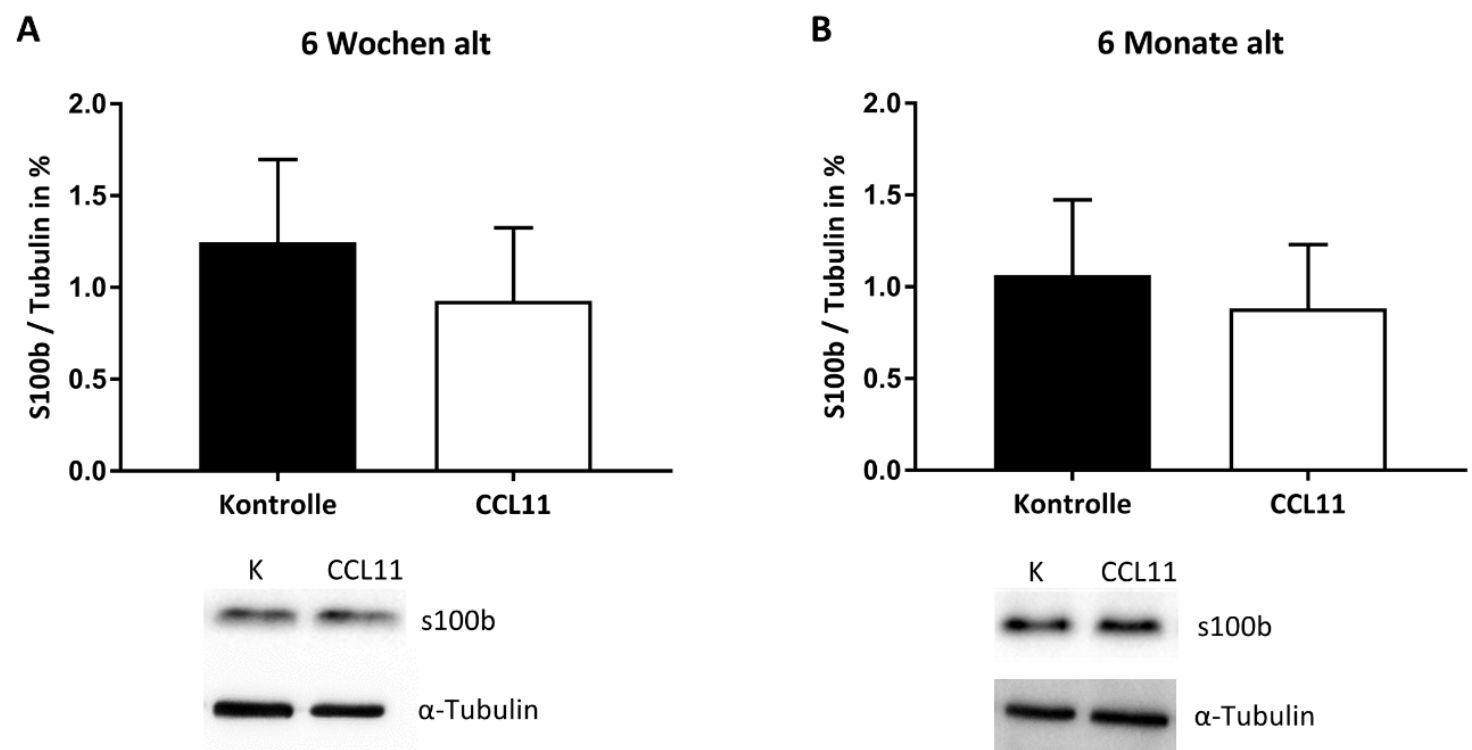

\begin{abstract}
Abbildung 21: Eotaxin-1 hat keinen Einfluss auf die Expression von s100b. C57BL6-Mäuse erhielten nach 45-minütiger zerebraler Ischämie mit Beginn der Reperfusion und an den folgenden sieben Tagen täglich intraperitoneal $10 \mu \mathrm{g}$ pro kg KG Eotaxin-1 oder $100 \mu \mathrm{l}$ PBS als Kontrolle. Nach sieben Tagen wurde das Gewebe der mittels Western-Blot-Analyse untersucht. Gezeigt werden die densitometrisch quantitative Auswertung in (A) von s100b der sechs Wochen alten Tiere, und in (B) von s100b der sechs Monate alten Tiere $(\alpha$-Tubulin wurde als Ladekontrolle verwendet, repräsentative Blots sind unterhalb der Graphen abgebildet). Die Ergebnisse sind dargestellt als Mittelwerte \pm Standardabweichung, Abkürzung: $\mathrm{K}=$ Kontrolle.
\end{abstract}

Nach einem ischämischen Insult kann eine Zelle über einen nicht-apoptotischen, programmierten Signalweg, in den sogenannten autophagosomalen Zelltod übergehen. Die Autophagie ist durch die Entsorgung beschädigter, fehl gefalteter Proteine oder ganzer Zellorganellen gekennzeichnet und auch gleichzeitig ein Selbstmordprogramm (Kim et al. 2018). In den Autophagosomen sind Bestandteile des Zytosols enthalten, unter anderem die zytosolische Form von LC3 I. Durch autophagosomale Aktivität entsteht LC3 II (Kim et al. 2018). In den adoleszenten und in den adulten Tieren konnte kein Einfluss von Eotaxin-1 auf die Autophagie über LC3 II festgestellt werden (Abb. 22). 
A

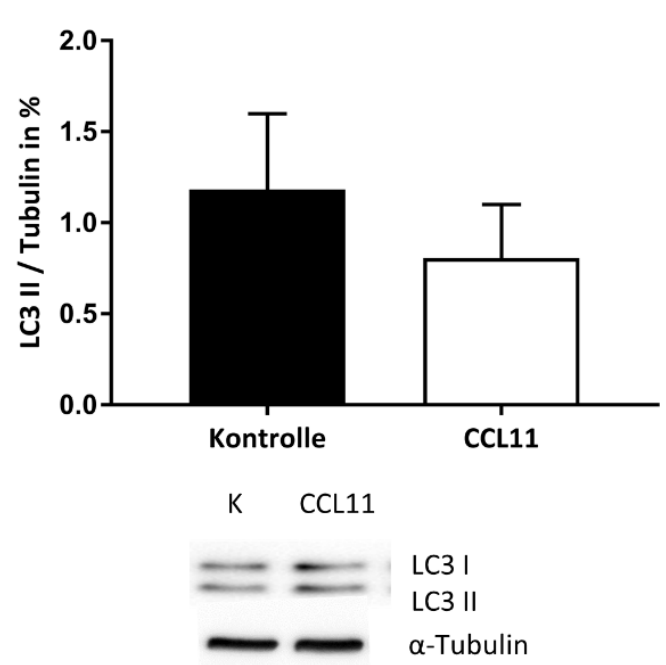

B

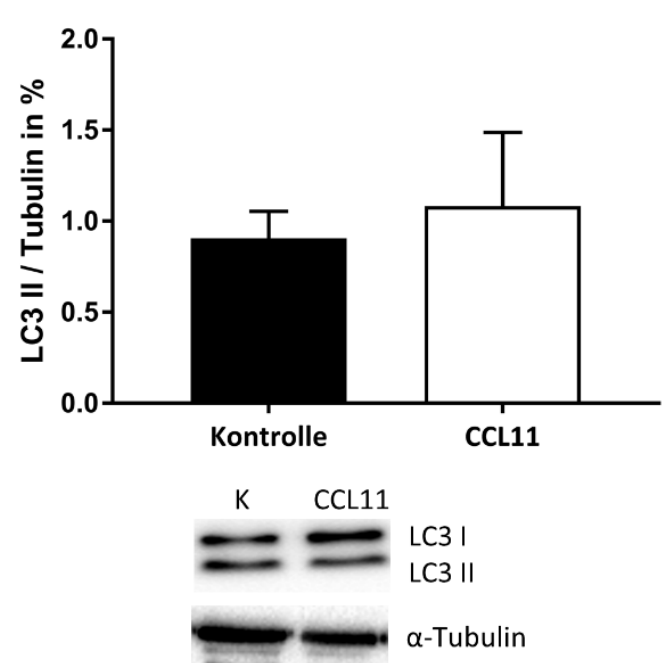

Abbildung 22: Eotaxin-1 hat keinen Einfluss auf Autophagie. C57BL6-Mäuse erhielten nach 45-minütiger zerebraler Ischämie mit Beginn der Reperfusion und an den folgenden sieben Tagen täglich intraperitoneal 10 $\mu \mathrm{g}$ pro kg KG Eotaxin-1 oder $100 \mu \mathrm{l}$ PBS als Kontrolle. Nach sieben Tagen wurde das Gewebe der mittels Western-Blot-Analyse untersucht. Gezeigt werden die densitometrisch quantitative Auswertung in (A) von LC3 der sechs Wochen alten Tiere, und in (B) von LC3 der sechs Monate alten Tiere ( $\alpha$-Tubulin wurde als Ladekontrolle verwendet, repräsentative Blots sind unterhalb der Graphen abgebildet). Die Ergebnisse sind dargestellt als Mittelwerte \pm Standardabweichung, Abkürzung: $K=$ Kontrolle.

Die Apoptose, der programmierte Zelltod, verläuft unter strenger Kontrolle im Gegensatz zur Nekrose. Eingeleitet wird die Apoptose durch pro-apoptotische Signale, diese können von Immunzellen ausgehen oder intrinsisch entsendet werden. Ein Mitspieler ist die CDK5, phosphoryliert mit p35 zu CDK5/p25 führt sie zum Zelluntergang (Shah und Lahiri 2014). In den adoleszenten Tieren konnte keine Regulation von Eotaxin-1 über CDK5/p35 zu CDK5/p25 und somit pro-apoptotische Signalwege festgestellt werden (Abb. 23 A, B). In den adulten Tieren zeigte sich isoliert eine erhöhte Expression von CDK5 in der mit Eotaxin-1 behandelten Gruppe (Abb. 23 C), jedoch konnte man keinen signifikanten Einfluss auf die p35/p25 Expression feststellen (Abb. 23 D). 
A

6 Wochen alt

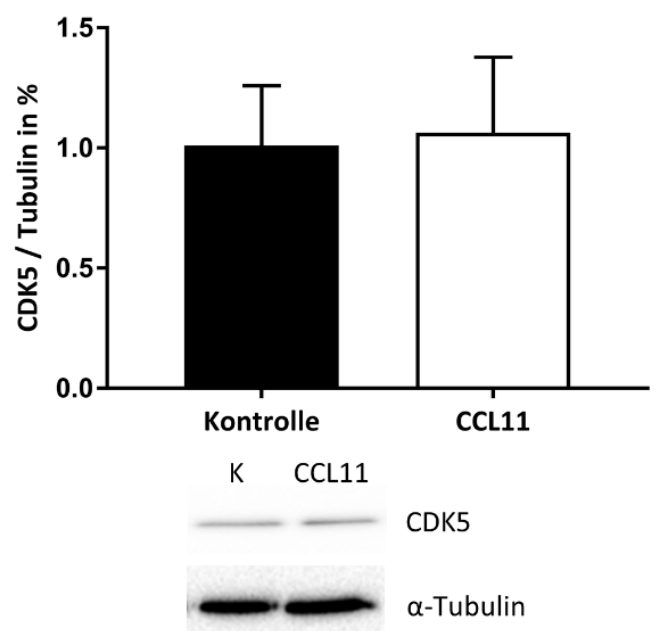

C

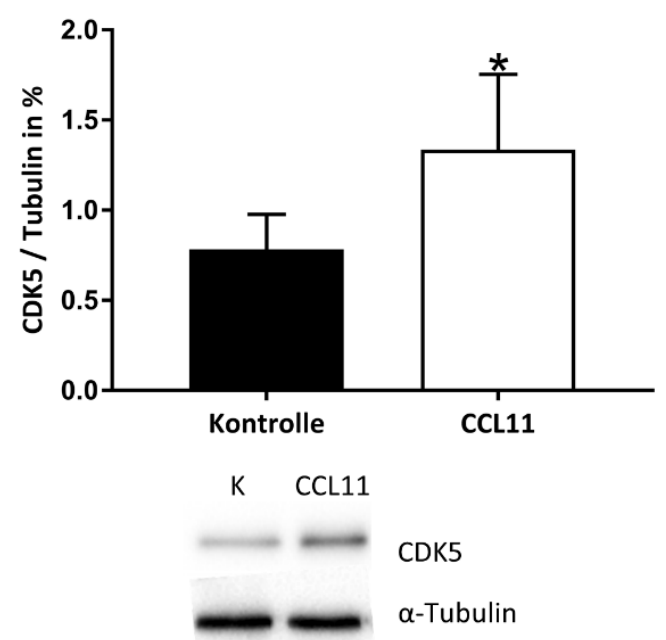

B

6 Wochen alt

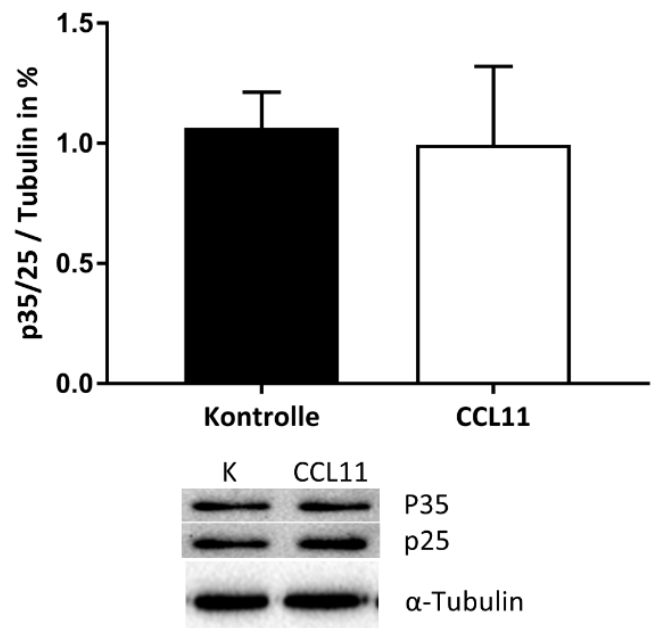

D 6 Monate alt

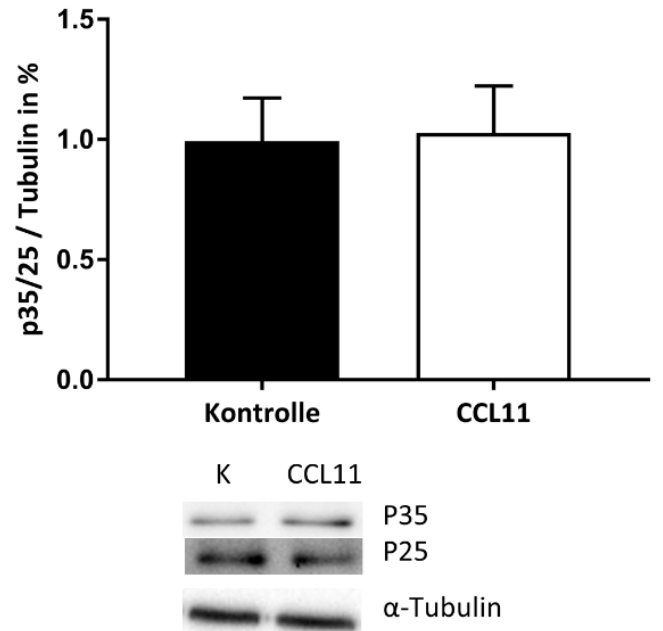

Abbildung 23: Eotaxin-1 wirkt unabhängig von pro-apoptotischen Signalwegen. C57BL6-Mäuse erhielten nach 45-minütiger zerebraler Ischämie mit Beginn der Reperfusion und an den folgenden sieben Tagen täglich intraperitoneal $10 \mu \mathrm{g}$ pro kg KG Eotaxin-1 oder $100 \mu \mathrm{l}$ PBS als Kontrolle. Nach sieben Tagen wurde das Gewebe der mittels Western-Blot-Analyse untersucht. Gezeigt werden die densitometrisch quantitative Auswertung in (A) von CDK5, in (B) von p35 der sechs Wochen alten Tiere, in (C) von CDK5, in (D) von p35 der sechs Monate alten Tiere ( $\alpha$-Tubulin wurde als Ladekontrolle verwendet, repräsentative Blots sind unterhalb der Graphen abgebildet). Die Ergebnisse sind dargestellt als Mittelwerte \pm Standardabweichung, Abkürzung: $\mathrm{K}=$ Kontrolle. *Signifikant unterschiedlich zur Kontrollgruppe, $\mathrm{p}<0,05$. 


\subsection{Die Inhibition von CCR3 ist neuroprotektiv in adulten Mäusen}

Durch die ektope Applikation von Eotaxin-1 kommt es zu einer Aggravation der Zellschädigung nach zerebraler Ischämie der adulten Maus. Folgerichtig stellte sich die Frage, inwiefern eine Inhibition dieses Signalweges zu einer akuten Neuroprotektion in diesen Tieren beiträgt. In Analogie zu den zuvor geschilderten Experimenten hinsichtlich der Applikation von Eotaxin-1 in der Akutphase der Ischämie wurde im weiteren Verlauf der Chemokinrezeptor CCR3 durch den Inhibitor SB297006 antagonisiert. Die Inhibition von CCR3 führte in diesem Zusammenhang zu keinem Effekt auf das Schlaganfallvolumen in den adoleszenten Mäusen (Abb. 24 A). Ebenso hatte die Applikation von SB297006 keinen Effekt auf die neuronale Dichte oder die mikrogliale Aktivierung (Abb. 24 B, C). Diese Daten bestätigen somit indirekt den fehlenden Einfluss des Eotaxin-1-Signalweges auf CCR3 unter diesen akut-ischämischen Bedingungen in der adoleszenten Maus.
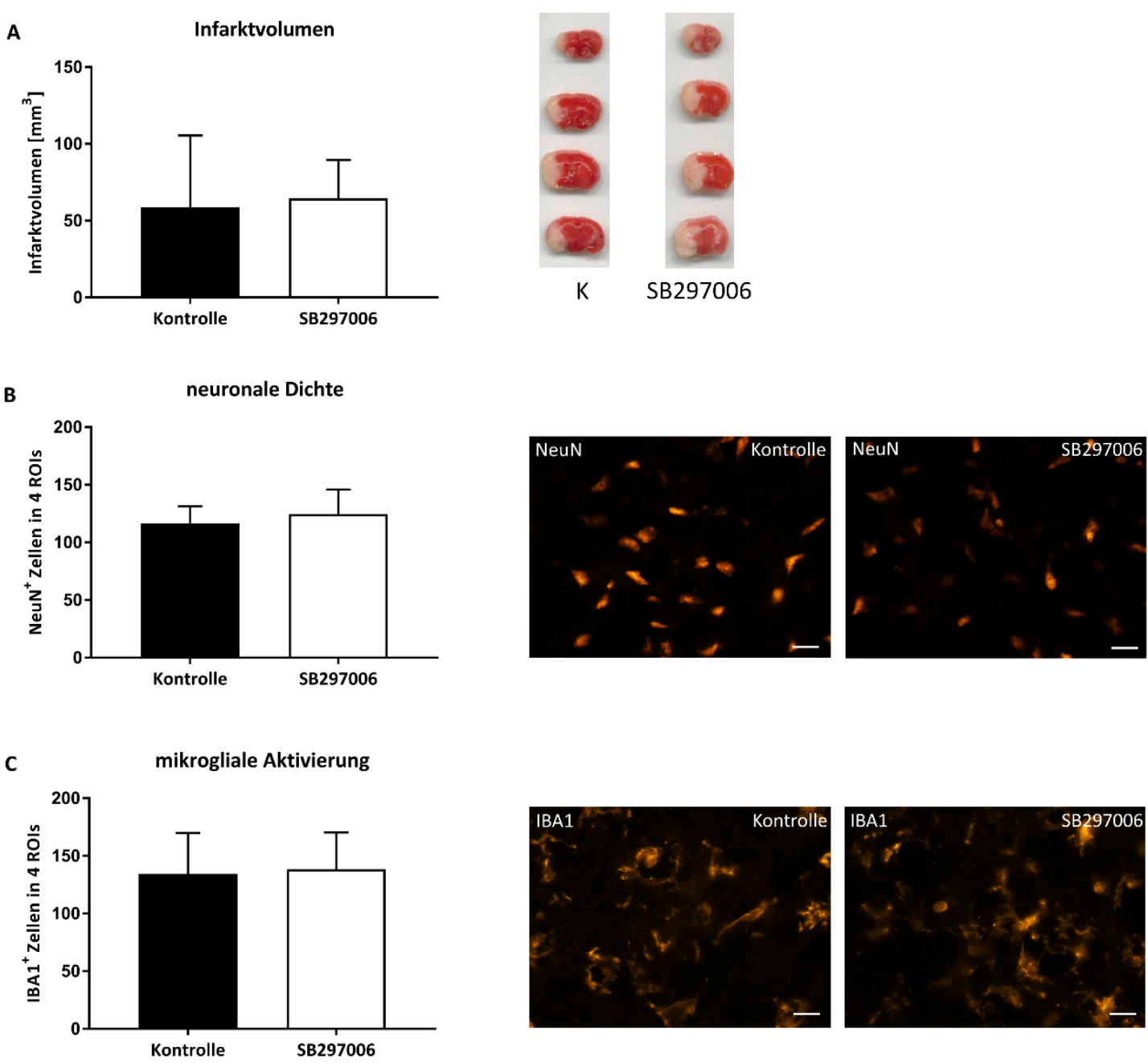

Abbildung 24: SB297006 hat keinen Einfluss auf den akuten Gewebeschaden in adoleszenten Mäusen. C57BL6-Mäuse erhielten nach 45-minütiger zerebraler Ischämie mit Reperfusion und an den folgenden drei 
Tagen täglich intraperitoneal $1 \mathrm{mg}$ pro kg KG SB297006 oder $50 \mu \mathrm{L}$ DMSO als Kontrolle. Nach drei Tagen Überleben wurde in (A) das Infarktvolumen mittels T'TC-Färbung gemessen, die neuronale Dichte anhand von NeuN-Färbung (B) und die mikrogliale Aktivität anhand des Markers IBA1 (C) bestimmt. Repräsentative Bilder der TTC-Färbung und der Immunhistochemie sind neben den Graphen abgebildet. Die Ergebnisse sind dargestellt als Mittelwerte \pm Standardabweichung, Abkürzung: $\mathrm{K}=$ Kontrolle, Maßstab $10 \mu \mathrm{m}$.

Anders stellte sich die Situation in der Gruppe der adulten Tiere dar. Dort kam es durch die Gabe von SB297006 zu einer signifikanten Reduktion des akuten Gewebeschadens, wie sich an reduziertem Infarktvolumen und erhöhter neuronaler Dichte zeigt (Abb. 25 A, B). Interessanterweise erbrachte die Mikrogliaanalyse eine signifikant erhöhte Zahl an $\mathrm{IBA}^{+}{ }_{-}$ Zellen in der Experimentalgruppe (Abb. 25 C). Diese Daten untermauern einen akuten neuroprotektiven Effekt durch Inhibition von CCR3 im Schlaganfallmodell der adulten Maus. 

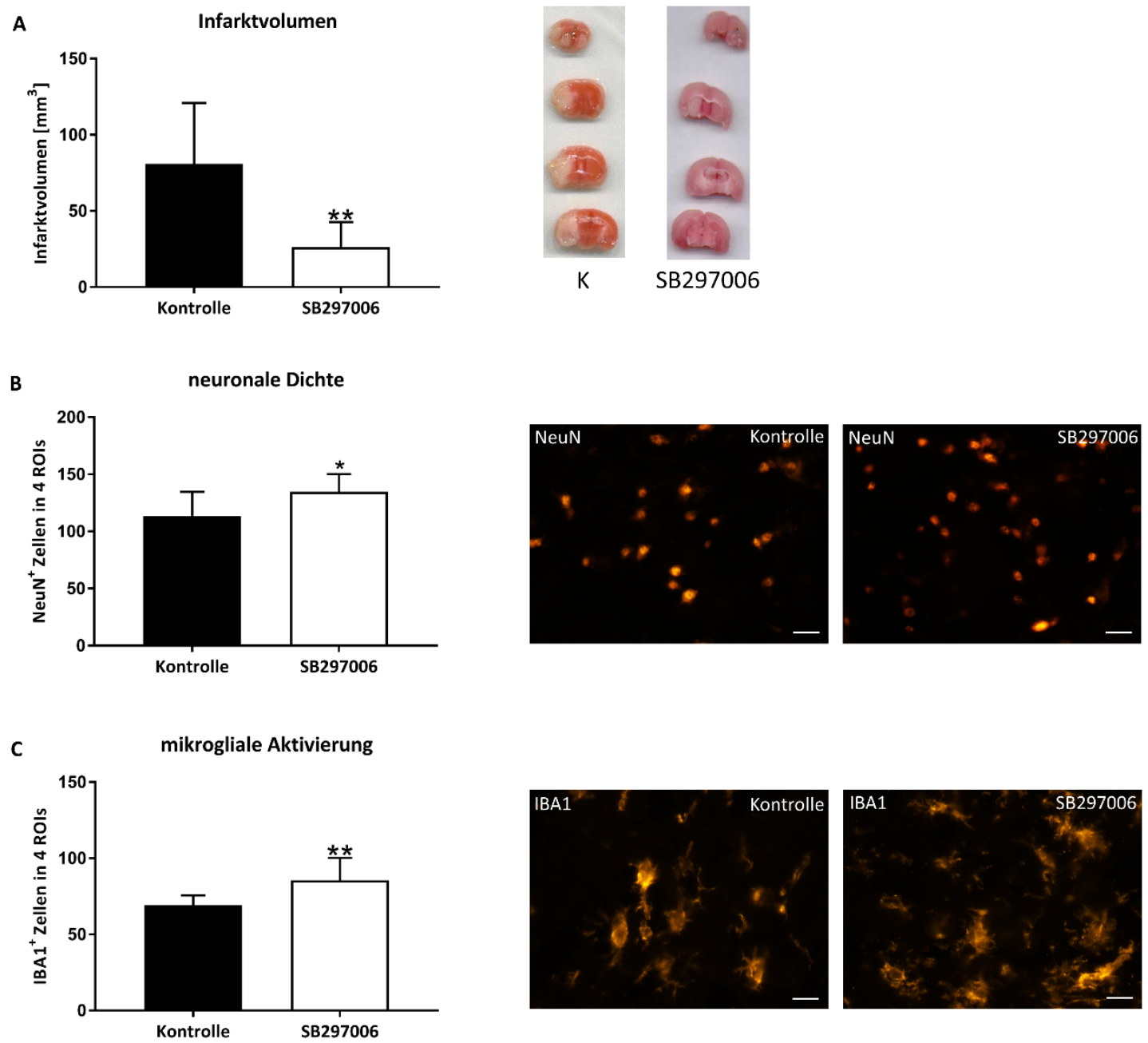

Abbildung 25: SB297006 inhibiert die Verschlechterung des akuten Gewebeschadens in adulten Mäusen. C57BL6-Mäuse erhielten nach 45-minütiger zerebraler Ischämie mit Reperfusion und an den folgenden drei Tagen täglich intraperitoneal $1 \mathrm{mg}$ pro $\mathrm{kg}$ KG SB297006 oder $50 \mu \mathrm{l}$ DMSO als Kontrolle. Nach drei Tagen Überleben wurde in (A) das Infarktvolumen mittels TTC-Färbung gemessen, die neuronale Dichte anhand von NeuN-Färbung (B) und die mikrogliale Aktivität anhand des Markers IBA1 (C) bestimmt. Repräsentative Bilder der TTC-Färbung und der Immunhistochemie sind neben den Graphen abgebildet. Die Ergebnisse sind dargestellt als Mittelwerte \pm Standardabweichung. *Signifikant unterschiedlich zur Kontrollgruppe, $\mathrm{p}<0,05$ **Signifikant unterschiedlich zur Kontrollgruppe, $\mathrm{p}<0,01$, Abkürzung: $\mathrm{K}=$ Kontrolle, Maßstab $10 \mu \mathrm{m}$.

Nachdem ein akut-therapeutischer Effekt durch Inhibition eines Eotaxin-1-abhängigen Signalweges im adulten Gehirn gezeigt werden konnte, stellte sich im weiteren Verlauf die Frage, inwiefern sich die Applikation von SB297006 auf das chronische Stadium des Schlaganfalls auswirken kann. Im Langzeitversuch über vier Wochen zeigte sich in den Verhaltenstests nach Antagonisieren von CCR3 in den adoleszenten Tieren kein Unterschied im Vergleich zur Kontrollgruppe (Abb. 26 A, B). In den adulten Tieren zeigte sich ebenfalls kein Unterschied zwischen der Experimentalgruppe und der Kontrollgruppe (Abb. 26 C, D). Vor dem Hintergrund der Tatsache, dass die ektope Applikation von Eotaxin-1 zu einer 
transienten Verschlechterung der neurologischen Erholung führte (Abb. 8 C, D), könnte die Gabe des Antagonisten diesen Effekt von Eotaxin-1 aushebeln.

A

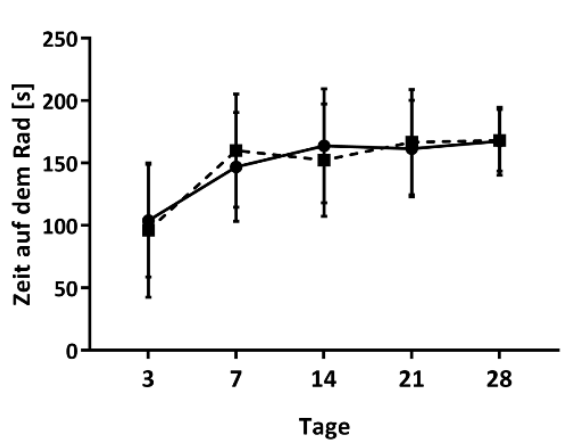

C

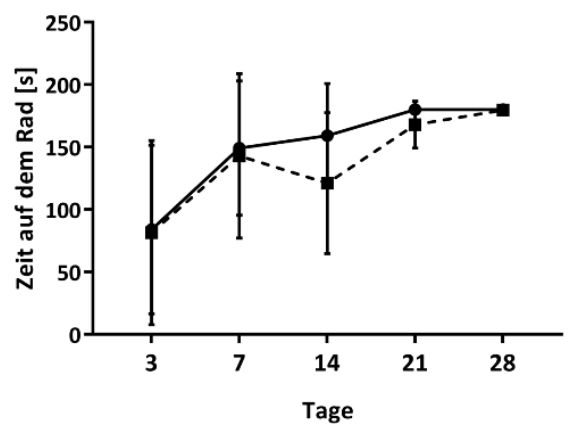

B

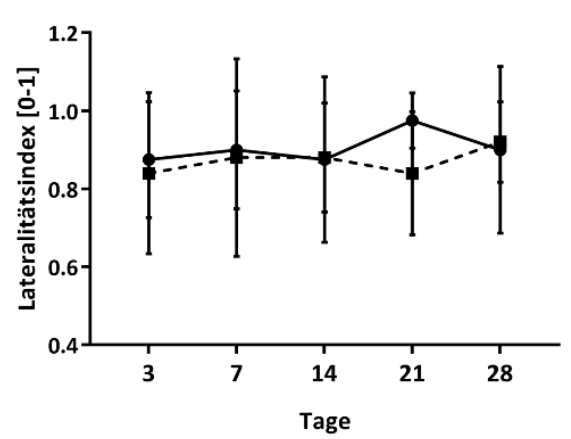

D

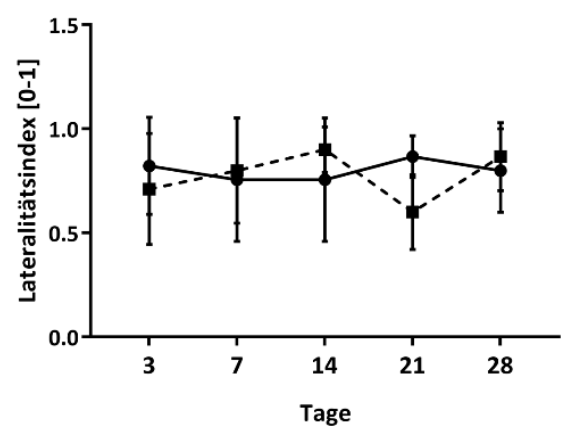

Abbildung 26: SB297006 hat keinen Einfluss auf die funktionale Erholung nach zerebraler Ischämie der Maus. C57BL6-Mäuse erhielten nach 45-minütiger zerebraler Ischämie mit Beginn der Reperfusion und an den folgenden sieben Tagen täglich intraperitoneal $1 \mathrm{mg}$ pro $\mathrm{kg} \mathrm{KG} \mathrm{SB297006} \mathrm{oder} 50 \mu \mathrm{l}$ DMSO als Kontrolle. Die Tiere wurden nach 28 Tagen euthanasiert. Die Verhaltenstests wurden an Tag 3, 7, 14,21 und 28 nach der zerebralen Ischämie durchgeführt. Der Rota-Rod-Test und der Corner-Turn-Test wurden jeweils an adoleszenten (A, B) und adulten (C, D) Tieren durchgeführt. Die Ergebnisse sind dargestellt als Mittelwerte \pm Standardabweichung.

Der chronische Gewebeschaden wurde, wie bereits zuvor geschildert, vier Wochen nach Induktion der zerebralen Ischämie untersucht. Passend zu den soeben erzielten Ergebnissen in den Verhaltenstests konnte gezeigt werden, dass die Gabe des Antagonisten in den adoleszenten Versuchstieren die chronische neuronale Dichte sowie die chronische mikrogliale Aktivierung nicht beeinflusst (Abb. 27). 
A
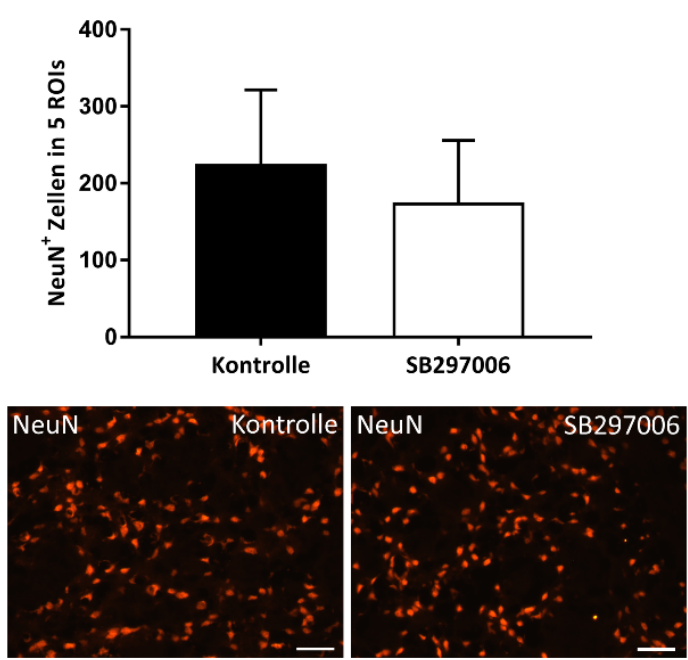

B

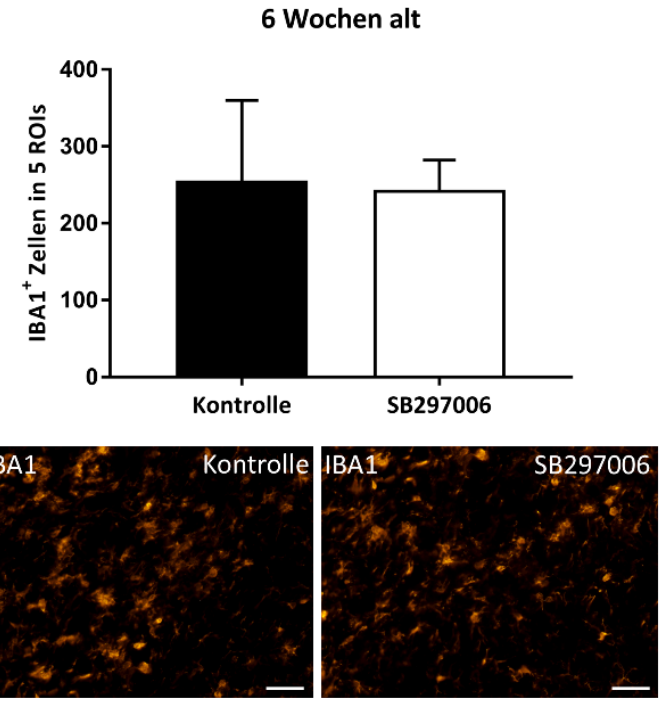

Abbildung 27: SB297006 beeinflusst nicht den chronischen Gewebeschaden der adoleszenten Mäuse. C57BL6-Mäuse erhielten nach 45-minütiger zerebraler Ischämie mit Beginn der Reperfusion und an den folgenden sieben Tagen täglich intraperitoneal $1 \mathrm{mg}$ pro $\mathrm{kg}$ SB297006 oder $50 \mu \mathrm{l}$ DMSO als Kontrolle. Die Tiere wurden nach 28 Tagen euthanasiert. Es wurden am Tag 28 sowohl die neuronale Dichte (A) als auch das Ausmaß der mikroglialen Aktivierung (B) analysiert. Repräsentative Bilder der quantitativen Analyse finden sich jeweils unterhalb der Diagramme. Die Ergebnisse sind dargestellt als Mittelwerte \pm Standardabweichung, Maßstab $20 \mu \mathrm{m}$.

Auch im adulten Schlaganfallmodell konnte kein Effekt durch die Applikation des Eotaxin-1-Antagonisten erzielt werden (Abb. 28).

A
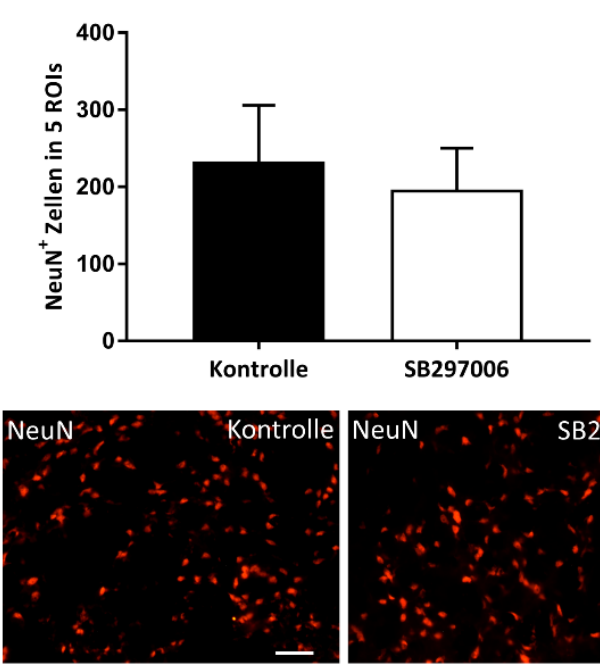

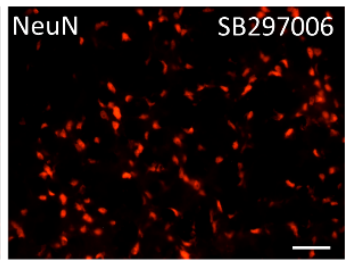

B
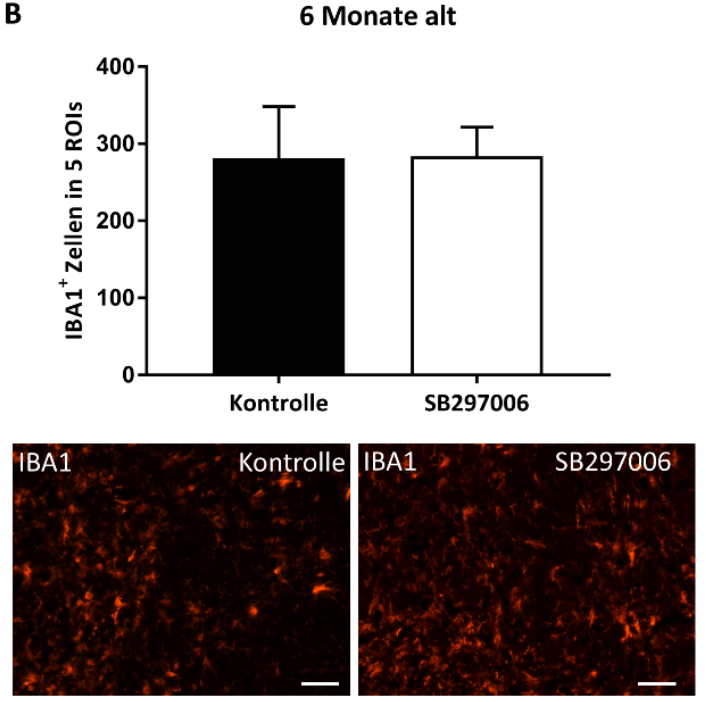

Abbildung 28: SB297006 beeinflusst nicht den chronischen Gewebeschaden der adulten Mäuse. C57BL6-Mäuse erhielten nach 45-minütiger zerebraler Ischämie mit Beginn der Reperfusion und an den folgenden sieben Tagen täglich intraperitoneal $1 \mathrm{mg}$ pro $\mathrm{kg}$ SB297006 oder $50 \mu \mathrm{l}$ DMSO als Kontrolle. Die Tiere wurden nach 28 Tagen euthanasiert. Es wurden am Tag 28 sowohl die neuronale Dichte (A) als auch das Ausmaß der mikroglialen Aktivierung (B) analysiert. Repräsentative Bilder der quantitativen Analyse finden sich 
jeweils unterhalb der Diagramme. Die Ergebnisse sind dargestellt als Mittelwerte \pm Standardabweichung, Maßstab $20 \mu \mathrm{m}$.

Neben Verhaltenstests und den immunhistochemischen Färbungen wurden mögliche Effekte der Antagonisierung von CCR3 im Hinblick auf die post-ischämische Gliogenese und Neurogenese untersucht. Die post-ischämische endogene Zellproliferation der adoleszenten Mäuse zeigte sich nach Gabe von SB297006 signifikant reduziert im Vergleich zu den Kontrollen (Abb. 29 A). Eotaxin-1 förderte die Zellproliferation der adoleszenten Tiere (Abb. 11 A). Die Gabe des Antagonisten konnte diesen Effekt auf die Zellproliferation also nicht nur aufheben, sondern sogar umkehren. In den adulten Tieren hingegen beeinflusste der Antagonist die Zellproliferation nicht signifikant (Abb. 29 B).

A

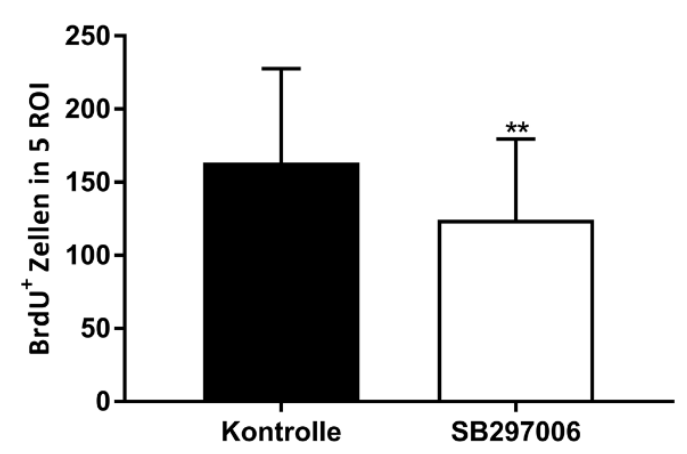

B

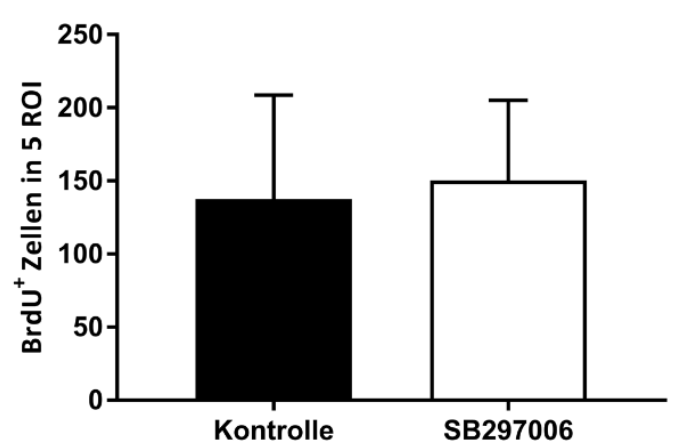

Abbildung 29: SB297006 hemmt die Zellproliferation der adoleszenten Mäuse. C57BL6-Mäuse erhielten nach 45-minütiger zerebraler Ischämie mit Beginn der Reperfusion und an den folgenden sieben Tagen täglich intraperitoneal $1 \mathrm{mg}$ pro kg SB297006 oder $50 \mu \mathrm{l}$ DMSO als Kontrolle. An den Tagen 8-18 wurde BrdU intraperitoneal verabreicht. Die Tiere wurden nach 28 Tagen euthanasiert. Die Zellproliferation wurde anhand $\mathrm{BrdU}^{+}$-Zellen sowohl in adoleszenten (A) wie auch in adulten (B) Mäusen quantifiziert. Die Ergebnisse sind

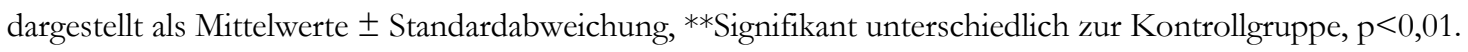

In den adoleszenten Mäusen inhibierte die Gabe des Antagonisten die neuroregenerativen Prozesse. Der Eotaxin-1-vermittelte Effekt konnte somit aufgehoben werden. In einer Doppelfärbung gegen BrdU und gegen neuronale Marker zeigte sich überdies eine Inhibition der Neurogenese durch den Antagonisten in den adoleszenten Mäusen verglichen zur Kontrollgruppe (Abb. 30). In den adulten Tieren zeigte sich hingegen kein Unterschied zwischen der Experimentalgruppe und der Kontrollgruppe (Abb. 31). 
A

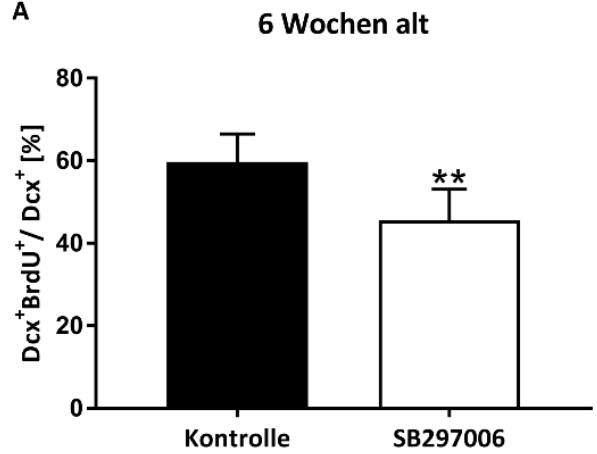

B

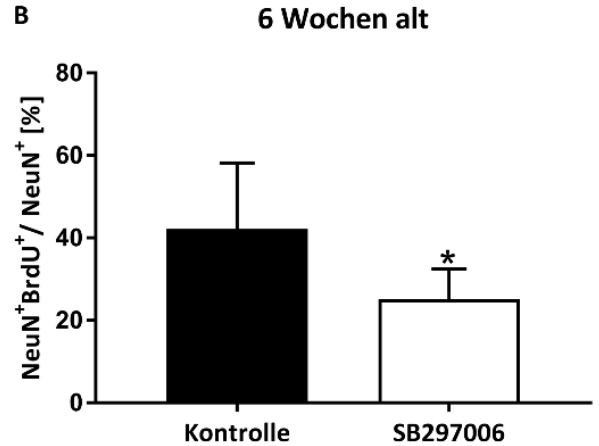

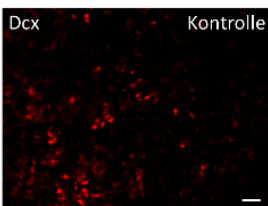
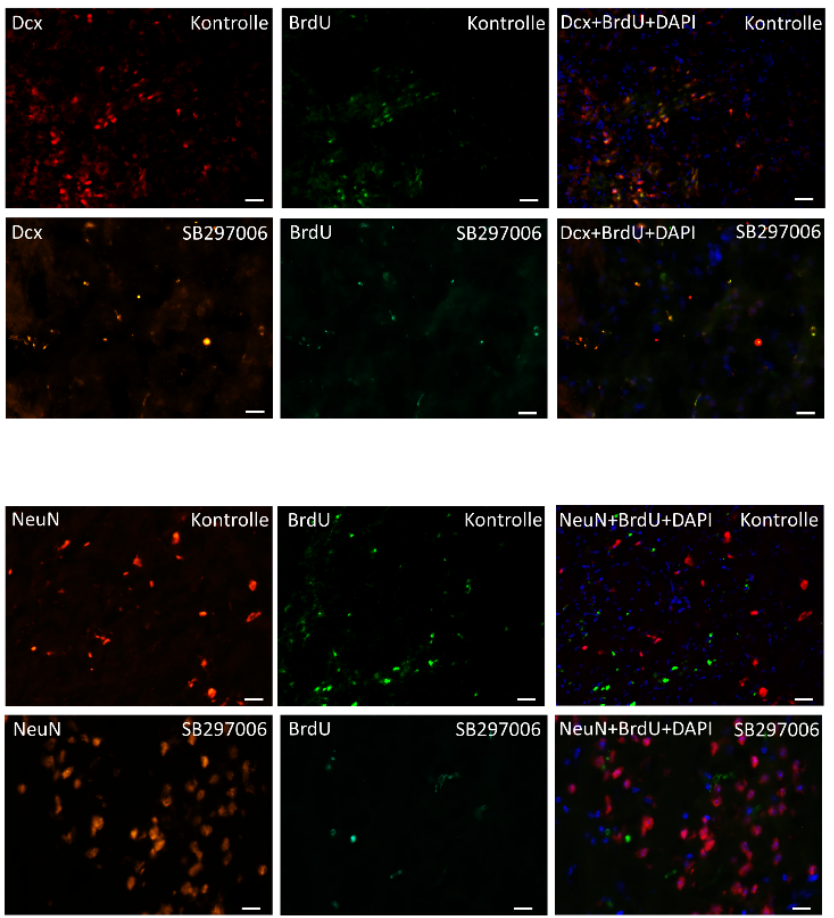

Abbildung 30: SB297006 inhibiert die Neurogenese in adoleszenten Mäusen. C57BL6-Mäuse erhielten nach 45-minütiger zerebraler Ischämie mit Beginn der Reperfusion und an den folgenden sieben Tagen täglich intraperitoneal $1 \mathrm{mg}$ pro kg SB297006 oder $50 \mu \mathrm{l}$ DMSO als Kontrolle. An den Tagen 8-18 BrdU intraperitoneal verabreicht. Die Tiere wurden nach 28 Tagen euthanasiert. Die Neurogenese in den adoleszenten Mäusen wurde anhand einer Doppelfärbung mit BrdU gegen den neuronalen Markern Dcx (A) und NeuN (B) evaluiert. Repräsentative Bilder der jeweiligen Färbung sind neben den Graphen abgebildet. Die Ergebnisse sind dargestellt als Mittelwerte \pm Standardabweichung, *Signifikant unterschiedlich zur Kontrollgruppe, $\mathrm{p}<0,05$, **Signifikant unterschiedlich zur Kontrollgruppe, $\mathrm{p}<0,01$, Maßstab $20 \mu \mathrm{m}$. 
A

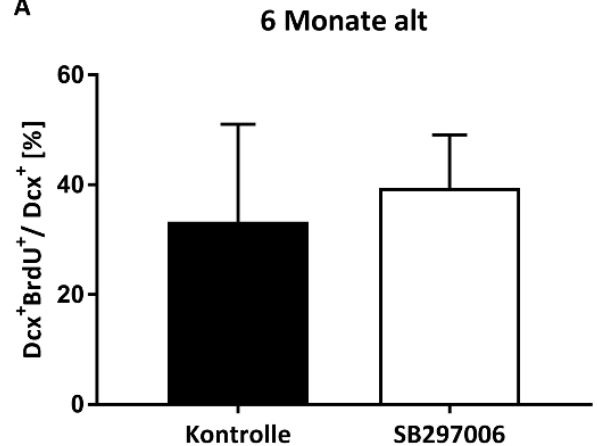

B

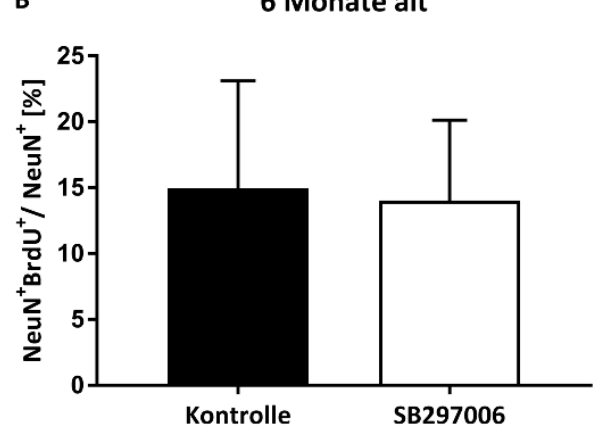

Dcx
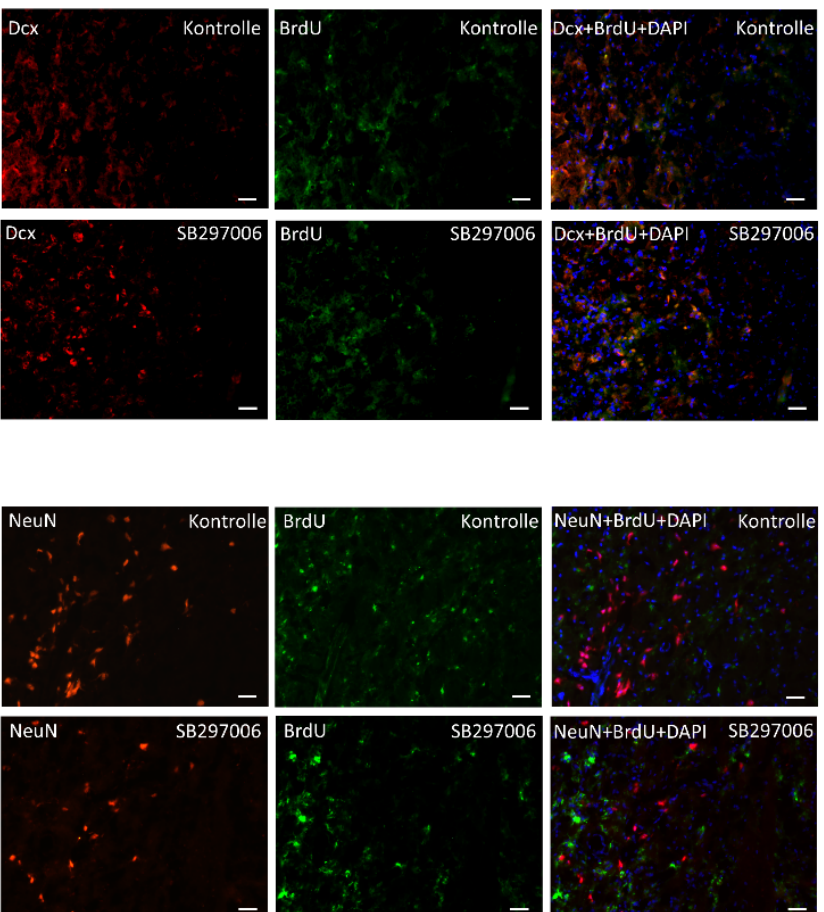

Abbildung 31: SB297006 beeinflusst nicht die Neurogenese in adulten Mäusen. C57BL6-Mäuse erhielten nach 45-minütiger zerebraler Ischämie mit Beginn der Reperfusion und an den folgenden sieben Tagen täglich intraperitoneal $1 \mathrm{mg}$ pro kg SB297006 oder $50 \mu \mathrm{l}$ DMSO als Kontrolle. An den Tagen 8-18 BrdU intraperitoneal verabreicht. Die Tiere wurden nach 28 Tagen euthanasiert. Die Neurogenese in den adulten Mäusen wurde anhand einer Doppelfärbung mit BrdU gegen den neuronalen Markern Dcx (A) und NeuN (B) evaluiert. Repräsentative Bilder der jeweiligen Färbung sind neben den Graphen abgebildet. Die Ergebnisse sind dargestellt als Mittelwerte \pm Standardabweichung, Maßstab $20 \mu \mathrm{m}$.

Eotaxin-1 förderte die post-ischämische Gliogenese in den adoleszenten Tieren nach 28 Tagen (Abb. 14). Durch die Antagonisierung von CCR3 konnte dieser Effekt aufgehoben werden. Die Gabe des Antagonisten inhibierte überdies die Gliogenese in den adoleszenten Tieren (Abb. 32). In den adulten Tieren beeinflusste Eotaxin-1 die Gliogenese jedoch nicht. Dementsprechend zeigte die Inhibierung des Eotaxin-1-Signalwegs ebenfalls keinen Einfluss auf die Gliogenese in den adulten Mäusen (Abb. 33). 
A

6 Wochen alt
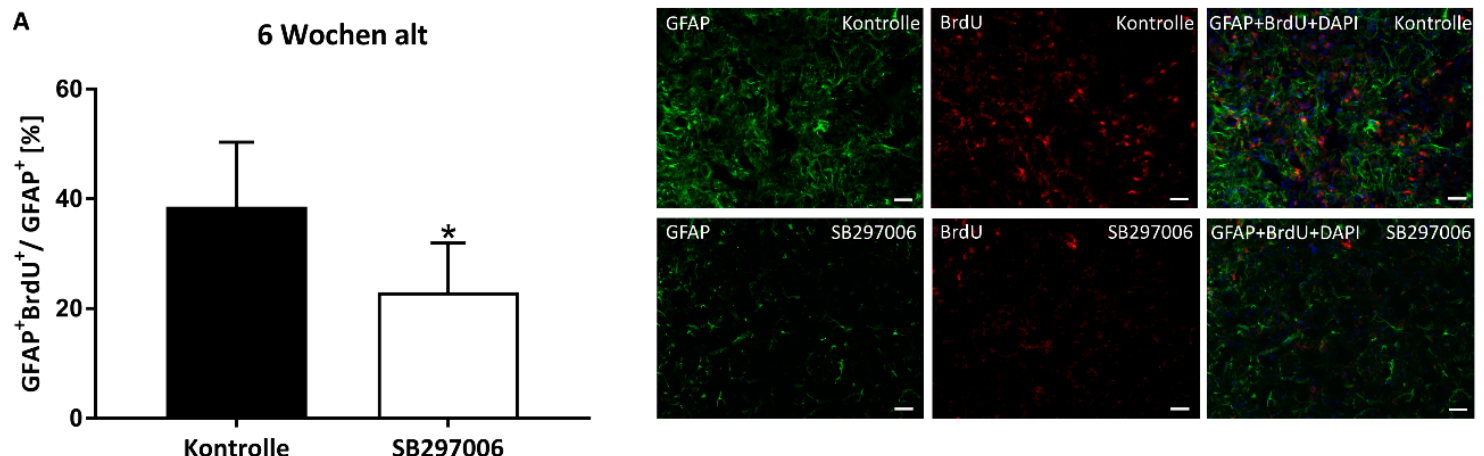

Kontrolle
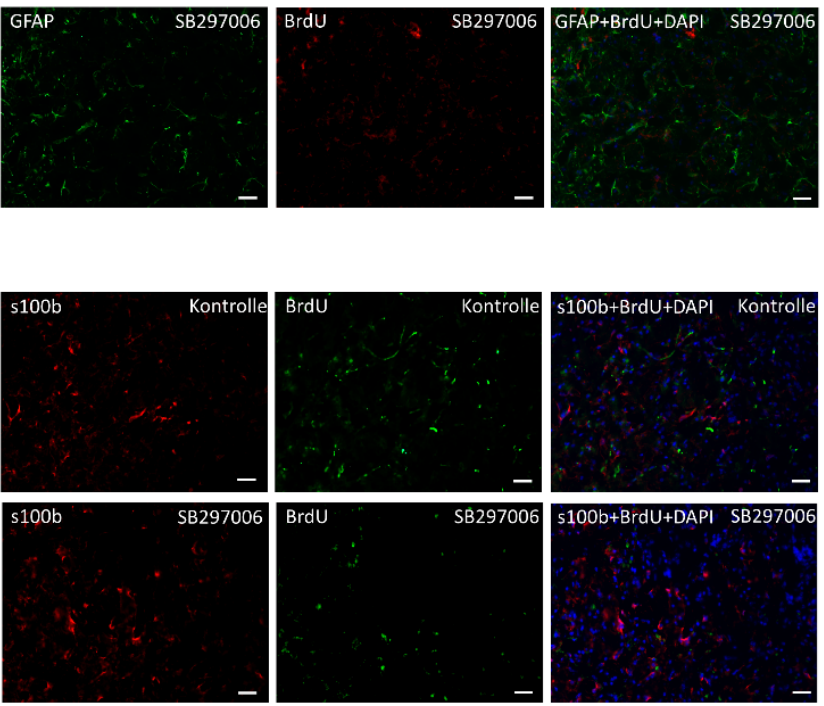

B

6 Wochen alt

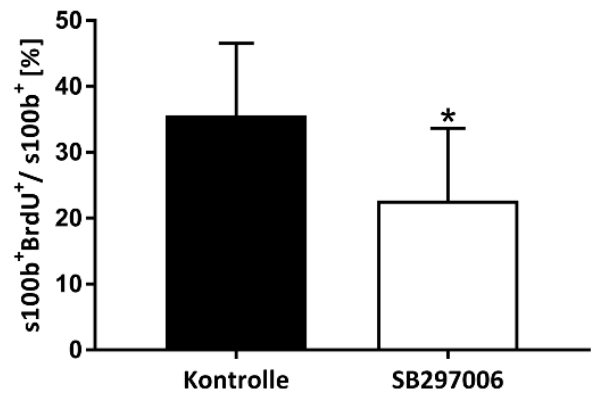

Abbildung 32: SB297006 hemmt die Gliogenese in adoleszenten Mäusen. C57BL6-Mäuse erhielten nach 45-minütiger zerebraler Ischämie mit Beginn der Reperfusion und an den folgenden sieben Tagen täglich intraperitoneal $1 \mathrm{mg}$ pro kg SB297006 oder $50 \mu \mathrm{l}$ DMSO als Kontrolle. An Tag 8-18 wurde BrdU intraperitoneal verabreicht. Die Tiere wurden nach 28 Tagen euthanasiert. Die Gliogenese in den sechs Wochen alten Tieren wurde anhand einer Doppelfärbung mit BrdU und den glialen Markern GFAP (A) und s100b (B) evaluiert. Repräsentative Bilder der jeweiligen Färbung sind neben den Graphen abgebildet. Die Ergebnisse sind dargestellt als Mittelwerte \pm Standardabweichung, *Signifikant unterschiedlich zur Kontrollgruppe, $\mathrm{p}<0,05$, Maßstab $20 \mu \mathrm{m}$. 
A
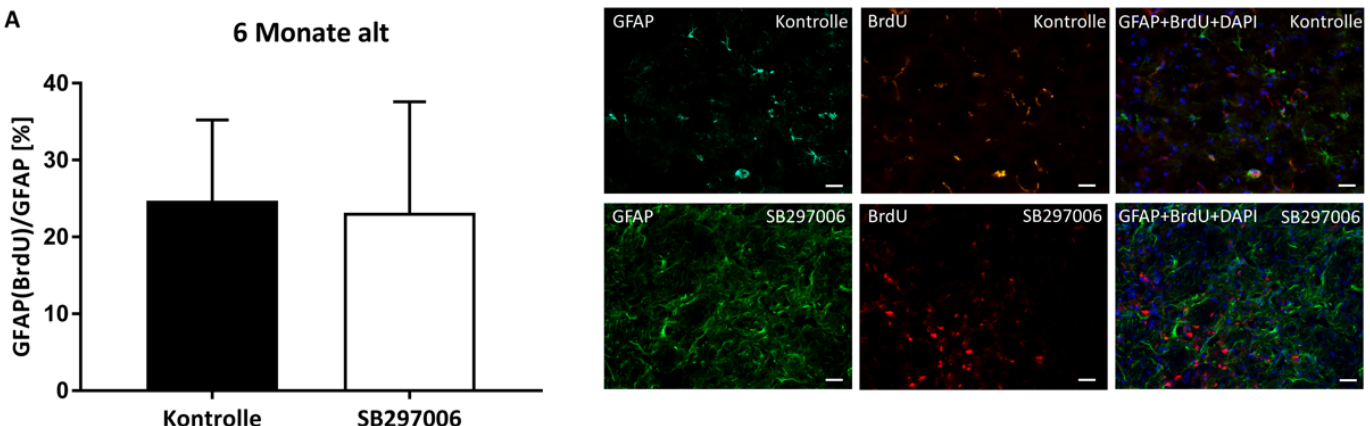

B

6 Monate alt
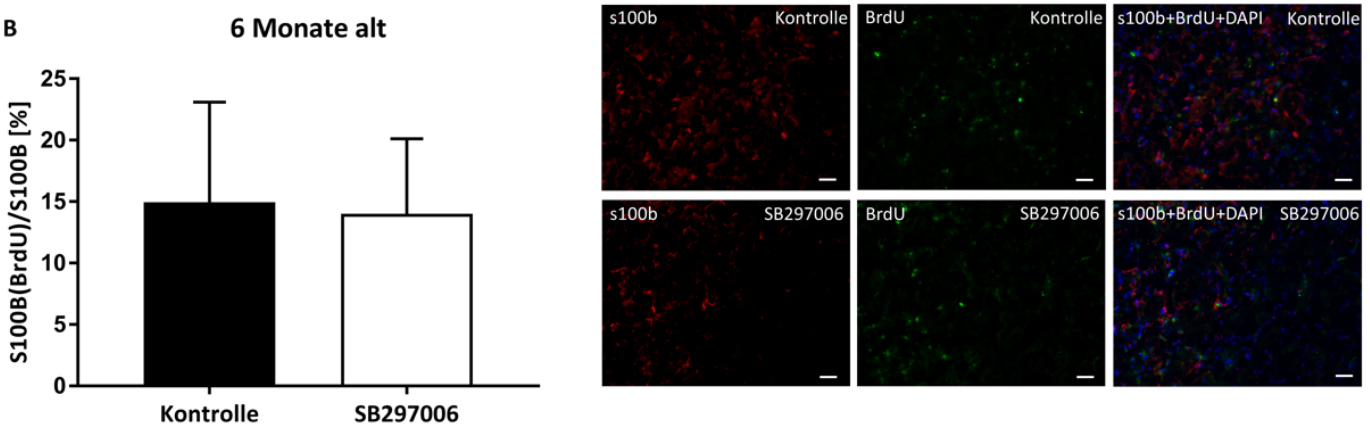

Abbildung 33: SB297006 beeinflusst nicht die Gliogenese der adulten Mäuse. C57BL6-Mäuse erhielten nach 45-minütiger zerebraler Ischämie mit Beginn der Reperfusion und an den folgenden sieben Tagen täglich intraperitoneal $1 \mathrm{mg}$ pro kg SB297006 oder $50 \mu \mathrm{l}$ DMSO als Kontrolle. An Tag 8-18 wurde BrdU intraperitoneal verabreicht. Die Tiere wurden nach 28 Tagen euthanasiert. Die Gliogenese in den sechs Monate alten Tieren wurde anhand einer Doppelfärbung mit BrdU und den glialen Markern GFAP (A) und s100b (B) evaluiert. Repräsentative Bilder der jeweiligen Färbung sind neben den Graphen abgebildet. Die Ergebnisse sind dargestellt als Mittelwerte \pm Standardabweichung, Maßstab $20 \mu \mathrm{m}$. 


\section{Diskussion}

In der komplexen Pathophysiologie des ischämischen Schlaganfalls bieten sich inflammatorische Signalkaskaden als potentielle Angriffspunkte für therapeutische Interventionen an. In diesem Zusammenhang dient Eotaxin-1 als ein Mediator von herausragender Rolle, insofern als dass Eotaxin-1 verantwortlich für die Chemotaxis und die Aktivierung verschiedener Immunzellen ist. Die vorliegende Arbeit untersuchte zum ersten Mal den Einfluss von ektopem Eotaxin-1 in einem Mausmodell der zerebralen Ischämie an adoleszenten und an adulten Tieren. Es zeigte sich, dass Eotaxin-1 eine Vielzahl distinkter Effekte sowohl während der Akutphase als auch während der chronischen Phase des ischämischen Schlaganfalls induziert. Diese Effekte stehen dabei in mechanistischem Zusammenhang mit dem Alter der Versuchstiere. Eotaxin-1 führt zu einer Aggravation des akuten ischämischen Zellschadens in adulten Mäusen, ohne einen Einfluss auf die akute Gewebeschädigung bei adoleszenten Tieren zu haben. Stattdessen stimuliert Eotaxin-1 die post-ischämische Regeneration in adoleszenten Tieren im Langzeitverlauf jedoch ohne eine funktionale Erholung zu erreichen. Vielmehr hemmt Eotaxin-1 in den adulten Versuchstieren die post-ischämische Neurogenese, was zu einer Beeinträchtigung der funktionalen Erholung führt. Das therapeutische Potenzial des Eotaxin-1-Signalwegs unter ischämischen Bedingungen zeigt sich durch die pharmakologische Blockierung dieses Signalweges. Der CCR3-Inhibitor SB297006 induziert bei adulten Mäusen eine akute Neuroprotektion und ist in der Lage, die Eotaxin-1 vermittelte Stimulation der Neuroregeneration in den adoleszenten Mäusen zu revidieren.

Im akuten Stadium des Schlaganfalls stehen pathophysiologisch die Exzitotoxizität und die akute Inflammation im Vordergrund. Aufgrund dessen wurde experimentell nach 24 Stunden der Einfluss von Eotaxin-1 auf den akuten Gewebeschaden, der neuronale Zellverlust und auf die mikrogliale Aktivierung untersucht. In dieser Studie zeigte sich, dass Eotaxin-1 bei adoleszenten Tieren keinen Einfluss auf die Exzitotoxizität und die akute Inflammation hat. Stattdessen ist Eotaxin-1 in den adulten Tieren akut neurotoxisch, wie sich anhand der vergrößerten Infarktvolumina und dem vermehrten neuronalen Zellverlust in der Experimentalgruppe zeigt. Der post-ischämische exzitatorische neuronale Untergang geht in der Regel mit der Aktivierung von Mikrogliazellen einher und leitet die zerebrale Inflammation ein (Chen et al. 2018; Iadecola und Anrather 2011). Pro-inflammatorische Effekte von Zytokinen wie Eotaxin-1 führen durch ihre Fähigkeit der Rekrutierung und Aktivierung von Immunzellen ebenfalls zum akuten Gewebeschaden (Chen et al. 2018). In den adulten Tieren, die mit Eotaxin-1 behandelt wurden, zeichnet sich jedoch überraschend 
eine Hemmung der mikroglialen Aktivierung ab. Interessanterweise wurde bereits zuvor, jedoch unter nicht ischämischen Bedingungen, von Parajuli et al. (2015) die Aktivierung von Mikrogliazellen durch Eotaxin-1 nachgewiesen. Sie untersuchten den Einfluss von Eotaxin-1 auf den exzitatorischen neuronalen Zelluntergang. Eotaxin-1 führte in Kokultur von Neuronen und Mikrogliazellen zu einem vermehrten exzitatorischen neuronalen Verlust, während eine neuronale Monokultur in Anwesenheit von Eotaxin-1 zu keiner Zellschädigung führte (Parajuli et al. 2015).

Die Ergebnisse von Parajuli et al. scheinen den vorliegenden Ergebnissen auf den ersten Blick zu widersprechen, da es trotz einer verringerten Anzahl an Mikrogliazellen zu einem vermehrten Eotaxin-1 vermittelten neuronalen Zellverlust der adulten Mäuse kam. Auch wenn eine genaue Erklärung dieses Phänomens fehlschlägt, ist die Rolle der Mikroglia nach zerebraler Ischämie noch nicht vollständig geklärt und Gegenstand der aktuellen Forschung (Ma et al. 2017). Tatsächlich lassen sich das von Parajuli et al. verwendete In-vitro-Modell und das hier vorliegende In-vivo-Schlaganfallmodell der Maus nicht vergleichen. Die genaue Rolle der Mikroglia nach zerebraler Ischämie zeigt vereinzelt Hinweise für eine protektive Wirkung dieser Zellen (Kim et al. 2009; Thored et al. 2009). Mikrogliazellen unterscheiden sich phänotypisch in M1 - oder M2-Mikrogliazellen. Der klassische Aktivierungsweg von M1Mikrogliazelle führt zur pro-inflammatorischen Immunantwort und spielt eine Rolle in der akuten Phase der zerebralen Ischämie; ihm wird eine neurotoxische Wirkung zugeschrieben. Vom klassischen Aktivierungsweg unterschieden wird der sogenannte alternative Aktivierungsweg. Dieser führt durch die Ausschüttung von anti-inflammatorischen Mediatoren zu einer anti-inflammatorischen Immunantwort der M2-Mikrogliazellen und begünstigt die Homöostase der Neuronen- und Gliazellverbände (Chen et al. 2019). Die Polarisation von Mikrogliazellen ist ein dynamischer Prozess, der eine Folge von verschiedenen Aktivierungswegen, mit ebenfalls bekannten Zwischenzuständen, ist. Der hier verwendete IBA1-Marker ist ein universeller Mikrogliazellmarker, der somit ungeeignet zur Unterscheidung zwischen M1- und M2-Mikrogliazellen oder deren Zwischenzuständen ist. Allerdings lag der Fokus dieser Studie nicht in der Untersuchung der Rolle von Mikrogliazellen, so dass diese Frage vorerst ungeklärt bleibt.

Im Hinblick auf die klinische und potenziell therapeutische Bedeutung von Eotaxin-1 reicht es nicht aus, nur die akute Neuroprotektion zu untersuchen. Deswegen wurde zusätzlich im chronischen Stadium der zerebralen Ischämie die neuronale Dichte nach 28 Tagen sowie die neurologische Erholung untersucht. Hierfür wurde unter Berücksichtigung der Biodistribution von Eotaxin-1 das Injektionsschema auf sieben Tage erweitert. Ein 
protrahierter post-ischämischer Gewebeschaden kann durch sekundäre Prozesse wie Apoptose und Inflammation entstehen und muss nicht mit einer verschlechterten funktionellen Erholung behaftet sein (Doeppner et al. 2014). Betrachtet man den neuronalen Verlust im Langzeitverlauf nach 28 Tagen in den adoleszenten Mäusen so stellte sich heraus, dass Eotaxin-1 keinen Einfluss auf den chronischen Gewebeschaden hat, passend zu den Ergebnissen der Verhaltenstests. Die neuronale Dichte in den adulten Tieren unterscheidet sich nicht, jedoch zeigen die mit Eotaxin-1 behandelten Tiere eine transiente Verschlechterung ihrer funktionalen Erholung in den Verhaltenstests während der Applikation von Eotaxin-1 über sieben Tage. Diese weisen eine transient signifikante Verschlechterung sowohl in dem Rota-Rod-Test an Tag eins und Tag drei als auch im Corner-Turn-Test an Tag drei nach zerebraler Ischämie auf. Am Ende der Eotaxin-1Behandlung nähert sich die Leistung der Experimentalgruppe an die Testergebnisse der Kontrollgruppe an. Interessanterweise scheint die mehrmalige Eotaxin-1-Gabe zum Zeitpunkt der Messung der neuronalen Dichte, nach 28 Tagen, keinen Einfluss auf den chronischen Gewebeschaden zu haben, obwohl die einmalige Gabe von Eotaxin-1 in den adulten Tieren akut neurotoxisch wirkte. Folglich scheint die Wiederherstellung der Funktionalität und die Erholung des akuten Gewebeschadens Ausdruck des mehrtägigen Verabreichungsprotokolls zu sein. Des Weiteren wurden die mikrogliale Aktivierung im Langzeitversuch untersucht. Es zeigte sich, dass Eotaxin-1 keinen Einfluss auf die protrahierte mikrogliale Aktivierung nach 28 Tagen in beiden Altersgruppen hat. Mikrogliazellen können per se auch im Verlauf weiterhin aktiviert werden und somit zu einer protrahierten Inflammation führen, andererseits aber auch neuroregenerative Prozesse einleiten (Chen et al. 2018). Dennoch kann die durch Eotaxin-1 vermittelte mikrogliale Modulation neuroregenerativer Mechanismen nicht ausgeschlossen werden.

Mikrogliazellen beeinflussen neuroregenerative Prozesse wie die endogene adulte Neurogenese, die durch die zerebrale Ischämie stimuliert wird (Ekdahl 2012). In den neurogenen Nischen wie der SVZ oder der subgranulären Zone des Gyrus dentatus befinden sich NPCs. Von dort aus wandern die NPCs in Richtung des ischämischen Gewebes. Die neurogenen Nischen enthalten jedoch nicht nur NPCs sondern beherbergen sowohl unter physiologischen wie auch pathologischen Gegebenheiten auch Mikrogliazellen (Adachi et al. 2010; Bulloch et al. 2008; Ekdahl et al. 2003). Tatsächlich kann die Aktivierung von Mikrogliazellen die endogene Neurogenese fördern. In einem experimentellen Ansatz führte die Inhibierung von Mikrogliazellen im gesunden Gehirn zu einer eingeschränkten Neurogenese, da Mikrogliazellen sensitiv für die Homöostase der neugeborenen Neurone sind und deren Überleben sicherten (Shigemoto-Mogami et al. 2014; Vukovic et al. 2012). 
Im Gegensatz dazu zeigte sich unter pathophysiologischen Bedingungen wie einem proinflammatorischen Milieu, dass die Inhibierung von Mikrogliazellen die Neurogenese förderte, sprich die mikrogliale Aktivierung scheint hier die Neurogenese zu hemmen (Sierra et al. 2010). Im ischämischen Gehirn findet man ebenfalls gegensätzliche Berichte zur mikroglialen Regulierung der endogenen Neurogenese. Auf der einen Seite kann die mikrogliale Aktivierung die post-ischämische Neurogenese hemmen (Hoehn et al. 2005; Liu et al. 2007) und andererseits wurde berichtet, dass die mikrogliale Aktivierung die postischämische Neurogenese fördert (Kim et al. 2009; Thored et al. 2009). Die genaue Rolle der Mikroglia im Hinblick auf die post-ischämische Neuroregeneration scheint also unklar zu sein.

Zytokine beeinflussen ebenfalls die neuroregenerativen Prozesse. Eotaxin-1 fördert die endogene Neurogenese in neonatalen Nagern (Wang et al. 2017), wohingegen Eotaxin-1 die Neurogenese bei gealterten Mäusen unter sonst physiologischen Bedingungen hemmt, was zu einer Beeinträchtigung von Lernen und Gedächtnis führen kann (Villeda et al. 2011). Interessanterweise waren in der hier vorliegenden Arbeit sowohl die Gliogenese als auch die Neurogenese in den adoleszenten Mäusen nach der Eotaxin-1-Behandlung signifikant erhöht. Dies steht in Einklang mit früheren Arbeiten, in denen konstitutive Eigenschaften von Eotaxin-1, wie die (Re)-Organisation und Überwachung von gesundem und wachsendem Gewebe, gezeigt wurde (Maysami et al. 2006; Wang et al. 2017). Adulte Mäuse hingegen zeigten in der hier vorliegenden Arbeit nicht nur nach der Eotaxin-1-Behandlung keine Stimulation der Neurogenese, sondern zeigten vielmehr vier Wochen nach dem Schlaganfall eine verringerte Neurogenese. Im Hinblick auf die Eotaxin-1 vermittelte Gliogenese wurden Astrozyten und oligodendrogliale Zellen untersucht. Oligodendrozyten sind postmitotisch und somit ist deren Proliferation limitiert. Astrozyten stammen von den Radialgliazellen aus der embryonalen Entwicklung ab und können sich mitotisch vermehren. Es ist bekannt, dass die Migration von oligodendroglialen Vorläufern durch Eotaxin-1 chemotaktisch gefördert wird (Maysami et al. 2006). Eotaxin-1 ist in der Lage über den CCR3-Chemokinrezeptor Astrozyten zu aktivieren (Luo et al. 2002). Die Aktivierung von Gliazellen führt ihrerseits zur Expression von Zytokinen wie Eotaxin-1 und letzteres zu einer Induktion einer Inflammation bzw. Proliferation der Zellen. Das Zusammenspiel von Inflammation und Proliferation kann schlussendlich zur Regeneration und zur Aufrechterhaltung der Zellhomöostase führen. In den adoleszenten Mäusen förderte Eotaxin-1 hier die Gliogenese, während Eotaxin-1 diese in den adulten Tieren nicht beeinflusste. 
Neben der post-ischämischen Neuro- und Gliogenese trägt ebenso die Angiogenese zur Geweberegeneration bei. Tatsächlich beeinflussen sich Angiogenese auf der einen Seite und Neurogliogenese auf der anderen Seite gegenseitig (Hermann und Chopp 2012). Die postischämische Angiogenese begünstigt das Einwandern der neuronalen Vorläufer und die Aktivierung der glialen Zellen und Neurone (Teng et al. 2008). Die Angiogenese fördert die Freisetzung von Wachstumsfaktoren, die wiederum die Angiogenese weiter verstärken können (Wang et al. 2005). Die Analyse der post-ischämischen Angiogenese nach Applikation von Eotaxin-1 übertraf jedoch das Ausmaß der hier vorliegenden Arbeit und könnte Gegenstand weiterer Untersuchungen in der Zukunft sein. Es bleibt also festzuhalten, dass Eotaxin-1 in dem hier gewählten experimentellen Paradigma zu einer postischämischen Stimulation der Neuroregeneration in adoleszenten Tieren führt, die jedoch von funktionell untergeordneter Bedeutung zu sein scheint.

Der ischämische Schlaganfall geht mit einer zentralen sowie systemischen Inflammation ein her. Während sich in den ersten Stunden nach einem Schlaganfall eine systemische proinflammatorische Immunantwort einstellt, kommt es nach Tagen zu einer ausgeprägten Immunsuppression mit Lymphopenie (Iadecola und Anrather 2011). In der Durchflusszytometrie am siebten Tag nach Induktion der zerebralen Ischämie wurde der Frage nachgegangen, ob Eotaxin-1 einen Einfluss auf die systemische und auf die zentrale Immunantwort hat. Wie erwartet, beeinflusst die ektope Eotaxin-1-Gabe sowohl das periphere als auch das zentrale Immunsystem. In den adoleszenten und in den adulten Tieren zeigte sich eine relativ erhöhte Anzahl an B-Zellen im ZNS und im Blut. B-Zellen sekretieren Eotaxin-1, können aber ebenso durch dieses aktiviert werden, indem Eotaxin-1 die $\mathrm{T}_{\mathrm{H} 2^{-}}$ Immunantwort fördert und B-Zellen aktiviert (Jinquan et al. 2003; Nocturne et al. 2015; Rehman et al. 2013). In ähnlicher Weise wird berichtet, dass Eotaxin-1 T-Zellen aktiviert, was den vorliegenden Ergebnissen entspricht, und eine relativ erhöhte Anzahl von T-Zellen in beiden Altersgruppen im Blut zeigt (Jinquan et al. 2003). Ebenso ist die relative Anzahl an T-Zellen in den adoleszenten Tieren nach Eotaxin-1 Behandlungen signifikant im Gehirn erhöht, und auch in den adulten Versuchstieren zeigt sich eine Tendenz zur relativen Eotaxin-1 vermittelten Infiltration der T-Zellen in die ischämische Hemisphäre. Neben der Analyse der Mikrogliazellen und Lymphozyten zeigte sich jedoch kein Unterschied in der relativen Anzahl der neutrophilen Granulozyten im Gehirn der adoleszenten und adulten Mäuse, die mit Eotaxin-1 behandelt wurden. Tatsächlich erfordert die Transmigration von Immunzellen in das entzündliche Gewebe die Aktivierung von Endothelzellen. Zudem produzieren Endothelzellen Interleukin-8/CXCL8, ein neutrophilenspezifisches Zytokin, das eine Schlüsselrolle in der Rekrutierung von neutrophilen Granulozyten spielt. Die 
Aktivierung der Endothelzellen durch Zytokine ist abhängig von dem Interleukin8/CXCL8-Signalweg und ermöglicht die Transmigration von neutrophilen Granulozyten in entzündliches Gewebe (Cheng et al. 2002). Eotaxin-1 hemmt diesen Signalweg und führt zur verminderten Einwanderung von neutrophilen Granulozyten in das entzündete Gewebe (Cheng et al. 2002). Wenn die Endothelzellaktivierung gestört ist, bleibt der Stimulus für die Rekrutierung und die Aktivierung von neutrophilen Granulozyten aus. Aktivierte neutrophile Granulozyten exprimieren zudem den für die Hauptwirkung von Eotaxin-1 nötigen Rezeptor CCR3 und folgen chemotaktisch Eotaxin-1 in vitro. Die Aktivierung von Eotaxin-1 bzw. CCR3 kann als antimigratorischer Faktor durch heterologe Desensibilisierung anderer Chemokinrezeptoren auf neutrophilen Granulozyten oder durch die Induktion eines hyperadhäsiven Phänotyps wirken (Richardson et al. 2000). Im Blut der adoleszenten und adulten mit Eoatxin-1 behandelten Tiere führt die Erhöhung der B- und T-Zellen methodisch bedingt zu einer signifikanten Verringerung der relativen Anzahl an neutrophilen Granulozyten. Abgesehen von dem Einfluss von Eotaxin-1, direkt oder indirekt, auf die neutrophilen Granulozyten ist die Infiltration von neutrophilen Granulozyten ein Prozess, der zu einem frühen Zeitpunkt nach einem zerebralen Insult eintritt, wohingegen die Messung am siebten post-operativen Tag erfolgte.

Eotaxin-1 übt eine distinkte Modulation des Immunsystems aus, die über die bloße Beteiligung einzelner immunkompetenter Zellen hinausgeht. Infolgedessen hat man weitere Signalwege untersucht, die möglicherweise durch die ektope Gabe von Eotaxin-1 im ischämischen Gewebe beeinflusst werden könnten. Mikrogliazellen induzieren unter anderem den Mannoserezeptor-Signalweg, der konstitutiv auf M2-Mikrogliazellen exprimiert wird und zur Zellmigration, intrazellulären Signalwegen, Phagozytose und Reorganisation von entzündlichem Gewebe beiträgt (Gazi und Martinez-Pomares 2009). Aus früheren Berichten geht hervor, dass die Mannoserezeptor-Expression in Mikrogliazellen im Gehirn von Mäusen in der ersten Lebenswoche am höchsten ist und danach anschließend abnimmt und auf geringem Niveau stabil bleibt (Burudi und Regnier-Vigouroux 2001). Demgegenüber steht, dass Giraldi-Guimaraes et al. (2012) in einem Rattenmodell des ischämischen Schlaganfalls eine erhöhte Expression des Mannoserezeptors sieben Tage nach zerebraler Ischämie festgestellt hat, die von phagozytischen Makrophagen bzw. Mikrogliazellen stammte und eine restaurative Wirkung zusammen mit mononukleären Knochenmarkszellen induziert. Der murine Mannoserezeptor wird darüber hinaus von meningealen und parenchymal perivaskulären Makrophagen exprimiert, aber auch von Neuronen und Astrozyten (Galea et al. 2005). Dennoch beeinflusst Eotaxin-1 in der hier vorliegenden Arbeit nicht die Expression des Mannoserezeptor. Eine Verknüpfung von Eotaxin-1 und 
des M2 induzierten Mannoserezeptor-Signalwegs konnte in diesem Versuchsaufbau nicht hergestellt werden. Eine indirekte Bestimmung der M1-Mikrogliazellaktivierung kann über intrazelluläre, kalziumabhängige Signale mittels s100b erreicht werden. S100b wirkt als Regulator in der Kaliumhomöostase, Proteinphosphorylierung und Zellproliferation (Zhou et al. 2018). In einem Mausmodell der zerebralen Ischämie wurde festgestellt, dass die s100b Expression in den ersten 14 Tagen nach Schlaganfall erhöht ist und mit der Expressionsdynamik von M1-Mikrogliazellen einher geht. Die s100b-abhängige Inflammation wird über den NF-kB-Signalweg aktiviert und führt zu einer Aggravation des akuten Gewebeschadens (Zhou et al. 2018). Eotaxin-1 führt in dem hier vorliegenden Modell nicht zur Signalwegsinduktion über s100b bzw. zur erhöhten Expression von s100b in beiden Altersgruppen sieben Tagen nach zerebraler Ischämie. Im vorliegenden experimentellen Paradigma ist der s100b-Signalweg offensichtlich von untergeordneter Relevanz. Neben Signalwegen der zellulären Immunantwort wurde der Fokus auf Signalwege bzw. Mechanismen des Zellüberlebens gelegt. Die sekundäre Zellschädigung nach Induktion der zerebralen Ischämie ist mit einer Vielzahl von pro-apoptotischen Signalwegen verbunden (Khoshnam et al. 2017), von denen die Aktivierung des CDK5/p35-Signalweg einen schädlichen Effekt aufweist (Shah und Lahiri 2014; Timsit und Menn 2007). CDK5 gehört zu der Gruppe der Zyklin-abhängigen Kinasen, Proteinkinasen, die ihre Funktion in der Transkription und der Kontrolle des Zellzyklus ausüben, indem sie verschiedene Proteine an bestimmter Stelle phosphorylieren. Im Gegensatz zu den anderen Zyklin-abhängigen Kinasen greift CDK5 nicht in den Zellzyklus proliferierender Zellen ein, sondern kann aberrant Komponenten des Zellzyklus aktivieren, wenn dieser in postmitotischen Neuronen dysreguliert ist (Chang et al. 2012). Folglich führt die Aktivierung von CDK5 zum programmierten Zelltod. CDK5 benötigt für seine Aktivierung den spezifischen Bindungspartner p35 (Tsai et al. 1994). In der Embryonalphase ist CDK5 für die normale Gehirnentwicklung wesentlich. In pathophysiologischen Prozessen spielt es eine Rolle für das neuronale Überleben. In einem Mausmodell der Alzheimer Erkrankung stellte man fest, dass Eotaxin-1 den CDK5-Signalweg aktiviert, der zur Hyperphosphorylierung von Tau und A $\beta$-Produktion und schlussendlich zu neuronaler Apoptose führt (Zhu et al. 2017). In dieser hier vorliegenden Studie konnte jedoch kein Einfluss von Eotaxin-1 auf den CDK5 Signalweg nachgewiesen werden, weder in den adoleszenten noch in den adulten Mäusen.

Neben der Apoptose spielt auch der sogenannte autophagosomale Zelltod eine Rolle bei ischämischen Gewebeschädigungen (Kim et al. 2018). Demnach deuten neuere Berichte auf eine mögliche Rolle für die Autophagie hin, die vermutlich unter verschiedenen pathologischen Bedingungen, einschließlich der zerebralen Ischämie, reguliert wird. 
Autophagie ist zeitgleich ein Recycling- und ein Suizidprogramm. Man unterscheidet zwischen der basalen und der induzierten Autophagie. Die basale Autophagie ist der Reinigungsprozess der Neuronen, während die induzierte Autophagie zweischneidige Auswirkungen auf Neuronen hat (Feng et al. 2017). Die zerebrale Ischämie kann Autophagie auslösen. Es bleibt jedoch offen, ob die induzierte Autophagie dem Zellüberleben zugutekommt oder den Zelltod fördert. Letztlich steht fest, dass eine erhöhte Autophagie im ZNS als Reaktion auf die ischämische Verletzung auftritt und die Zelle die basale Autophagie zur Aufrechterhaltung der Gehirnfunktion benötigt. Als Marker für die Autophagie wurde LC3 gewählt. In der hier vorliegenden Studie liegt der Schwerpunkt nicht bei der Untersuchung der Rolle von Autophagie nach ischämischem Schlaganfall, sondern wird lediglich als möglicher Signalweg analysiert, der durch Eotaxin-1 beeinflusst werden könnte. Die Autophagie scheint jedoch durch Eotaxin-1 in den adoleszenten Mäusen nicht beeinflusst zu sein und bei Eotaxin-1 vermittelter Aggravation des akuten Gewebeschadens keine Ursache in den adulten Tieren darzustellen. Letztere ist daher eher eine Folge der Eotaxin-1 abhängigen Immunzellregulation als eine Folge der Modulation apoptotischer oder autophagischer Signalwege.

Die vorliegende Studie zeigte zum ersten Mal überhaupt die Bedeutung einer ektopen Applikation von Eotaxin-1 in einem nicht-neonatalen Schlaganfallmodell. Gleichwohl gibt es limitierende Faktoren dieser Arbeit, die im Folgenden skizziert werden sollen. Zum einen ist die gewählte Dosis von Eotaxin-1 geringer im Vergleich zu anderen publizierten Arbeiten. Dies erfolgte vor dem Hintergrund der hier beabsichtigten intraperitonealen und somit systemischen Gabe, letztere erfolgte auch im Hinblick auf die Analyse der peripheren Effekte. Ebenso verändern sich auch die endogenen Konzentrationen von Eotaxin-1 sowohl im Plasma wie auch im Liquor; es kommt im Verlauf des Lebens physiologischerweise zu einem Konzentrationsanstieg (Villeda et al. 2011). Möglicherweise waren in einzelnen Versuchsserien die so erzielten Eotaxin-1-Konzentrationen zu niedrig. Folgerichtig könnte einem weiteren Versuchsansatz eine Erhöhung der Dosis diskutiert werden, wenngleich auch toxische Effekte zu berücksichtigen wären. Die Messung der tatsächlich vorhandenen Eotaxin-1-Dosis in Blut und Hirn jeweils vor und nach Gabe von ektopem Eotaxin-1 könnte ein eleganter Weg sein, um diesem Dilemma Abhilfe zu schaffen, war aber jenseits dieser Doktorarbeit angesiedelt.

Ein weiterer limitierender Faktor dieser Arbeit liegt in der Wahl des CCR3-Antagonisten. Basierend auf den in vitro Arbeiten von Wang et al. (2017) wurde in dieser Studie der Antagonist SB297006 verwendet. Verlässliche in vivo Daten zu SB297006 liegen jedoch in 
nicht vor, und es ist tatsächlich unklar, inwiefern SB297006 überhaupt die BHS überwinden kann oder lediglich in der Peripherie wirkt. Festzuhalten bleibt allerdings, dass durch die Induktion einer zerebralen Ischämie es zumindest transient zu einer Öffnung der BHS in den ersten Stunden kommt.

Der Transfer von der Maus auf den Menschen wurde in einer aktuellen Studie von RoyO'Reilly et al. (2017) untersucht. Dort wurde zunächst analysiert, ob die Eotaxin-1Konzentrationen nach einem Schlaganfall in der adulten Maus erhöht sind. Im nächsten Schritt haben Roy-O'Reilly et al. die Eotaxin-1-Level im Menschen nach einem Schlaganfall über einen längeren Zeitraum im Serum gemessen. Es stellte sich heraus, dass niedrige Eotaxin-1-Level nach einem Schlaganfall im Menschen mit einem funktional schlechteren Outcome einhergehen (Roy-O'Reilly et al. 2017). Die Wirkungen von Eotaxin-1 in Mäusen und in Menschen scheint somit kontrovers zu sein. Umso bedeutender ist es mechanistisch den Eotaxin-1-Signalweg zu untersuchen und zu verstehen.

Letztlich zeigt die vorliegende Studie, dass Eotaxin-1 in Abhängigkeit des Alters in einem möglichen therapeutischen Ansatz gegen den Schlaganfall eine wichtige Rolle spielt. Es konnte gezeigt werden, dass Eotaxin-1 sowohl vorteilhafte als auch schädliche Auswirkungen auf das post-ischämische Ergebnis hat. Es werden jedoch weitere präklinische Studien zur Untersuchung des Eotaxin-1-Signalweges benötigt, bevor weitere experimentelle, translationale Versuche oder klinische Studien angedacht werden. 


\section{$5 \quad$ Zusammenfassung}

Der ischämische Schlaganfall ist eine der häufigsten Todesursachen in der westlichen Welt und führt oftmals zu einer dauerhaften Behinderung mit relevanten sozioökonomischen Konsequenzen. Die kausale Therapie besteht aus der Wiederherstellung des zerebralen Blutflusses mittels systemischer Thrombolyse oder mechanischer Thrombektomie. Nur eine Minorität der Patienten erhält vor dem Hintergrund des engen therapeutischen Zeitfensters, der möglichen Nebenwirkungen und eventuell vorhandener Kontraindikationen diese Form der Therapie. Die Entwicklung neuer, adjuvanter Therapien ist daher in der translationalen Schlaganfallforschung essentiell. Da die komplexe Pathophysiologie der zerebralen Ischämie insbesondere auch eine ausgeprägte inflammatorische Komponente beinhaltet, bietet sich letztere als therapeutisches Angriffsziel an. Eotaxin-1 (CCL11) ist eine solche inflammatorische Komponente, die als immunregulatorisches Chemokin sowohl immunkompetente wie auch nicht-immunkompetente Zellen rekrutiert und aktiviert. Eotaxin-1 stellt sich folgerichtig als ein interessantes Ziel für die Entwicklung adjuvanter Schlaganfalltherapien dar.

Ziel dieser Arbeit war es, erstmals überhaupt die Rolle von Eotaxin-1 nach zerebraler Ischämie im Mausmodell im Hinblick auf Neuroprotektion, Neuroregeneration, funktioneller Erholung und inflammatorischen Aspekten einschließlich etwaiger zellschädigender Signalwege herauszuarbeiten. Hierfür wurde männlichen C57BL6-Mäusen zweier Altersgruppen (adoleszent bzw. adult) nach Induktion einer zerebralen Ischämie Eotaxin-1 oder eine Trägersubstanz (Kontrollgruppe) intraperitoneal injiziert. Das experimentelle Versuchsdesign beinhaltete unterschiedliche Überlebenszeitpunkte, als da wären Kurzzeitversuche (24 Stunden), Intermediärversuche (7 Tage) und Langzeitversuche (28 Tage).

Nach 24 Stunden zeigte sich, dass die Applikation von Eotaxin-1 in adulten Mäusen neurotoxisch wirkt, ohne einen Einfluss auf den Gewebeschaden in den adoleszenten Tieren zu haben. In den adulten Tieren kam es zu einer Zunahme des Infarktvolumens und zu einer Reduktion der neuronalen Dichte sowie der post-ischämischen mikroglialen Immunantwort. Im Langzeitverlauf kam es in den adoleszenten Mäusen hingegen zu einer Stimulation sowohl der Gliogenese als auch der Neurogenese. Die Aktivierung dieser endogenen Reparaturprozesse war jedoch nicht mit einer verbesserten funktionellen, neurologischen Erholung vergesellschaftet. Adulte Mäuse wiesen hingegen eine Hemmung der postischämischen Neurogenese auf, die mit einer transienten Verschlechterung der funktionalen Erholung während der ersten sieben Tage entsprechend der Applikationsdauer von 
Eotaxin-1 einherging. Eoatxin-1 als immunregulatorischer Mediator inflammatorischer Signalkaskaden führte in den adoleszenten Mäusen zu einer vermehrten Infiltration von Bund T-Zellen in das ischämische Hirnparenchym und führte zu einer Erhöhung dieser im Blut. In den adulten Mäusen induzierte Eotxain-1 eine vermehrte zerebrale Infiltration von B-Zellen und führte im Blut zu einer Erhöhung der B- und T-Zellen. Hinsichtlich der Modulation zellschädigender oder neuroprotektiver Signalkaskaden konnte gezeigt werden, dass Eotaxin-1 unabhängig von herkömmlichen pro-apoptotischen oder autophagischen Signalwegen wirkt. LC3 als Indikator für Autophagie zeigte sowohl in den adoleszenten als auch in den adulten Tieren keine Beeinflussung durch Eotaxin-1. Die Aktivierung von CDK5 und seinem spezifischen Bindungspartner p35 führt zu einer vermehrten Zellschädigung, jedoch konnte keine Eotaxin-1 vermittelte Stimulation dieser in beiden Altersgruppen festgestellt werden. Die hervorgehobene Bedeutung von Eotaxin-1 im Rahmen seiner zellschädigenden Wirkung bei zerebraler Ischämie ließ sich darüber hinaus durch die Applikation des CCR3-Rezeptorantagonisten SB297006 weiter bekräftigen. Die Behandlung adulter Mäuse mit SB297006 war in der Lage, die vormals beobachtete Aggravation des Gewebeschadens durch die ektope Gabe von Eotaxin-1 nicht nur aufzuheben sondern ins Gegenteil zu kehren; SB297006 war akut neuroprotektiv.

Zusammenfassend konnte in dieser Dissertation die hervorragende Rolle von Eotaxin-1 in der Entwicklung des Gewebeschadens nach zerebraler Ischämie gezeigt werden. Vor dem Hintergrund der komplexen Pathophysiologie der zerebralen Ischämie ist es nicht verwunderlich, dass Eotaxin-1 in diesem Zusammenhang pleiotrope Effekte sowohl im peripheren wie auch im zentralen Nervensystem aufweist. Interessanterweise sind die zugrundeliegenden Mechanismen der Wirkung von Eotaxin-1 klar altersabhängig und teilweise konträr zueinander. Weitere präklinische Studien hinsichtlich eines besseren Verständnisses des Eotaxin-1-Signalweges unter zerebral ischämischen Bedingungen und seine potentiell therapeutische Relevanz sind jedoch vonnöten bevor translationale Paradigmen oder klinische Studien angedacht werden können. 


\section{$6 \quad$ Literaturverzeichnis}

Adachi M, Abe M, Sasaki T, Kato H, Kasahara J, Araki T (2010): Role of inducible or neuronal nitric oxide synthase in neurogenesis of the dentate gyrus in aged mice. Metab Brain Dis $\underline{25}$, 419424

Adzemovic MZ, Öckinger J, Zeitelhofer M, Hochmeister S, Beyeen AD, Paulson A, Gillett A, Thessen Hedreul M, Covacu R, Lassmann H et al. (2012): Expression of Ccl11 associates with immune response modulation and protection against neuroinflammation in rats. PLoS One $\underline{\underline{7}}$, e39794

Allan SM, Rothwell NJ (2001): Cytokines and acute neurodegeneration. Nature Medicine 2, $734-$ 744

Baron JC (2001): Perfusion thresholds in human cerebral ischemia: Historical Perspective and Therapeutic Implications. Cerebrovascular Diseases 11, 2-8

Baruch K, Ron-Harel N, Gal H, Deczkowska A, Shifrut E, Ndifon W, Mirlas-Neisberg N, Cardon M, Vaknin I, Cahalon L et al. (2013): CNS-specific immunity at the choroid plexus shifts toward destructive Th2 inflammation in brain aging. Proc Natl Acad Sci U S A 110, 2264-2269

Baruch K, Deczkowska A, David E, Castellano JM, Miller O, Kertser A, Berkutzki T, BarnettItzhaki Z, Bezalel D, Wyss-Coray T et al. (2014): Aging-induced type I interferon response at the choroid plexus negatively affects brain function. Science $\underline{346}, 89-93$

Bulloch K, Miller MM, Gal-Toth J, Milner TA, Gottfried-Blackmore A, Waters EM, Kaunzner UW, Liu K, Lindquist R, Nussenzweig MC et al. (2008): CD11c/EYFP transgene illuminates a discrete network of dendritic cells within the embryonic, neonatal, adult, and injured mouse brain. J Comp Neurol 508, 687-710

Burudi EM, Regnier-Vigouroux A (2001): Regional and cellular expression of the mannose receptor in the post-natal developing mouse brain. Cell Tissue Res $\underline{303}$, 307-317

Chamorro A, Meisel A, Planas AM, Urra X, van de Beek D, Veltkamp R (2012): The immunology of acute stroke. Nat Rev Neurol $\underline{8}, 401-410$

Chang KH, Vincent F, Shah K (2012): Deregulated Cdk5 triggers aberrant activation of cell cycle kinases and phosphatases inducing neuronal death. J Cell Sci $\underline{125}$, 5124-5137

Chen AQ, Fang Z, Chen XL, Yang S, Zhou YF, Mao L, Xia YP, Jin HJ, Li YN, You MF et al. (2019): Microglia-derived TNF-alpha mediates endothelial necroptosis aggravating blood brainbarrier distuption after ischemic stroke. Cell Death Dis $\underline{10}, 487$

Chen C, Chu SF, Liu DD, Zhang Z, Kong LL, Zhou X, Chen NH (2018): Chemokines play complex roles in cerebral ischemia. Neurochem Int 112, 146-158 
Cheng SS, Lukacs NW, Kunkel SL (2002): Eotaxin/CCL11 is a negative regulator of neutrophil recruitment in a murine model of endotoxemia. Exp Mol Pathol $\underline{73}$, 1-8

Cherry JD, Stein TD, Tripodis Y, Alvarez VE, Huber BR, Au R, Kiernan PT, Daneshvar DH, Mez J, Solomon TM et al. (2017): CCL11 is increased in the CNS in chronic traumatic encephalopathy but not in Alzheimer's disease. PLoS One 12, e0185541

Choi C, Jeong JH, Jang JS, Choi K, Lee J, Kwon J, Choi KG, Lee JS, Kang SW (2008): Multiplex analysis of cytokines in the serum and cerebrospinal fluid of patients with Alzheimer's disease by color-coded bead technology. Journal of Clinical Neurology 4 , 84-88

DEGAM (2012): Schlaganfall (Leitlinie der DEGAM). DEGAM-Leitlinie Nr. 8 der Deutschen Gesellschaft für Allgemeinmedizin und Familienmedizin.

https://www.awmf.org/uploads/tx_szleitlinien/053-0111_S3_Schlaganfall_2012-abgelaufen.pdf; abgerufen 14.11.2019

de Miranda AS, Brant F, Campos AC, Vieira LB, Rocha NP, Cisalpino D, Binda NS, Rodrigues DH, Ransohoff RM, Machado FS et al. (2015): Evidence for the contribution of adult neurogenesis and hippocampal cell death in experimental cerebral malaria cognitive outcome. Neuroscience 284, 920-933

DGN (2012): Akuttherapie des ischämischen Schlaganfalls (Leitlinien der DGN). S1-Leitlinie der Deutschen Gesellschaft für Neurologie. https:/ / www.dgn.org/leitlinien/2310-11-22-2012akuttherapie-des-ischaemischen-schlaganfalls; abgerufen 14.11.2019

Dirnagl U, Iadecola C, Moskowitz MA (1999): Pathobiology of ischeamic stroke: an integrated view. Trends Neurosci $\underline{22}, 391-397$

Doeppner TR, Bretschneider E, Doehring M, Segura I, Senturk A, Acker-Palmer A, Hasan MR, ElAli A, Hermann DM, Bähr M (2011): Enhancement of endogenous neurogenesis in ephrin-B3 deficient mice after transient focal cerebral ischemia. Acta Neuropathol 122, 429-442

Doeppner TR, Kaltwasser B, Bähr M, Hermann DM (2014): Effects of neural progenitor cells on post-stroke neurological impairment - a detailed and comprehensive analysis of behavioral tests. Front Cell Neurosci $\underline{8}, 338$

Doeppner TR, Doehring M, Kaltwasser B, Majid A, Lin F, Bähr M, Kilic E, Hermann DM (2017): Ischemic post-conditioning induces post-stroke neuroprotection via Hsp70-Mediated proteasome inhibition and facilitates neural progenitor cell transplantation. Mol Neurobiol 54, 6061-6073

Donato R, Sorci G, Riuzzi F, Arcuri C, Bianchi R, Brozzi F, Tubaro C, Giambanco I (2009): S100B's double life: intracellular regulator and extracellular signal. Biochim Biophys Acta 1793, 1008-1022 
Ekdahl CT (2012): Microglial activation - tuning and pruning adult neurogenesis. Front Pharmacol $\underline{3}, 41$

Ekdahl CT, Claasen JH, Bonde S, Kokaia Z, Lindvall O (2003): Inflammation is detrimental for neurogenesis in adult brain. Proc Natl Acad Sci U S A $\underline{100}, 13632-13637$

Erickson MA, Morofuji Y, Owen JB, Banks WA (2014): Rapid transport of CCL11 across the blood-brain barrier: regional variation and importance of blood cells. J Pharmacol Exp Ther $\underline{349}$, 497-507

Feng J, Chen X, Shen J (2017): Reactive nitrogen species as therapeutic targets for autophagy: implication for ischemic stroke. Expert Opin Ther Targets 21, 305-317

Foerch S, Singer OC, Neumann-Haefelin T, du Mesnil de Rochemont R, Steinmetz H, Sitzer M (2005): Evaluation of serum S100B as a surrogate marker for long-term outcome and infarct volume in acute middle cerebral artery infarction. Arch Neurol $\underline{62}, 1130-1134$

Frisen J (2016): Neurogenesis and gliogenesis in nervous system plasticity and repair. Annu Rev Cell Dev Biol $\underline{32}, 127-141$

Furukawa T, Matsui N, Fujita K, Nodera H, Shimizu F, Miyamoto K, Takahashi Y, Kanda T, Kusunoki S, Izumi Y et al. (2015): CSF cytokine profile distinguishes multifocal motor neuropathy from progressive muscular atrophy. Neurol Neuroimmunol Neuroinflamm 2, e138

Galea I, Palin K, Newman TA, Van Rooijen N, Perry VH, Boche D (2005): Mannose receptor expression specifically reveals perivascular macrophages in normal, injured, and diseased mouse brain. Glia 49, 375-384

Garcia-Zepeda EA, Rothenberg ME, Ownbey RT, Celestin J, Leder P, Luster AD (1996): Human eotaxin is a specific chemoattractant for eosinophil cells and provides a new mechanism to explain tissue eosinophilia. Nature Medicine 2, 449-456

Gazi U, Martinez-Pomares L (2009): Influence of the mannose receptor in host immune responses. Immunobiology 214, 554-561

Granger DN, Kvietys PR (2015): Reperfusion injury and reactive oxygen species: The evolution of a concept. Redox Biol $\underline{6}, 524-551$

Guillemot F (2007): Cell fate specification in the mammalian telencephalon. Prog Neurobiol $\underline{83}, 37-$ 52

Hachem S, Laurenson AS, Hugnot JP, Legraverend C (2007): Expression of S100B during embryonic development of the mouse cerebellum. BMC Dev Biol 7, 17 
Hermann DM, Chopp M (2012): Promoting brain remodelling and plasticity for stroke recovery: therapeutic promise and potential pitfalls of clinical translation. The Lancet Neurology $\underline{11}, 369-380$

Hoehn BD, Palmer TD, Steinberg GK (2005): Neurogenesis in rats after focal cerebral ischemia is enhanced by indomethacin. Stroke $\underline{36}, 2718-2724$

Huber AK, Giles DA, Segal BM, Irani DN (2018): An emerging role for eotaxins in neurodegenerative disease. Clin Immunol 189, 29-33

Iadecola C, Anrather J (2011): The immunology of stroke: from mechanisms to translation. Nature Medicine 17, 796-808

Jinquan T, Jacobi HH, Jing C, Millner A, Sten E, Hviid L, Anting L, Ryder LP, Glue C, Skov PS et al. (2003): CCR3 expression induced by IL-2 and IL-4 functioning as a death receptor for B cells. J Immunol $\underline{171}, 1722-1731$

Khoshnam SE, Winlow W, Farzaneh M, Farbood Y, Moghaddam HF (2017): Pathogenic mechanisms following ischemic stroke. Neurol Sci $\underline{38}, 1167-1186$

Kim BJ, Kim MJ, Park JM, Lee SH, Kim YJ, Ryu S, Kim YH, Yoon BW (2009): Reduced neurogenesis after suppressed inflammation by minocycline in transient cerebral ischemia in rat. J Neurol Sci 279, 70-75

Kim KA, Shin D, Kim JH, Shin YJ, Rajanikant GK, Majid A, Baek SH, Bae ON (2018): Role of autophagy in endothelial damage and blood-brain barrier disruption in ischemic stroke. Stroke $\underline{49}$, 1571-1579

Kodali RB, Kim WJ, Galaria, II, Miller C, Schecter AD, Lira SA, Taubman MB (2004): CCL11 (Eotaxin) induces CCR3-dependent smooth muscle cell migration. Arterioscler Thromb Vasc Biol 24, 1211-1216

Leppälä JM, Virtamo J, Fogelholm R, Albanes D, Heinonen OP (1999): Different risk factors for different stroke subtypes: Association of Blood Pressure, Cholesterol, and Antioxidants. Stroke $\underline{30}$, $2535-2540$

Liu Z, Fan Y, Won SJ, Neumann M, Hu D, Zhou L, Weinstein PR, Liu J (2007): Chronic treatment with minocycline preserves adult new neurons and reduces functional impairment after focal cerebral ischemia. Stroke $\underline{38}, 146-152$

Lo EH (2008): A new penumbra: transitioning from injury into repair after stroke. Nature Medicine 14, 497-500

Luo Y, Berman MA, Zhai Q, Fischer FR, Abromson-Leeman SR, Zhang Y, Kuziel WA, Gerard C, Dorf ME (2002): RANTES stimulates inflammatory cascades and receptor modulation in murine astrocytes. Glia $\underline{39}, 19-30$ 
Ma Y, Wang J, Wang Y, Yang GY (2017): The biphasic function of microglia in ischemic stroke. Prog Neurobiol 157, 247-272

Maysami S, Nguyen D, Zobel F, Heine S, Höpfner M, Stangel M (2006): Oligodendrocyte precursor cells express a functional chemokine receptor CCR3: implications for myelination. J Neuroimmunol 178, 17-23

Millard CJ, Ludeman JP, Canals M, Bridgford JL, Hinds MG, Clayton DJ, Christopoulos A, Payne RJ, Stone MJ (2014): Structural basis of receptor sulfotyrosine recognition by a CC chemokine: the $\mathrm{N}$-terminal region of CCR3 bound to CCL11/eotaxin-1. Structure 22, 1571-1581

Mir A, Minguez M, Tatay J, Pascual I, Pena A, Sanchiz V, Almela P, Mora F, Benages A (2002): Elevated serum eotaxin levels in patients with inflammatory bowel disease. 97, 1452-1457

Neumann J, Riek-Burchardt M, Herz J, Doeppner TR, König R, Hütten H, Etemire E, Männ L, Klingberg A, Fischer T et al. (2015): Very-late-antigen-4 (VLA-4)-mediated brain invasion by neutrophils leads to interactions with microglia, increased ischemic injury and impaired behavior in experimental stroke. Acta Neuropathol 129, 259-277

Nocturne G, Seror R, Fogel O, Belkhir R, Boudaoud S, Saraux A, Larroche C, Le Guern V, Gottenberg JE, Mariette X (2015): CXCL13 and CCL11 serum levels and lymphoma and disease activity in primary Sjogren's syndrome. Arthritis Rheumatol 67, 3226-3233

Parajuli B, Horiuchi H, Mizuno T, Takeuchi H, Suzumura A (2015): CCL11 enhances excitotoxic neuronal death by producing reactive oxygen species in microglia. Glia $\underline{63}, 2274-2284$

Psychogios MN, Maier IL, Tsogkas I, Hesse AC, Brehm A, Behme D, Schnieder M, Schregel K, Papageorgiou I, Liebeskind DS et al. (2019): One-Stop management of 230 consecutive acute stroke patients: Report of procedural times and clinical outcome. J Clin Med $\underline{8}, 2185$

Pundik S, Xu K, Sundararajan S (2012): Reperfusion brain injury: Focus on cellular bioenergetics. Neurology $\underline{79}, 44-51$

Rehman MQ, Beal D, Liang Y, Noronha A, Winter H, Farraye FA, Ganley-Leal L (2013): B cells secrete eotaxin-1 in human inflammatory bowel disease. Inflamm Bowel Dis 19, 922-933

Roy-O'Reilly M, Ritzel RM, Conway SE, Staff I, Fortunato G, McCullough LD (2017): CCL11 (Eotaxin-1) levels predict long-term functional outcomes in patients following ischemic stroke. Transl Stroke Res $\underline{8}, 578-584$

Shah K, Lahiri DK (2014): Cdk5 activity in the brain - multiple paths of regulation. J Cell Sci $\underline{127}$, 2391-2400 
Shigemoto-Mogami Y, Hoshikawa K, Goldman JE, Sekino Y, Sato K (2014): Microglia enhance neurogenesis and oligodendrogenesis in the early postnatal subventricular zone. J Neurosci $\underline{34}$, $2231-2243$

Shim R, Wong C (2016): Ischemia, immunosuppression and infection -Tackling the predicaments of post-stroke complications. Int J Mol Sci $\underline{17}, 64$

Sierra A, Encinas JM, Deudero JJ, Chancey JH, Enikolopov G, Overstreet-Wadiche LS, Tsirka SE, Maletic-Savatic M (2010): Microglia shape adult hippocampal neurogenesis through apoptosiscoupled phagocytosis. Cell Stem Cell 7 , 483-495

Richardson RM, Pridgen BC, Haribabu B, Snyderman R (2000): Regulation of the human chemokine receptor CCR1: Cross-regulation by CXCR1 and CXCR2. Journal of Biological Chemistry 275, 9201-9208

Stuart MJ, Singhal G, Baune BT (2015): Systematic review of the neurobiological relevance of chemokines to psychiatric disorders. Front Cell Neurosci $\underline{9}, 357$

Sun B (2013): S100B protein in serum is elevated after global cerebral ischemic injury. World J Emerg Med 4, 165-168

Taupin P (2007): BrdU immunohistochemistry for studying adult neurogenesis: paradigms, pitfalls, limitations, and validation. Brain Res Rev $\underline{53}, 198-214$

Taylor A, Verhagen J, Blaser K, Akdis M, Akdis CA (2006): Mechanisms of immune suppression by interleukin-10 and transforming growth factor-beta: the role of T regulatory cells. Immunology 117, 433-442

Taylor RA, Sansing LH (2013): Microglial responses after ischemic stroke and intracerebral hemorrhage. Clin Dev Immunol 2013, 746068

Teng H, Zhang ZG, Wang L, Zhang RL, Zhang L, Morris D, Gregg SR, Wu Z, Jiang A, Lu M et al. (2008): Coupling of angiogenesis and neurogenesis in cultured endothelial cells and neural progenitor cells after stroke. J Cereb Blood Flow Metab 28, 764-771

Thomalla G, Gerloff C (2019): Acute imaging for evidence-based treatment of ischemic stroke. Curr Opin Neurol 32, 521-529

Thored P, Heldmann U, Gomes-Leal W, Gisler R, Darsalia V, Taneera J, Nygren JM, Jacobsen SE, Ekdahl CT, Kokaia Z et al. (2009): Long-term accumulation of microglia with proneurogenic phenotype concomitant with persistent neurogenesis in adult subventricular zone after stroke. Glia 57, 835-849

Timsit S, Menn B (2007): Cerebral ischemia, cell cycle elements and Cdk5. Biotechnol J 2 2, 958-966 
Tsai L, Delalle I, Caviness VS, Chae T, Harlow E (1994): p35 is a neural-specific regulatory subunit of cyclin-dependent kinase 5. Nature $\underline{371}, 419-423$

Venkatasubba Rao CC, Suarez JI (2018): Management of stroke in the neurocritical care unit. Continuum (Minneap Minn) 24, 1658-1682

Villeda SA, Luo J, Mosher KI, Zou B, Britschgi M, Bieri G, Stan TM, Fainberg N, Ding Z, Eggel A et al. (2011): The ageing systemic milieu negatively regulates neurogenesis and cognitive function. Nature $\underline{477}, 90-94$

Vukovic J, Colditz MJ, Blackmore DG, Ruitenberg MJ, Bartlett PF (2012): Microglia modulate hippocampal neural precursor activity in response to exercise and aging. J Neurosci $\underline{32}$, 6435-6443

Wang F, Baba N, Shen Y, Yamashita T, Tsuru E, Tsuda M, Maeda N, Sagara Y (2017): CCL11 promotes migration and proliferation of mouse neural progenitor cells. Stem Cell Res Ther $\underline{8}, 26$

Wang Y, Kilic E, Kilic U, Weber B, Bassetti CL, Marti HH, Hermann DM (2005): VEGF overexpression induces post-ischaemic neuroprotection, but facilitates haemodynamic steal phenomena. Brain $\underline{128}, 52-63$

Wild E, Magnusson A, Lahiri N, Krus U, Orth M, Tabrizi SJ, Bjorkqvist M (2011): Abnormal peripheral chemokine profile in Huntington's disease. PLoS Curr $\underline{3}$, RRN1231

Yilmaz G, Granger DN (2010): Leukocyte recruitment and ischemic brain injury. Neuromolecular Med 12, 193-204

Zhou S, Zhu W, Zhang Y, Pan S, Bao J (2018): S100B promotes microglia M1 polarization and migration to aggravate cerebral ischemia. Inflamm Res $\underline{67}, 937-949$

Zhu C, Xu B, Sun X, Zhu Q, Sui Y (2017): Targeting CCR3 to reduce amyloid-beta production, Tau hyperphosphorylation, and synaptic loss in a mouse model of Alzheimer's disease. Mol Neurobiol 느, 7964-7978 